\title{
ipen
}

INSTITUTO DE PESQUISAS ENERGÉTICAS E NUCLEARES

Autarquia associada à Universidade de São Paulo

\section{EFEITO DA FASE ALFA LINHA NAS PROPRIEDADES MECÂNICAS E DE RESISTÊNCIA À CORROSÃO DO AÇO INOXIDÁVEL DUPLEX UR 52N+}

\section{TALITA FILIER FONTES}

Dissertação apresentada como parte dos requisitos para obtenção do Grau de Mestre em ciências na área de Tecnologia Nuclear - Materiais.

Orientador:

Dra.Isolda Costa

SÃO PAULO

2009 


\section{ipen}

INSTITUTO DE PESQUISAS ENERGÉTICAS E NUCLEARES Autarquia associada à Universidade de São Paulo

\section{EFEITO DA FASE ALFA LINHA NAS PROPRIEDADES MECÂNICAS E DE RESISTÊNCIA À CORROSÃO DO AÇO INOXIDÁVEL DUPLEX UR 52N+}

\section{TALITA FILIER FONTES}

Dissertação apresentada como parte dos requisitos para obtenção do Grau de Mestre em ciências na área de Tecnologia Nuclear - Materiais.

Orientador:

Dra.Isolda Costa 
Aos meus antepassados com minha eterna gratidão e amor. 


\section{AGRADECIMENTOS}

A Deus pela força e coragem que me deu para realizar este trabalho e não desistir diante dos inúmeros obstáculos que apareceram ao longo desse trabalho.

A todos os meus antepassados pela oportunidade que me deram de nascer e poder desfrutar da mais preciosa dádiva: aprender sempre!

À Professora Dra. Isolda Costa pela amizade, orientação, sugestões e pela confiança no meu trabalho.

Ao Professor Dr. Rodrigo Magnabosco pelas sugestões, disponibilidade em ajudar, amizade, pelo incentivo desde a época da iniciação científica e pelo convite de realizar grande parte do trabalho experimental na FEl.

Ao Professor Dr. Angelo Fernando Padilha pelas suas sugestões, correções, por ter participado da minha banca no seminário de área, pela disponibilidade em ajudar e pela doação do aço estudado.

Ao Professor Dr. Lalgudi V. Ramanathan por ter aceitado o convite para participar da banca.

Ao Centro Universitário da FEI pelo convite e permissão na utilização do laboratório do Centro de Desenvolvimento de Materiais Metálicos da FEl.

Ao Professor Dr. Fernando J.G. Landgraf da EPUSP e ao Doutorando Sergio Antonio Romero do IF/USP pela disponibilidade em ajudar sempre que preciso.

Ao IPEN pela oportunidade de realizar este trabalho e utilizar seus laboratórios e dependências.

Ao Engenheiro Luiz Crestana da Sandvik e à Sandvik do Brasil pelos documentos enviados a respeito dos aços inoxidáveis dúplex.

A todos os colegas do laboratório de Corrosão pelo incentivo, ao técnico Olandir pela ajuda na utilização dos equipamentos e à Dona Judit pelas marcações no MEV.

A todos os técnicos do Centro de Desenvolvimento de Materiais Metálicos da FEI pela colaboração e ao Airton Morassi do IPEI/FEI pelas fotos dos cp's fraturados.

A CNEN pela concessão da bolsa de estudo de mestrado.

À Dra. Marina Magnani pelas micrografias dos pites no MEV. 
À Dra. Maysa Terada e ao técnico René (IPEN) pelo ensaio de difração de Raios-X.

Aos técnicos do laboratório de microscopia e microanálise do IPEN: Celso, Glauson e Nildemar pelas análises de MEV.

À minha família, em especial aos meus pais Osmar e Vilma que suportaram meus momentos de crise e mau-humor e me fizeram acreditar que era possível.

Aos amigos da Seicho- No -le pelo incentivo, apoio e reconhecimento que me fazem progredir sempre.

Aos meus amigos todos, em especial à Cynthia Nishimura e ao meu irmão de coração Bruno Ferrari da Silva por terem me incentivado sempre e agüentado ouvir pacientemente sobre o meu trabalho de mestrado todas as vezes que nos encontrávamos ou conversávamos sobre qualquer assunto.

Aos meus avós Lucia e Osmar e à minha tia Edna pela ajuda sempre que foi possível com meus estudos na época da Faculdade e por acreditarem na minha capacidade.

À minha avó Maria (in memorian) pelo orgulho que tinha da neta "estudiosa" e pelas palavras de carinho com que ela se referia a mim perante todas as pessoas.

À vida que tem me ensinado a ter fé, a superar os obstáculos, a querer sempre progredir e ter vontade de viver da melhor maneira possível.

Aos meus amigos queridos e especiais Claire, Yuri e Max pelo exemplo que são para mim de perseverança e força de vontade para superar seus limites.

A todos que direta ou indiretamente contribuíram para que esse trabalho fosse realizado.

A Deus que é o princípio e o fim e a força infinita.

Muito obrigada! Muito Obrigada! 
"O que você mentaliza continuamente norteia a sua vida, traça o seu destino".

Masaharu Taniguchi 


\title{
EFEITO DA FASE ALFA LINHA NAS PROPRIEDADES MECÂNICAS E DE RESISTÊNCIA À CORROSÃO DO AÇO INOXIDÁVEL DUPLEX UR 52N+
}

\section{Talita Filier Fontes}

\begin{abstract}
RESUMO
A fase alfa linha provoca uma diminuição brusca da resistência à corrosão e perda das propriedades mecânicas dos aços inoxidáveis dúplex. Neste trabalho realizaram-se ensaios mecânicos e eletroquímicos no aço inoxidável dúplex UR 52N+ envelhecido a $475^{\circ} \mathrm{C}$ por vários tempos para avaliar a sensibilidade dos ensaios à presença de alfa linha. Os ensaios de dureza mostraram aumento gradual nos valores da mesma, já os ensaios de impacto revelaram que com $12 \mathrm{~h}$ de envelhecimento o material já perde cerca de $80 \%$ da energia absorvida inicialmente pela amostra solubilizada. No entanto, os ensaios de polarização cíclica mostraram que mudanças significativas só são percebidas para tempos de envelhecimento superiores a 96h.
\end{abstract}




\title{
Alpha prime effect on mechanical properties and corrosion resistance of UR
} $52 \mathrm{~N}+$ Duplex Stainless Steel

\section{Talita Filier Fontes}

\begin{abstract}
Alpha prime phase leads to decreased corrosion resistance and mechanical properties losses of duplex stainless steels. In this work mechanical and electrochemical tests were performed in duplex stainless steel UR $52 \mathrm{~N}+$ aged at $475^{\circ} \mathrm{C}$ for various periods in order to determine the sensibility of these tests to alpha prime presence. Hardness tests showed a gradual increase in its values; on the other hand, impact tests revealed that the material aged for $12 \mathrm{~h}$ losses about $80 \%$ of energy absorption capacity of the solution annealed sample. Notwithstanding cyclic polarization tests showed that significant changes are only noted for aging times greater than $96 \mathrm{~h}$.
\end{abstract}




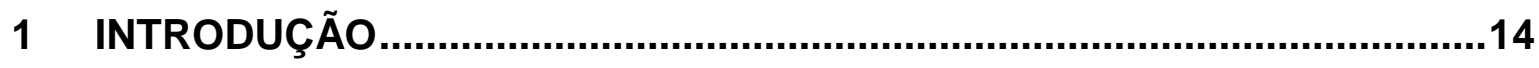

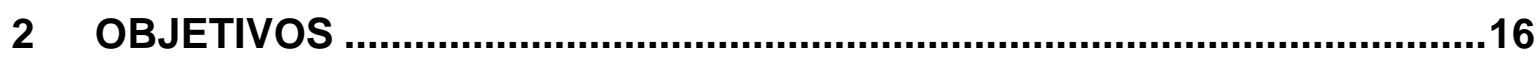

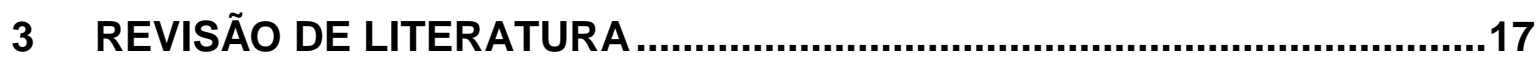

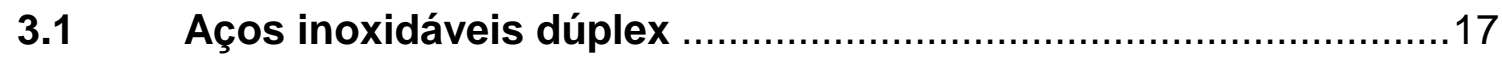

3.2 Efeito dos elementos de liga nos aços inoxidáveis dúplex ..........20

3.3 Propriedades mecânicas dos aços inoxidáveis dúplex.................22

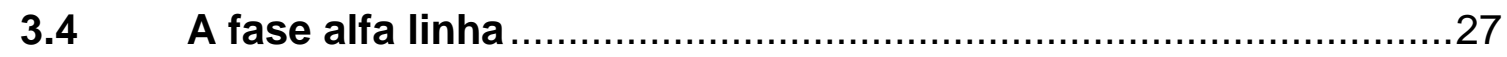

3.5 Efeito da fase alfa linha nas propriedades mecânicas e na resistência à corrosão de aços inoxidáveis dúplex. .....................................31

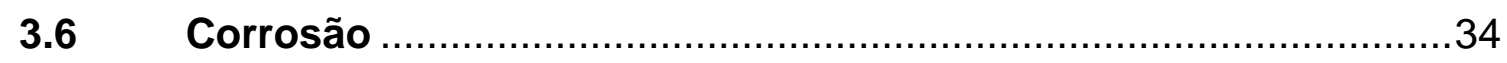

3.6.1 Corrosão por pite em aços inoxidáveis dúplex ..............................35

3.6.2 Técnicas eletroquímicas em corrosão e relação com a microestrutura.

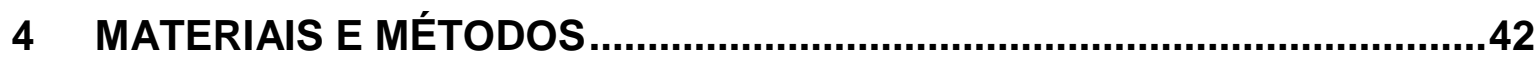

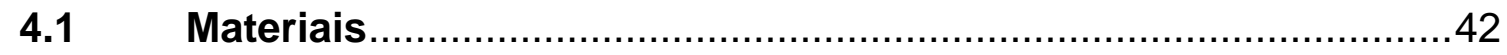

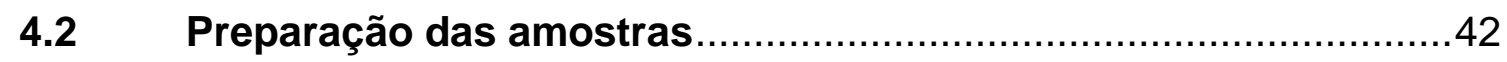

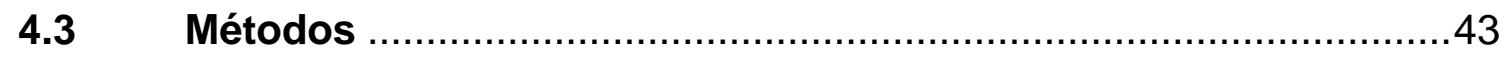

4.3.1 Caracterização Microestrutural ...............................................43

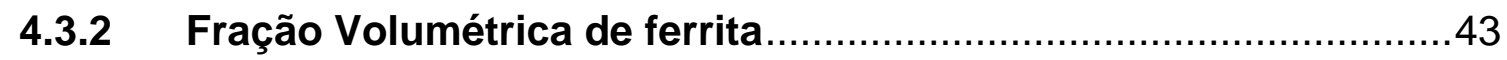

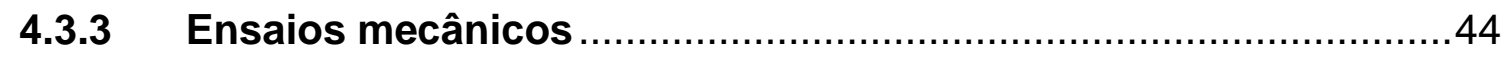

4.3.4 Microscopia Ótica e Microscopia Eletrônica de Varredura ............44

4.3.5 Ensaios Eletroquímicos ........................................................... 45

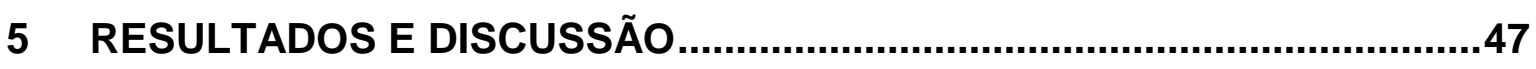

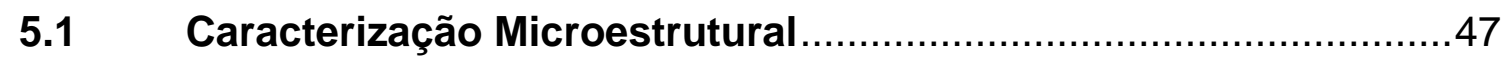

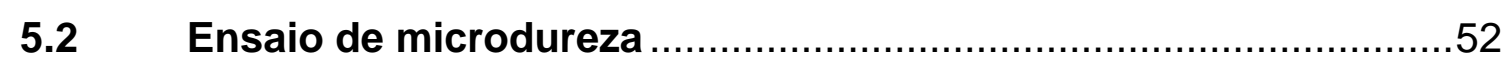

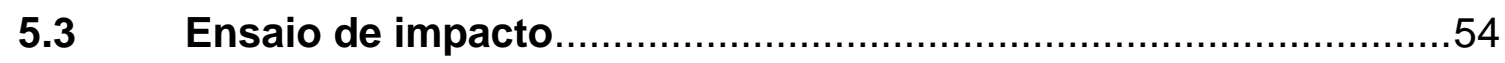

5.4 Ensaios de polarização cíclica..................................................58

5.5 Ensaios de espectroscopia de impedância eletroquímica .............63

5.6 Ajuste dos dados de EIE através de circuitos elétricos equivalentes. 
5.7 Comparação entre os resultados obtidos ..............................68

6 CONCLUSÃO .......................................................................................

APÊNDICE 1 - Ajuste de CEE para a amostra solubilizada e envelhecidas a

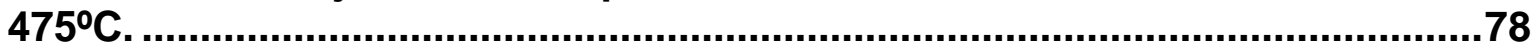

REFERÊNCIAS BIBLIOGRÁFICAS ........................................................ 


\section{LISTA DE FIGURAS}

Página

FIGURA1: CURVA TENSÃO VS. DEFORMAÇÃO VERDADEIRAS DE UM AÇO

DÚPLEX (50\%-60\% EM MASSA DE FERRITA) COMPARADA COM

CURVAS EQUIVALENTES PARA MATERIAL FERRÍTICO E AUSTENÍTICO

(FLOREEN E RAYDEN, 1968).

FIGURA 2: COMPARAÇÃO DO LIMITE DE ESCOAMENTO E SUA

DEPENDÊNCIA COM A TEMPERATURA PARA AÇOS INOXIDÁVEIS

DÚPLEX CONTENDO 50 A $60 \%$ EM PESO DE FERRITA, COM AÇOS

INOXIDÁVEIS FERRÍTICOS E AUSTENITTICOS (FLOREEN E RAYDEN,

1968).

FIGURA 3: DEPENDÊNCIA DO LIMITE DE ESCOAMENTO DE AÇOS INOXIDÁVEIS DÚPLEX COM A PORCENTAGEM EM VOLUME DE FERRITA (FLOREEN E RAYDEN, 1968).

FIGURA 4:DEPENDÊNCIA DO LIMITE DE RESISTÊNCIA DE AÇOS INOXIDÁVEIS DÚPLEX COM A PORCENTAGEM EM VOLUME DE FERRITA (FLOREEN E RAYDEN, 1968).

FIGURA 5:DEPENDÊNCIA DA ENERGIA DE IMPACTO DE AÇOS INOXIDÁVEIS DÚPLEX COM A PORCENTAGEM EM VOLUME DE FERRITA (FLOREEN E RAYDEN, 1968).

FIGURA 6: ASPECTO DE FACETAS DE CLIVAGEM COM RIOS CARACTERÍSTICOS QUE INDICAM O SENTIDO DO LOCAL DE PROPAGAÇÃO DA FRATURA (ABM,1979)... 26

FIGURA 7:DIAGRAMA TTT PARA PRECIPITAÇÃO DE ALFA LINHA (TERADA, 2003).

FIGURA 8: DIAGRAMA ESQUEMÁTICO DAS VARIÁVEIS METALÚRGICAS QUE PODEM AFETAR A PASSIVIDADE DE AÇOS INOXIDÁVEIS (SEDRIKS, 1986)

FIGURA 9: CURVA DE POLARIZAÇÃO CÍCLICA TÍPICA DE UM AÇO INOXIDÁVEL EM SOLUÇÃO CONTENDO ÍONS CLORETO. E*:POTENCIAL DE CORROSÃO. E PROT1 $_{\text {E EROT2 }}$ : POTENCIAL DE PROTEÇÃO. E EITE: POTENCIAL DE PITE. IREV: DENSIDADE DE CORRENTE DE REVERSÃO (MAGNABOSCO, 2001).

FIGURA 10: CIRCUITOS ELÉTRICOS EQUIVALENTES PROPOSTOS PARA CARACTERIZAR A CAMADA PASSIVA DOS AÇOS INOXIDÁVEIS (AZUMI ET AL., 1986; BUNDY ET AL., 1993; MONTEMOR ET AL, 2000; LIU ET AL., 2003; ANTUNES, 2006; TERADA, 2008). 
FIGURA 11: CORPO DE PROVA UTILIZADO NO ENSAIO DE IMPACTO CHARPY.

FIGURA 12: AMOSTRA SOLUBILIZADA A 1200ㄷ POR $1 \mathrm{H}$ DO AÇO INOXIDÁVEL SUPER-DÚPLEX UR 52N+. ATAQUE: BEHARA MODIFICADO.

FIGURA 13: AMOSTRA ENVELHECIDA POR 4H À 475ㄷ DO AÇO INOXIDÁVEL SUPER-DÚPLEX UR 52N+. ATAQUE: BEHARA MODIFICADO.

FIGURA 14: MICROGRAFIA DA AMOSTRA ENVELHECIDA POR 1032H À 475C DO AÇO INOXIDÁVEL SUPER-DÚPLEX UR 52N+. ATAQUE: BEHARA MODIFICADO.

FIGURA 15: DIFRATOGRAMA DA AMOSTRA ENVELHECIDA POR 12H A $475^{\circ} \mathrm{C}$.

FIGURA 16: VARIAÇÃO DA FRAÇÃO VOLUMÉTRICA DE FERRITA VERSUS TEMPO DE TRATAMENTO TÉRMICO À $475^{\circ} \mathrm{C}$. O TEMPO DE $0,01 \mathrm{H}$ REPRESENTA A AMOSTRA SOLUBILIZADA A $1200^{\circ} \mathrm{C}$ POR $1 \mathrm{H}$.

FIGURA 17: GRÁFICO DE DUREZA DA AMOSTRA SOLUBILIZADA E ENVELHECIDAS À 475으. O TEMPO DE 0,01H REPRESENTA A AMOSTRA SOLUBILIZADA A $1200^{\circ} \mathrm{C}$ POR $1 \mathrm{H}$.

FIGURA 18: GRÁFICO DE ENERGIA ABSORVIDA NO ENSAIO DE IMPACTO EM FUNÇÃO DO TEMPO DE ENVELHECIMENTO A 475드, E ASPECTO DOS CORPOS-DE-PROVA FRATURADOS. O TEMPO DE 0,01H CORRESPONDE À AMOSTRA SOLUBILIZADA.

FIGURA 19: MEV DA AMOSTRA SOLUBILIZADA APÓS ENSAIO DE IMPACTO.NOTA-SE A PRESENÇA DE MUITOS ALVÉOLOS (DIMPLES), CARACTERÍSTICOS DE FRATURA DÚCTIL.

FIGURA 20: MEV DA AMOSTRA ENVELHECIDA POR 12H APÓS ENSAIO DE IMPACTO. NOTA-SE A PRESENÇA DE PLANOS DE CLIVAGEM EM GRANDE EXTENSÃO DA SUPERFÍCIE DE FRATURA E POUCOS ALVÉOLOS (DIMPLES) NO CANTO SUPERIOR ESQUERDO.

FIGURA 21: MEV DA AMOSTRA ENVELHECIDA POR 1032H APÓS ENSAIO DE IMPACTO. NOTA-SE A PRESENÇA DE PLANOS DE CLIVAGEM EM PRATICAMENTE TODA A EXTENSÃO DA SUPERFÍCIE DE FRATURA, CARACTERÍSTICOS DE FRATURA FRÁGIL.

FIGURA 22: CURVA DE POLARIZAÇÃO CÍCLICA DA AMOSTRA SOLUBILIZADA.

FIGURA 23: CURVA DE POLARIZAÇÃO CÍCLICA DA AMOSTRA ENVELHECIDA POR 4H A 475ㅇ. 
FIGURA 24: CURVA DE POLARIZAÇÃO CÍCLICA DA AMOSTRA

ENVELHECIDA POR $12 \mathrm{H}$ A $475^{\circ} \mathrm{C}$.

FIGURA 25: CURVA DE POLARIZAÇÃO CÍCLICA DA AMOSTRA

ENVELHECIDA POR $48 \mathrm{H}$ A $475^{\circ} \mathrm{C}$.

FIGURA 26: CURVA DE POLARIZAÇÃO CÍCLICA DA AMOSTRA

ENVELHECIDA POR $1032 \mathrm{H}$ A $475^{\circ} \mathrm{C}$.

FIGURA 27: CURVA DE POLARIZAÇÃO CÍCLICA DAS AMOSTRAS

SOLUBILIZADA E ENVELHECIDAS A 475ํㅡ SOBREPOSTAS.

FIGURA 28: MEV DA AMOSTRA SOLUBILIZADA ( FIGURA 28 A) E

ENVELHECIDA (FIGURA 28 B) POR 1032H A 475ㄷ DO AÇO UR 52N+

APÓS POLARIZAÇÃO CÍCLICA EM NACL.

FIGURA 29: DETALHE AMPLIADO DOS PITES DA AMOSTRA SOLUBILIZADA OBTIDO POR MEV.

FIGURA 30: DIAGRAMAS DE NYQUIST DA AMOSTRA SOLUBILIZADA E ENVELHECIDAS A 475ㅇ.

FIGURA 31: DIAGRAMAS DE MÓDULO DE Z DA AMOSTRA SOLUBILIZADA E ENVELHECIDAS A.

FIGURA 32: DIAGRAMAS DE ÂNGULO DE FASE DE BODE DA AMOSTRA SOLUBILIZADA E ENVELHECIDAS A 475ํㅡ.

FIGURA 33: CIRCUITO EQUIVALENTE UTILIZADO PARA AJUSTE DOS DADOS DO ENSAIO DE EIE.

FIGURA 34: ENERGIA ABSORVIDA E DUREZA EM FUNÇÃO DO TEMPO DE ENVELHECIMENTO. O TEMPO DE 0,01H CORRESPONDE À AMOSTRA SOLUBILIZADA.

FIGURA 35: DUREZA E POTENCIAL DE PITE EM FUNÇÃO DO TEMPO DE ENVELHECIMENTO À 475드.O TEMPO DE 0,01H CORRESPONDE À AMOSTRA SOLUBILIZADA.

FIGURA 36:R2 E ENERGIA ABSORVIDA EM FUNÇÃO DO TEMPO DE ENVELHECIMENTO À $475^{\circ} \mathrm{C}$. O TEMPO DE 0,01H CORRESPONDE À AMOSTRA SOLUBILIZADA.

FIGURA 37: DIAGRAMAS DE BODE (MÓDULO DE Z E ÂNGULO DE FASE)

PARA A AMOSTRA SOLUBILIZADA E ENVELHECIDA A 475ㅇ. 73

FIGURA 38: COMPARATIVO DA VARIAÇÃO DAS PROPRIEDADES COM O TEMPO DE ENVELHECIMENTO. 


\section{LISTA DE TABELAS}

\section{Página}

TABELA 1- COMPOSIÇÃO QUÍMICA (\% EM MASSA) DO AÇO ESTUDADO...42

TABELA 2 - FRAÇÃO VOLUMÉTRICA DE FERRITA (MAGNÉTICA) MEDIDA POR FERRITOSCOPIA

TABELA 3 - VARIAÇÃO DA FRAÇÃO VOLUMÉTRICA DE FERRITA MEDIDA POR FERRITOSCOPIA PARA OS DIVERSOS TEMPOS DE ENVELHECIMENTO TÉRMICO A 475ㄷ․

TABELA 4 - MEDIDAS OBTIDAS NO ENSAIO DE MICRODUREZA.................52

TABELA 5 - DE VARIAÇÃO DA DUREZA PARA OS DIVERSOS TEMPOS DE ENVELHECIMENTO

TABELA 6 - DADOS OBTIDOS NO ENSAIO DE IMPACTO CHARPY. .54

TABELA 7 - VALORES DOS PARÂMETROS AJUSTADOS UTILIZANDO O CEE APRESENTADO NA FIG.33. 


\section{INTRODUÇÃo}

Os aços inoxidáveis dúplex (AID's) têm sido amplamente utilizados nas indústrias nucleares, químicas e petroquímicas, devido às suas excelentes propriedades mecânicas e de resistência à corrosão, especialmente em ambientes agressivos. Contudo, quando esses aços são expostos a temperaturas entre $300^{\circ} \mathrm{C}$ e $550^{\circ} \mathrm{C}$, ocorre a formação da fase alfa linha. A formação dessa fase enriquecida em cromo cujo efeito mais pronunciado ocorre a $475 \stackrel{\circ}{\circ} \mathrm{C}$ tem sido amplamente estudada (Bandel e Tofaute, 1942; Fisher et al., 1953; Chandra e Schwartz, 1971; Solomon e Levinson, 1978; Isalgue e Anglada, 1990; Kuwano et al., 1991; Rechemberg et al., 1993; Mathon et al., 2003; Bley, 1992; Lee et al., 2007).

A fase alfa linha provoca uma diminuição brusca da resistência ao impacto e da resistência à corrosão desses materiais (Fischer et al., 1953; Solomon e Levinson, 1978; Grobner, 1973; Chung e Chopra, 1985; Williams e Paxton, 1957). Essa fase possui estrutura CCC, coerente com a matriz ferrítica e elevada resistência ao coalescimento, mesmo para longos tempos de envelhecimento, devido à baixa energia de interface entre a ferrita e a alfa linha $\left(\alpha^{\prime}\right)$.

Como essa fase possui tamanho reduzido e estrutura similar à da matriz ferrítica, ela não pode ser observada diretamente por microscopia ótica ou eletrônica de transmissão, nem por difração de raios $X$, sendo, portanto, necessários métodos de análise indiretos, como a variação no comportamento mecânico, eletroquímico, magnético, entre outros.

O mecanismo de formação da fase alfa linha é ainda bastante controverso e varia de uma liga para outra, contudo na literatura discute-se que a fase alfa linha pode ser formada por dois mecanismos diferentes, dependendo da quantidade de cromo e da temperatura de tratamento térmico. Esses mecanismos são chamados de decomposição espinodal e nucleação e crescimento (Chandra e Schwartz, 1971; Solomon e Levinson, 1978; Isalgue e Anglada, 1990; Grobner, 1973; Marcinkowski et al., 1964; Anglada et al., 1989; Ura et al., 1995; Jacobsson et al., 1975; Newell, 1946; Blackburn e Nutting, 1964). Segundo lacoviello et al. (2005) a formação da fase $\alpha^{\prime}$ em aços inoxidáveis dúplex semelhantes ao UNS 
S31803 (UR 52N+), e envelhecidos a $475^{\circ} \mathrm{C}$ por $1000 \mathrm{~h}$, se dá por decomposição espinodal da ferrita.

Devido às flutuações do teor de cromo no interior dos grãos de ferrita 0 material apresenta alta susceptibilidade à corrosão localizada. Essas flutuações podem ser geradas tanto pelo mecanismo de decomposição espinodal, que se caracteriza por uma queda gradual do teor de cromo com o tempo de envelhecimento, quanto por nucleação e crescimento, que provoca um efeito mais intenso para os momentos iniciais de formação de alfa linha.

A presença das partículas de alfa linha também promove endurecimento do material e a perda de tenacidade, uma vez que o movimento das discordâncias é inibido por essas partículas.

Embora a presença de alfa linha na microestrutura aumente a resistência mecânica e a dureza do aço, as consequências de sua presença são predominantemente negativas, pois tornam o material menos tenaz (frágil) e menos resistente à corrosão. Apesar de esses comportamentos serem conhecidos é importante quantificá-los especialmente levando em questão as diferentes condições de tempos e temperaturas de envelhecimento que irão determinar o grau de fragilização do material e, consequentemente, irão restringir suas aplicações e o tempo de vida útil.

Finalmente, a identificação do grau de fragilização e a determinação da sensibilidade à presença de alfa linha nos ensaios realizados neste trabalho são importantes para conduzir ao uso adequado do material e também determinar com maior precisão e menor tempo o método a ser utilizado para verificar indiretamente a presença dessa fase no material. 


\section{OBJETIVOS}

O objetivo do presente trabalho é estudar o efeito da fase alfa linha nas propriedades mecânicas e de resistência à corrosão dos aços inoxidáveis dúplex envelhecidos a $475^{\circ} \mathrm{C}$ por diversos tempos, procurando estabelecer correlações entre estas propriedades. Pretende-se também avaliar a sensibilidade dos ensaios mecânicos e eletroquímicos à determinação da presença de alfa linha no aço inoxidável UR $52 \mathrm{~N}+$ envelhecido a $475 \stackrel{\circ}{ } \mathrm{C}$ por até $1032 \mathrm{~h}$. 


\section{REVISÃO DE LITERATURA}

\subsection{Aços inoxidáveis dúplex}

A produção dos aços inoxidáveis dúplex somente emergiu por volta de 1987 (Lo et al., 2009). Apesar dessa classe de aços inoxidáveis contabilizar menos de $1 \%$ da produção total de aços inoxidáveis (Charles et al., 2009), é uma classe que está em crescimento, particularmente para aplicações que requerem alta resistência mecânica aliada à resistência à corrosão, em especial para meios que contenham íons cloreto em sua composição, proporcionando boa redução de custos, prolongando os intervalos de parada de produção para manutenção e troca de equipamentos, podendo ser considerados assim, materiais de alta performance.

Outro aspecto que contribui para elevar o consumo dos aços inoxidáveis dúplex são as bruscas oscilações que vem ocorrendo no preço do níquel. Segundo Lo et al. (2009) o preço da tonelada de níquel era de 15 mil doláres no ano de 2005, enquanto que o preço da tonelada de cromo eletrolítico para o mesmo período segundo o Metal Prices (2009) era de aproximadamente 10 mil dólares.

Geralmente o níquel está presente em concentrações em torno de 810\% (Charles et al., 2009) como elemento de liga nos aços inoxidáveis austeníticos, o que torna este tipo de material mais caro que os de outras classes de aços inoxidáveis por conterem um teor de níquel mais alto. Segundo Gironès e colaboradores (2004) a substituição dos aços inoxidáveis austeníticos pelos aços inoxidáveis dúplex tem se tornado uma tendência por causa da combinação superior das propriedades mecânicas e de resistência à corrosão oferecidas pelos aços inoxidáveis dúplex.

Questões econômicas a parte, reduzir o uso de níquel também contribui para proteção do meio ambiente, pois este elemento soma uma porcentagem significativa de energia usada na fabricação de aços inoxidáveis (Johnson et al., 2008). Outro problema associado ao uso de ligas contendo níquel é o potencial carcinogênico (IARC, 1999) em humanos e a causa de alergias em humanos e animais (Kimura, 2007; Turnbull et al., 2002).

Por essas razões alguns países da Europa e Estados Unidos estão limitando os usos dessas ligas em implantes médicos e as pesquisas estão cada 
vez mais intensas para desenvolver novos materiais contendo nenhuma ou baixa concentração de níquel (Mori e Bauernfeind, 2004; Uggowitzer et al.,1996; Sieurin et al., 2006; Fini et al., 2003; Montanaro et al., 2006).

Embora existam novas séries de aços inoxidáveis austeníticos que utilizam nitrogênio e manganês para substituir o níquel, os aços inoxidáveis dúplex e ferríticos, especialmente as séries 400, têm se tornado boas opções tanto em relação a essa brusca oscilação de preço do níquel quanto nas questões ambientais e de saúde comentadas anteriormente.

Os aços inoxidáveis dúplex são constituídos normalmente por frações volumétricas similares de austenita (paramagnética) e ferrita (ferromagnética), através do correto balanço entre os elementos de liga (Magnabosco,2001). Esses aços são produzidos através do sistema AOD (descarburação por sopro combinado de oxigênio e argônio) e, portanto, apresentam baixo teor de carbono (Sedriks, 1996).

Por apresentarem grande resistência mecânica combinada à resistência à corrosão, esses aços são frequentemente utilizados em indústrias nucleares, plantas de dessalinização, indústrias farmacêuticas, de fertilizantes, alimentícias, indústrias petroquímicas e químicas, trocadores de calor e indústrias de papel e celulose. (Yi e Shoji,1996; Fan et al., 2009; Cheon e Kim, 2000; Tavares et al., 2000; Da Silva et al., 2001; Shiao et al., 1994; Garfias-Mesias et al., 1996, Di Cocco et al., 2008; lacoviello et al., 2005; lacoviello et al., 1999; Park e Kwon, 2005).Os aços inoxidáveis dúplex são amplamente utilizados na fabricação de componentes de alta performance das indústrias nucleares, como por exemplo em tubulações, válvulas e flanges; também são largamente utilizados em componentes e tubulações do sistema de refrigeração primária de uma planta nuclear PWR. (Cícero et al., 2009; Mathew et al., 1999; Kawaguchi e Yamanaka, 2002; Cheon e Kim, 2000). Porém, os aços inoxidáveis dúplex quando expostos a altas pressões e à temperatura de trabalho dos reatores nucleares $\left(270^{\circ} \mathrm{C}\right.$ $\left.330^{\circ} \mathrm{C}\right)$ por longo período de tempo são suscetíveis a fragilização causada pelo envelhecimento térmico (Kwon et al., 2001; Cícero,2009; Callone et al., 2004; Shiao et al., 1994; Yamada et al., 2006; Tujikura e Urata,1999), ocorrendo então a precipitação da fase alfa linha que reduz a ductilidade, resistência ao impacto e a tenacidade à fratura e em contrapartida aumenta a dureza e a resistência mecânica do material. 
A estrutura típica destes aços é composta em média por 40 a $45 \%$ de ferrita e 55 a $60 \%$ de austenita, obtidas após solubilização entre $1000^{\circ} \mathrm{C}$ e $1200^{\circ} \mathrm{C}$ seguida por resfriamento brusco (Magnabosco,2001).

Há um pouco mais de 15 anos atrás, surgia um novo tipo de aços inoxidável da classe dúplex, o aço inoxidável super-dúplex, ou também conhecidos como a terceira geração (Gironés et al., 2004) tal como UNS S32750, S32760, UNS S32520. Esses aços são amplamente usados em indústrias como as de óleo e combustível, petroquímicas, nucleares, produção de energia e de processamento químico e geralmente possuem um PREN (Pitting Resistance Equivalent Number) maior que 40 (Tan et al., 2009). A popularidade desses aços é atribuída a uma combinação muito atrativa de elevada resistência à corrosão, excelentes propriedades mecânicas e também pelo seu custo relativamente baixo comparado a outros materiais de alta performance, tais como aços inoxidáveis super-austeníticos e ligas a base de Ni que são geralmente mais caras que as ligas que não contém níquel ou que contêm esse elemento em baixa quantidade.

Apesar das amplas aplicações para os aços super-dúplex e mesmo sabendo que quando submetido à água do mar em temperaturas mais baixas esses materiais não sofrem corrosão, apenas tem limitação de trabalho em temperaturas mais elevadas, (Sandvik, 2006), pois existem situações onde a resistência à corrosão dessa série ainda é insuficiente para um longo período de uso e, portanto, materiais mais caros e com maior resistência à corrosão são necessários. Para tanto, foi criada uma outra série de aços dúplex, os aços inoxidáveis hiper-dúplex, com resistência à corrosão mais elevada ainda que os super-dúplex e resistência mecânica melhorada, podendo ser utilizados em ambientes extremamente agressivos como água de mares tropicais, por exemplo, trocadores de calor, plantas químicas de produção de sais de boro, entre outros (Sandvik, 2006). Um exemplo de aço hiper-dúplex é o SAF 2707 HD ou UNS S32707, esse aço possui um PREN nominal de 49, enquanto que o super-dúplex, SAF 2507 apresenta um PREN nominal de 42 (Sandvik, 2006). 


\subsection{Efeito dos elementos de liga nos aços inoxidáveis dúplex}

Existem elementos que possuem a capacidade de estabilizar a ferrita, os chamados alfagênicos, como o cromo, molibdênio, silício, e de estabilizar a austenita, os chamados gamagênicos, como o níquel, nitrogênio, manganês, cobre e carbono. Os elementos de liga além de promoverem a estabilização de fases, com o correto balanço, podem proporcionar diversos comportamentos mecânicos e eletroquímicos, sendo que os principais elementos de liga que melhoram a resistência a corrosão por pite nos aços inoxidáveis duplex, são: o cromo, molibdênio e nitrogênio.

De acordo com Truman e Pirt (1983), cromo e o molibdênio devem estar presentes em proporções adequadas, pois uma quantidade de $2 \%$ em volume desses elementos já é suficiente para promover a formação de uma fase muito frágil e rica nesses elementos, chamada fase sigma.

A porcentagem relativa dos elementos de liga é expressa em termos de níquel equivalente (estabilizador de austenita), ou gamagênico e cromo equivalente (estabilizador de ferrita), ou alfagênico, com base na porcentagem em massa (Sedriks, 1996), sendo esta calculada, por exemplo, através da proposição de DeLong, como mostram as equações 1 e 2 :

$$
\begin{aligned}
& \mathrm{Cr}_{\text {eq }}=\% \mathrm{Cr}+\% \mathrm{Mo}+1,5 \% \mathrm{Si}+0,5 \% \mathrm{Nb} \\
& \mathrm{Ni}_{\text {eq }}=\% \mathrm{Ni}+0,5 \% \mathrm{Mn}+30(\% \mathrm{C}+\% \mathrm{~N})
\end{aligned}
$$

Portanto, pode-se considerar que esses aços são compostos basicamente por ferro, cromo e níquel, e assim o estudo da metalurgia física destes aços pode ser feito através da análise do sistema ternário Fe-Cr-Ni.

\subsubsection{Efeito do cromo}

O cromo é um elemento essencial para conferir ao aço sua propriedade inoxidável, além de endurecer a ferrita e a austenita por solução sólida.

Em aços, nos quais o teor de cromo é superior a $11 \%$, é formada uma película aderente e não porosa na superfície do material, protegendo-o do meio corrosivo (Sedriks, 1996), chamada de película passiva. 


\subsubsection{Efeito do níquel}

O níquel, por ter caráter gamagênico, é um elemento de liga que confere ao aço inoxidável uma maior ductilidade, resistência mecânica, resistência à corrosão,sendo que seu principal efeito é o de aumentar a tenacidade do material (Terada, 2009). Porém, como citado anteriormente, além de ser um elemento de liga relativamente caro, por questões ambientais e de saúde está sendo cada vez menos utilizado na produção de aços inoxidáveis.

\subsubsection{Efeito do molibdênio}

O molibdênio além de ser um elemento alfagênico, é de fundamental importância na passividade dos aços inoxidáveis aumentando a resistência à corrosão por pite e em frestas, principalmente em meio contendo íon cloreto, uma vez que a passividade do cromo nesses meios é pouco estável (Fontana e Greene, 1978). O molibdênio também é utilizado para melhorar a dureza do aço. Outros elementos que estão sendo estudados para substituir o molibdênio são: tungstênio, vanádio e tântalo (Gelles e Hamilton, 1987).

\subsubsection{Efeito do Nitrogênio}

Esse elemento de liga aumenta consideravelmente a resistência mecânica, e devido a estabilização da austenita, aumenta a tenacidade dos aços dúplex. Esse elemento de liga geralmente é acrescido em ligas contendo molibdênio, aumentando assim a resistência à corrosão em cloretos. O nitrogênio aumenta a resistência à corrosão por pite e reduz o índice de precipitação de carbonetos de cromo, diminuindo assim a susceptibilidade de sensitização, e também diminui a tendência de formação da fase sigma (Magnabosco,2001; Asm Metals Handbook v.1, 1990).

\subsubsection{Efeito do Manganês}

O manganês, elemento gamagênico, tem sua principal função em anular o efeito das impurezas perniciosas nos aços, como o oxigênio e o enxofre. Associado ao níquel, o manganês aumenta a resistência mecânica dos aços (Asm Metals Handbook Desk Edition, 1985). 


\subsection{Propriedades mecânicas dos aços inoxidáveis dúplex}

As propriedades mecânicas de um aço inoxidável dúplex refletem as propriedades mecânicas das fases individuais austenita e ferrita, particularmente a fase ferrita, sendo que além dos aços inoxidáveis ferríticos apresentarem um limite de escoamento maior que os aços inoxidáveis austeníticos, seu limite de escoamento também apresenta maior dependência da temperatura que os austeníticos. Portanto, a ferrita quando adicionada à austenita tem o papel de aumentar o limite de escoamento de um aço dúplex, especialmente em baixas temperaturas (Solomon e Devine, 1982).

O efeito da ferrita nas propriedades mecânicas dos aços dúplex é ilustrado na FIG. 1 a 5. A FIG. 1 mostra endurecimento devido à presença de 50$60 \%$ em volume de ferrita (a estrutura do "heat A"), comparado com as curvas de material austenítico e ferrítico com aproximadamente a mesma composição química de ferrita e austenita encontradas em "heat A". O limite de escoamento está entre 0 da austenita e da ferrita, porém mais próximo do limite de escoamento da ferrita do que prediz a regra das misturas. Acredita-se que o endurecimento extra se deva ao refinado tamanho de grão da estrutura dúplex comparado com os grosseiros grãos das fases separadas, ferrita e austenita (Solomon e Devine, 1982).

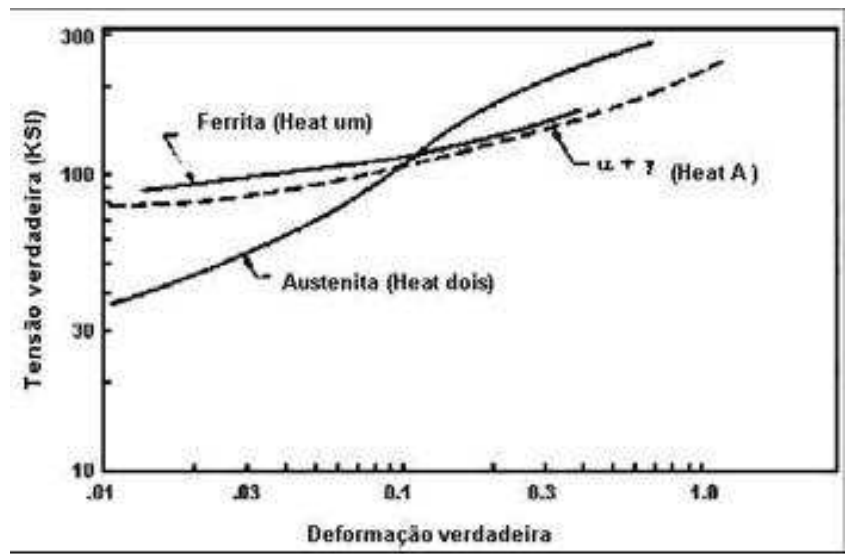

Figura1: Curva tensão vs. deformação verdadeiras de um aço dúplex (50\%-60\% em massa de ferrita) comparada com curvas equivalentes para material ferrítico e austenítico (Floreen e Rayden, 1968).

A FIG. 2 indica que a dependência da temperatura para o limite de escoamento do aço dúplex rico em ferrita é equivalente ao limite de escoamento 
para a ferrita pura. A FIG. 3, também de Floreen e Hayden (1968), ilustra que o limite de escoamento aumenta com o aumento da porcentagem volumétrica de ferrita. A FIG. 4 mostra, porém, que o inverso é válido para o limite de resistência, que diminui com o aumento da porcentagem volumétrica de ferrita. Já a FIG.5 mostra que o desenvolvimento de trincas de clivagem na fase ferrítica não apenas reduz a ductilidade, como também reduz extremamente a tenacidade, pois aumenta a temperatura da transição dúctil-frágil. (Solomon e Devine, 1982).

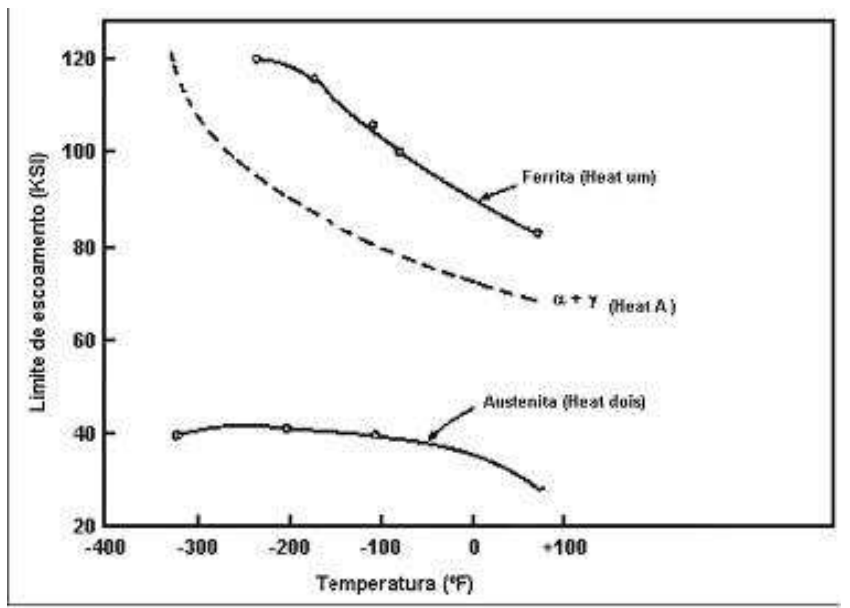

Figura 2: Comparação do limite de escoamento e sua dependência com a temperatura para aços inoxidáveis dúplex contendo 50 a $60 \%$ em peso de ferrita, com aços inoxidáveis ferríticos e austeníticos (Floreen e Rayden, 1968).

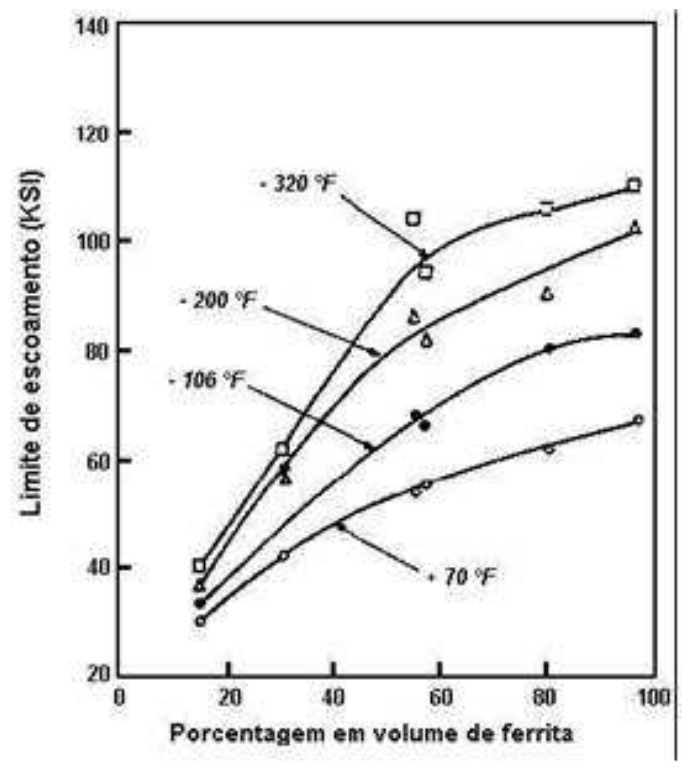

Figura 3: Dependência do limite de escoamento de aços inoxidáveis dúplex com a porcentagem em volume de ferrita (Floreen e Rayden, 1968). 


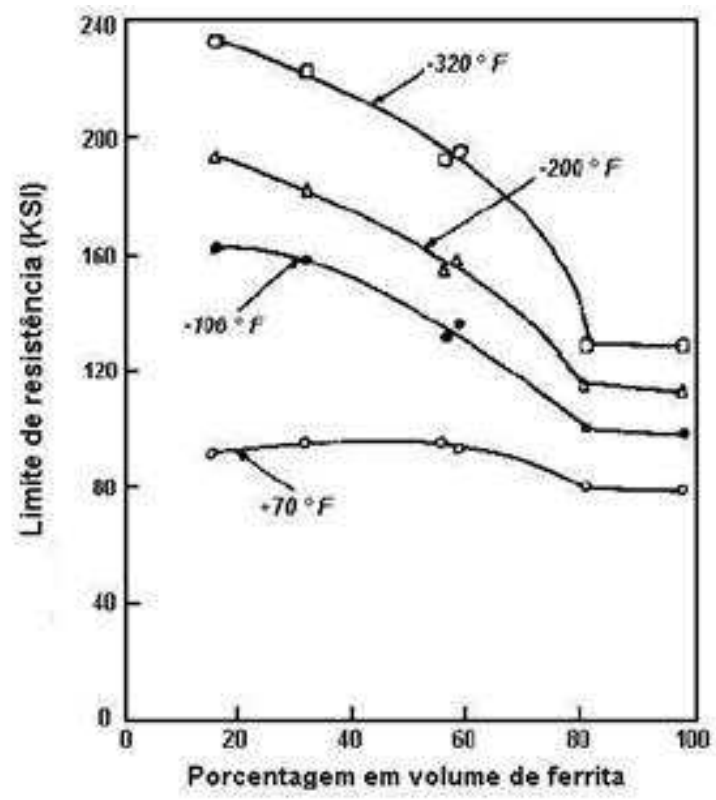

Figura 4:Dependência do limite de resistência de aços inoxidáveis dúplex com a porcentagem em volume de ferrita (Floreen e Rayden, 1968).

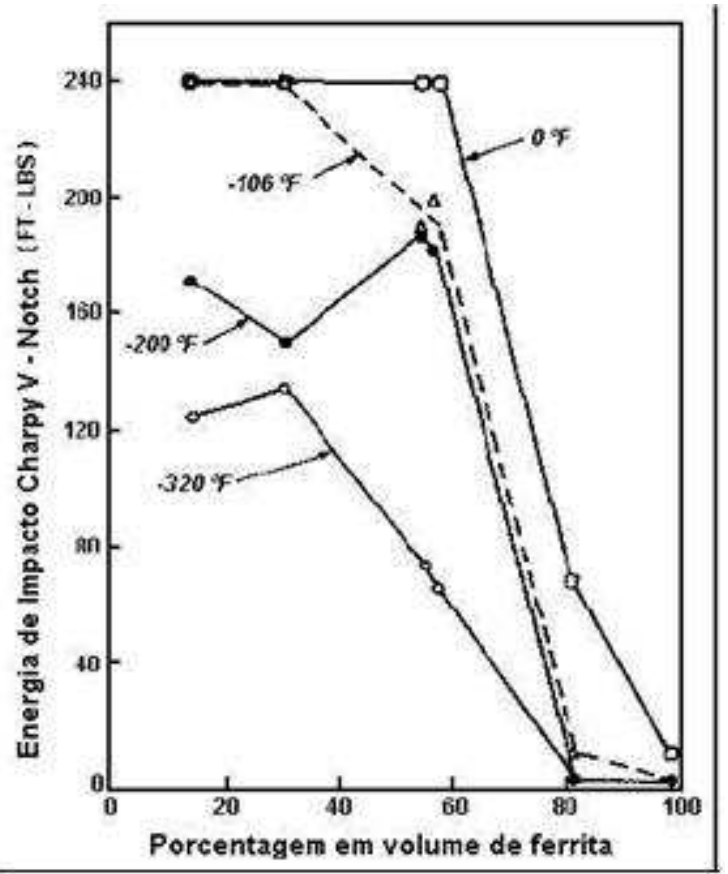

Figura 5:Dependência da energia de impacto de aços inoxidáveis dúplex com a porcentagem em volume de ferrita (Floreen e Rayden, 1968).

Em materiais na engenharia são possíveis dois modos de fratura, a saber, dúctil e frágil. Ambos envolvem a formação e a propagação de trincas. $A$ fratura dúctil é evidenciada pela presença de deformação plástica generalizada na 
superfície de fratura. Microscopicamente, são produzidas microcavidades (esféricas e/ou parabólicas) conhecidas como "dimples" ou alvéolos.

É importante notar que embora a fratura dúctil ocorra pela formação de dimples, a presença de dimples não exclui a possibilidade de a fratura ter ocorrido sem deformação plástica macroscópica.

As trincas em materiais dúcteis são ditas estáveis (isto é, resistem à extensão sem um aumento na tensão aplicada) e, como não são catastróficas, este tipo de fratura é quase sempre preferível (Callister, 2002).

No caso de fraturas de mecanismos frágeis as trincas são instáveis, e a superfície de fratura é relativamente plana e perpendicular à direção da carga de tração aplicada. A fratura frágil é aquela que ocorre sem deformação plástica macroscópica, porém é importante notar que nos metais e ligas, uma fratura é sempre iniciada e acompanhada de deformação plástica localizada; casos de fraturas transgranulares e intergranulares são encontrados em materiais frágeis policristalinos (Callister, 2002).

A fratura intergranular geralmente ocorre em materiais fragilizados em conseqüência de superaquecimento, ação do hidrogênio, precipitação de fase frágil em contorno de grão, por exemplo. Nestes casos não existem marcas que permitem localizar o ponto de início da fratura, mas a informação relevante que a fratura fornece é a própria fragilidade do material.

O aspecto mais característico da superfície de uma fratura frágil é aparecimento de facetas de clivagem. A fratura se propaga, continuamente, ao longo de planos cristalinos paralelos que se unem formando degraus, que tendem a convergir no sentido de propagação local da trinca, produzindo um aspecto característico de rios ou também chamados de "river patterns".

A clivagem de um cristal perfeito deveria produzir uma superfície plana, isto é, sem acidentes topográficos, superfície esta que seria coincidente com um plano cristalográfico. Como os cristais reais não são perfeitos, uma trinca de clivagem não se propaga ao longo de um único plano cristalográfico; a propagação se dá pelo avanço simultâneo de várias trincas em planos cristalográficos paralelos, estas trincas se unem pela formação de degraus produzidos por clivagem ao longo de um conjunto de planos de clivagem secundários ou pela separação ao longo da interface entre a matriz e uma região 
maclada do cristal, ou ainda, pela deformação plástica (cisalhamento) do material entre as trincas (ABM, 1979).

A orientação dos planos de clivagem evidentemente muda quando se atravessa um contorno de pequeno ângulo ou um contorno de grão. Quando a fratura atravessa essas regiões, observa-se um repentino aumento no número de degraus de clivagem, como ilustrado na FIG. 6.

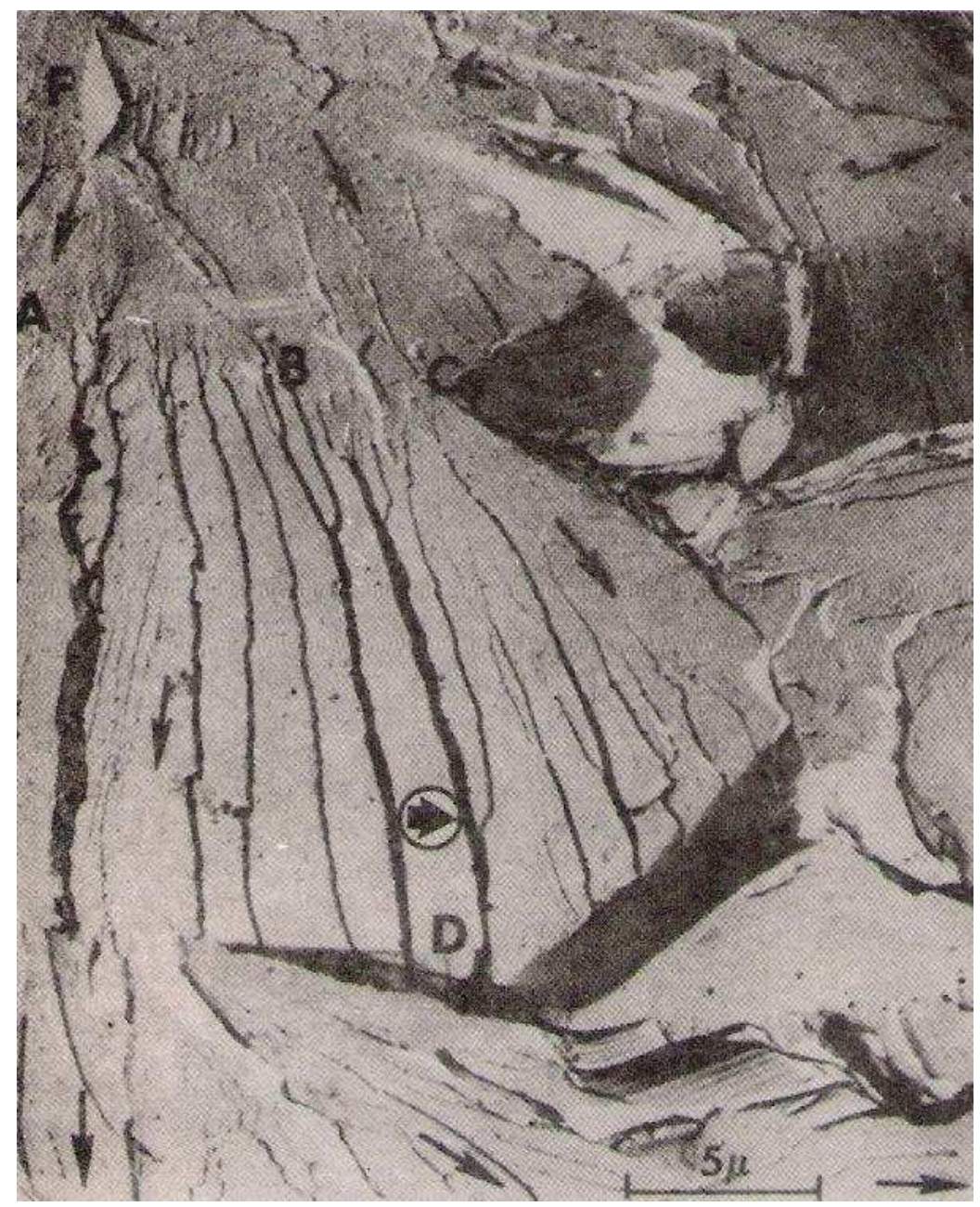

Figura 6: Aspecto de facetas de clivagem com rios característicos que indicam o sentido do local de propagação da fratura (ABM,1979).

A presença de austenita e ferrita não é importante apenas para melhorar as propriedades mecânicas de uma estrutura dúplex resultante, mas também permite com que esses aços se deformem superplasticamente durante trabalho a quente. A superplasticidade é caracterizada por grandes alongamentos sem a formação de estriç̧ão e é altamente favorecida pelos pequenos tamanhos de grão (1-10 $\mu \mathrm{m})$, os quais são provenientes da formação da austenita a partir da ferrita, presente em altas temperaturas durante seqüências de deformação a 
quente, pela formação de austenita por nucleação heterogênea na estrutura de discordâncias criada durante a deformação.

Durante envelhecimento isotérmico, pode ocorrer a precipitação de fases indesejáveis nos aços inoxidáveis dúplex, que causam tanto alteração de propriedades mecânicas quanto afetam a resistência à corrosão, resultando em diminuição na resistência e aumento na dureza do aço (Solomon e Levinson, 1978; Yi e Shoji, 1996).

Entre $700^{\circ} \mathrm{C}$ e $900^{\circ} \mathrm{C}$, pode ocorrer formação de fase sigma e, entre $300^{\circ} \mathrm{C}$ e $500^{\circ} \mathrm{C}$, pode ocorrer formação da fase alfa linha rica em cromo (Yi e Shoji, 1996).

A fase alfa linha $\left(\alpha^{\prime}\right)$ influencia fortemente o comportamento de aços inoxidáveis dúplex, devido ao endurecimento por partículas finamente dispersas de $\alpha^{\prime}$ na ferrita original, e a redução de tenacidade por esta provocada.

\subsection{A fase alfa linha}

A fase alfa linha $\left(\alpha^{\prime}\right)$ é uma fase de estrutura CCC, que contém principalmente cromo e ferro, porém é mais rica em cromo do que em ferro. Essa fase é responsável pelo fenômeno da fragilização que ocorre em aços inoxidáveis ferríticos e dúplex, na faixa de 270 a 550ํㅡ (Solomon e Levinson, 1978; Grobner, 1973; Chung e Chopra, 1986; Cicero et al., 2009; Kwon et al., 2001; Callone et al., 2004).

Este fenômeno foi nomeado fragilização a $475^{\circ} \mathrm{C}$, devido ao efeito pronunciado a esta temperatura (Fisher et al., 1953; Williams e Paxton, 1957; Gironès et al., 2004; lacoviello et al., 2005; lacoviello et al., 1999; Park e Kwon, 2005, Cortie e Pollak, 1995; Sahu et al., 2009).

Geralmente a precipitação de alfa linha nos componentes metálicos que estão em serviço por longo tempo em uma indústria nuclear ocorre em temperaturas em torno de $270-330^{\circ} \mathrm{C}$ que são as temperaturas de trabalho das plantas nucleares (Cicero et al., 2009, Shiao et al., 1994; Yamada et al., 2006).

A ocorrência da fase alfa linha pode ser apresentada na forma de um diagrama TTT, cujo nariz das curvas de precipitação encontra-se por volta de $475^{\circ} \mathrm{C}$, como mostra a FIG. 7.

O tempo de incubação para formação da fase alfa linha é reduzido à medida que o teor de cromo presente no aço aumenta, isto é, as curvas TTT 
sofrem um deslocamento para tempos mais curtos e intervalos de temperaturas mais ampliados.

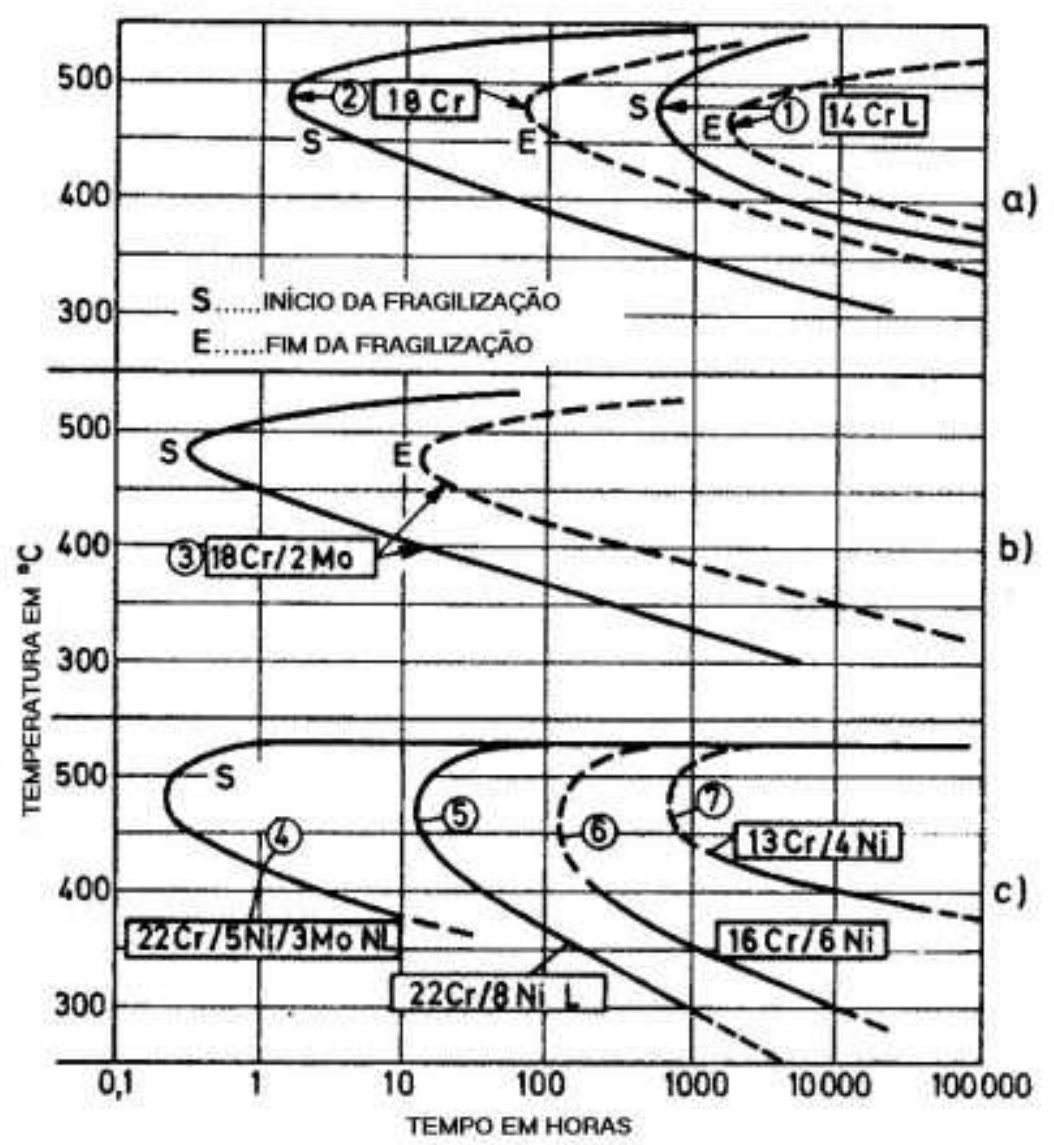

Figura 7:Diagrama TTT para precipitação de alfa linha (Terada, 2003).

A fase $\alpha^{\prime}$ é uma fase que possui uma grande resistência ao engrossamento, mesmo para tempos longos de exposição, devido à baixa energia de interface entre a ferrita e a alfa linha.

Esta fase enriquecida em cromo está finamente dispersa na ferrita, e essa ocorrência é devida ao fato da ferrita nos aços inoxidáveis dúplex apresentar um maior teor de cromo e maior velocidade de difusão do que a austenita.

Por apresentar tamanho reduzido, na faixa de 20 a $200 \AA$, pouco contraste e similaridade estrutural com a matriz ferrítica, a fase alfa linha é difícil de ser observada através de microscopia ótica e eletrônica. No entanto, segundo Terada (2003; 2009), a observação da fase alfa linha pode ser feita por microscopia eletrônica de transmissão após períodos muito longos de envelhecimento térmico. 
Atualmente pesquisadores têm avaliado o grau de fragilização à $475^{\circ} \mathrm{C}$ nos aços inoxidáveis ferríticos e dúplex através das mudanças nas propriedades magnéticas e eletroquímicas induzidas pela precipitação da fase alfa linha (Park e Kwon, 2005; Lo et al., 2009; Cheon e Kim, 2000).

Variações na energia termoelétrica (TEP), a qual aumenta com o progresso da decomposição espinodal, também tem demonstrado ser uma técnica de monitoramento promissora (Kawaguchi e Yamanaka, 2002; Niffenegger e Leber, 2009).

Mecanicamente, o teste de small punch (SP), que avalia as propriedades mecânicas diretamente através da superfície de fratura de pequenos corpos de prova, tem sido considerado para avaliar a fragilização causada pela decomposição espinodal. (Cheon e Kim, 2000); outro método que também é sensível ao monitoramento da decomposição espinodal é o $\mathrm{ABI}$ (Automated ball identation), um método que permite obter dados "on-line" dos componentes em serviço a respeito das suas propriedades mecânicas como resistência e tenacidade (Mathew et al., 1999).

Magneticamente, acredita-se que a alfa linha seja paramagnética devido ao enriquecimento em Cr e Mo (Vasconcelos et al., 2009; Lo et al., 2009; Bley, 1992). Foi notado que a precipitação desta fase aumenta a força coerciva (Pedrosa et al., 2001) e a temperatura de transição magnética (Tavares et al., 2000). Todas essas mudanças nas propriedades magnéticas podem ser avaliadas através de ensaios não destrutivos para avaliação da decomposição espinodal.

Um exemplo de avaliação do efeito da fragilização à $475^{\circ} \mathrm{C}$ através do estudo das propriedades magnéticas é feito pelo método da análise termomagnética (TMA). Nesse tipo de análise a temperatura Curie (Tc), temperatura de transição magnética, aumenta com o tempo de envelhecimento, e esse aumento pode ser explicado pelo fato de que durante o envelhecimento a fase ferrita se decompõe em domínios ricos em ferro e em domínios ricos em cromo, e de acordo com Solomon e Levinson (1978), a presença do níquel promove um maior enriquecimento de cromo nas regiões ricas em cromo (fase alfa linha), como conseqüência, esses domínios se tornam paramagnéticos a temperatura ambiente. Em contrapartida, como as regiões ferromagnéticas, ou seja, as regiões ricas em ferro contêm menos cromo, a Tc aumenta. Portanto, 
verifica-se o aumento da Tc com o tempo de envelhecimento como consequência da decomposição espinodal $\left(\alpha \rightarrow \alpha+\alpha^{\prime}\right)$ (Da Silva et al., 2001).

Quando um material está fragilizado pela formação da fase $\alpha$ ', sua dureza, limite de escoamento e seu limite de resistência são aumentados, enquanto o alongamento, a resistência ao impacto e à corrosão são diminuídos.

Uma vez que a precipitação da fase alfa linha ocorre por um processo controlado de difusão, sua taxa de precipitação pode ser retardada pela substituição parcial do molibdênio pelo tungstênio, que possui uma velocidade de difusão de 10 a 100 vezes mais baixa que a do molibdênio em ligas de ferro, contribuindo também para dificultar a difusão de outros elementos durante envelhecimento, portanto retardando a fragilização do material (Park e Kwon, 2002).

Park et al. (2006) verificaram que a substituição parcial de molibdênio por tungstênio não apenas melhora a resistência à corrosão localizada como também reduz a taxa de formação da fase sigma nas ligas.

A ferrita fragilizada pela presença de $\alpha^{\prime}$, em geral, apresenta fratura frágil do tipo clivagem, mesmo à temperatura ambiente (Ura et al., 1994).

A fase $\alpha^{\prime}$ pode ser formada por dois mecanismos: decomposição espinodal e nucleação e crescimento.

A decomposição espinodal e nucleação e crescimento tem sido assunto de investigação de muitos pesquisadores (Lo et al., 2009; Chandra e Schwartz, 1971; Solomon e Levinson, 1978; Isalgue e Anglada, 1990; Grobner, 1973; Marcinkowski et al., 1964; Anglada et al., 1989; Ura et al., 1995; Jacobsson et al., 1975; Newell, 1946; Blackburn e Nutting, 1964). Geralmente é aceito que o envelhecimento térmico abaixo de temperaturas de aproximadamente $550^{\circ} \mathrm{C}$ pode causar a decomposição espinodal. Além do envelhecimento térmico, a radiação também pode induzir a decomposição espinodal no sistema FeCr, como demonstra um estudo de Miller et al.(1996) e Gelles (1996).

Segundo Grobner (1973) a fase alfa linha pode se formar através de nucleação e crescimento se o teor de cromo na liga for menor que $17 \%$, caso contrário, a fase irá se formar através do mecanismo de decomposição espinodal. No entanto, estudos recentes (Hatterstrand et al., 2009) mostraram que a alfa linha pode formar na fase ferrita do aço inox dúplex SAF 2507 (\% Cr> 17) tanto através de nucleação e crescimento quanto por decomposição espinodal 
dependendo da temperatura de envelhecimento e se o material for plasticamente deformado. O trabalho de Vitek et al. (1991) mostrou também que tanto os mecanismos de decomposição espinodal quanto os de nucleação e crescimento podem ocorrer simultaneamente.

A deformação plástica facilita a decomposição espinodal porque as discordâncias geradas podem diminuir consideravelmente as tensões de coerência, pois estas tensões atuam como barreiras para o processo de decomposição espinodal (Hatterstrand et al., 2009).

Segundo lacoviello et al. (2005), a formação da fase $\alpha^{\prime}$ em aços inoxidáveis dúplex semelhantes ao UNS S31803, e envelhecidos a $475^{\circ} \mathrm{C}$ por 1000h, se dá por decomposição espinodal da ferrita. Devido às flutuações do teor de cromo no interior dos grãos de ferrita o material apresenta alta susceptibilidade à corrosão localizada. Essas flutuações podem ser geradas tanto pelo mecanismo de decomposição espinodal, que se caracteriza por uma queda gradual do teor de cromo com o tempo de envelhecimento, quanto por nucleação e crescimento, que provoca um efeito mais intenso para os momentos iniciais de formação de alfa linha.

No entanto, segundo Newell (1946), a remoção da fase alfa linha pode ser feita através de tratamento térmico a $582^{\circ} \mathrm{C}$ durante 5 horas.

\subsection{Efeito da fase alfa linha nas propriedades mecânicas e na resistência à corrosão de aços inoxidáveis dúplex.}

Conforme descrito anteriormente, quando um material está fragilizado pela formação da fase $\alpha$, sua dureza, limite de escoamento e seu limite de resistência são aumentados, enquanto o alongamento, a resistência ao impacto e à corrosão são diminuídos, essas mudanças nas propriedades do material se devem à diminuição da mobilidade das discordâncias, pela criação de micro espaços próximos aos precipitados ricos em cromo da alfa linha na matriz ferrítica e criação de regiões empobrecidas em cromo ao redor desses precipitados, tornando o material mais susceptível à corrosão localizada. Nos aços fragilizados pela alfa linha a dureza aumenta notavelmente com o aumento do tempo de envelhecimento e da quantidade de ferrita presente no aço.

Em estudos recentes (Yamada et al., 2006) verificou-se que apenas a dureza da fase ferrita é aumentada com o tempo de envelhecimento enquanto 
que a dureza da fase austenita não se altera, portanto pode-se concluir que a ductilidade do aço fragilizado é conferida então pelas regiões austeníticas da microestrutura.

Em aços inoxidáveis dúplex envelhecidos à $475^{\circ} \mathrm{C}$, a ferrita fragilizada pela presença dos precipitados de $\alpha^{\prime}$, tem grande tendência em apresentar fratura frágil do tipo clivagem, através da propagação das trincas em interfaces e contornos de grão (intergranular). Isto ocorre, pois a presença da fase $\alpha^{\prime}$, proveniente da decomposição espinodal da fase ferrita, dificulta a movimentação das discordâncias e restringe o escorregamento a poucos planos, ocasionando assim esse tipo de fratura frágil.

Segundo Tavares et al. (2000), o aspecto da fratura do aço inoxidável dúplex UNS S31803 se modifica de uma fratura completamente dúctil sem facetas de clivagem na fase ferrita na condição solubilizada, para uma fratura muito frágil após $300 \mathrm{~h}$ à $475^{\circ} \mathrm{C}$.

Qualitativamente, o comportamento de fratura dos materiais pode ser determinado utilizando-se as técnicas de ensaios de impacto Charpy e Izod. Com base na dependência dessa energia de impacto em relação à temperatura ou aparência da superfície de fratura, é possível afirmar se um material experimenta ou não transição dúctil-frágil, bem como a faixa de temperatura ao longo da qual essa transição ocorre (Callister, 2002).

De acordo com Yi e Shoji (1996), a diminuição da energia absorvida durante o ensaio de impacto de aços inoxidáveis dúplex envelhecidos é atribuído ao endurecimento da fase ferrita.

Ligas metálicas que possuem estruturas cristalinas CCC e HC experimentam essa transição e, para aplicações estruturais, devem ser utilizadas a temperaturas superiores a essa faixa de transição (Callister, 2002).

Segundo o trabalho de Martins et al. (2007) realizado com aços inoxidáveis dúplex CD4MCu e CD4MCuN, na condição solubilizada, resfriados em água e com tratamento térmico para alívio de tensões, a presença de nitrogênio na composição do material leva a uma maior concentração da fase austenita na microestrutura aumentando a capacidade de absorção de energia nos ensaios de impacto.

A superfície de fratura do aço CD4MCu foi facetada, ou seja, o aço CD4MCu apresentou uma fratura de clivagem, o que significa uma baixa 
tenacidade à fratura, apresentando o valor de 26J de energia absorvida no impacto na condição de 2 horas de tratamento para alívio de tensão a $550^{\circ} \mathrm{C}$ e $55 \mathrm{~J}$ em 4 horas de tratamento a $350^{\circ} \mathrm{C}$, esses valores são típicos de materiais frágeis, enquanto que o aço CD4MCuN apresentou uma superfície de fratura fibrosa que é típica de materiais que apresentam alta tenacidade à fratura, no estudo realizado, o valor da energia absorvida na condição de 2 horas de tratamento para alívio de tensão foi de $116 \mathrm{~J}$ e de 140J para 4 horas de tratamento (Martins et al., 2007).

A resistência à corrosão por pite, determinada através de ensaios de polarização cíclica em solução de $3,5 \% \mathrm{NaCl}$ é sensivelmente diminuída pela presença da fase alfa linha devido à formação de regiões empobrecidas em cromo e ricas em ferro ao redor dos precipitados de alfa linha. Essas regiões não são apenas susceptíveis à dissolução ativa como também contribuem para a degradação da estabilidade do filme passivo (Park et.al.,2004; Terada, 2003).

Em estudo recente (Terada et al., 2008) de aços inoxidáveis ferríticos envelhecidos a $475 \stackrel{\circ}{ } \mathrm{C}$ foi constatado que a resistência à corrosão por pite diminuiu, notou-se também que a densidade de pites aumentou juntamente com a profundidade dos mesmos. Park e Kwon (2002) também relataram em seu estudo com aço inoxidável dúplex envelhecido a $475^{\circ} \mathrm{C}$ que a resistência à corrosão por pite foi sensivelmente diminuída com o progresso do tempo de envelhecimento nesta temperatura e, nas zonas empobrecidas em cromo ao redor dos precipitados de alfa linha surgiu grande quantidade de micro pites durante o teste de polarização anódica.

Segundo Do Nascimento et al. (2008) para aços inoxidáveis contendo alto teor de cobre e envelhecidos a $475^{\circ} \mathrm{C}$, durante a decomposição espinodal além da formação da fase alfa linha também irá se formar precipitados muito finos da fase $\varepsilon$ e, esta fase por sua vez também promoverá a diminuição na resistência à corrosão por pite nesses materiais.

Terada et al. (2009) verificaram através de ensaios de impedância eletroquímica e de polarização potenciodinâmica que a resistência à corrosão generalizada e localizada diminuíram com o tempo de envelhecimento em $475^{\circ} \mathrm{C}$, contudo, até $100 \mathrm{~h}$ de envelhecimento não conseguiu se observar mudanças nas propriedades de resistência a corrosão da camada interna de óxido devido a grande quantidade de cromo do aço DIN 14575. 


\subsection{Corrosão}

A precipitação de fases ricas em cromo pode alterar a resistência à corrosão dos aços inoxidáveis dúplex, havendo, pois, regiões no metal empobrecidas em cromo e, conseqüentemente, com menor tendência à formação de camada passiva, favorecendo então o fenômeno da corrosão localizada.

A passivação é a modificação do comportamento eletroquímico de um metal ativo no sentido de diminuição de sua atividade devido à formação da película protetora chamada película passiva. A formação dessa película pode ocorrer por reação espontânea (passivação química natural) ou por imposição de potenciais mais nobres ao metal, fazendo-o funcionar como ânodo (passivação por polarização anódica).

Nos aços inoxidáveis a película passiva geralmente é formada por óxidos que apresentam caráter dúplex, contendo em sua camada externa óxidos ricos em hidróxidos e óxidos de ferro e uma camada interna constituída por óxidos ricos em cromo (Montemor, 2000; Da Cunha Belo et al., 1998; Hakiki e Da Cunha Belo, 1998; Bojinov et al., 1999; Castle e Clayton, 1977). Esta película é autoregenerativa e protege o metal do meio corrosivo, sendo que a resistência à corrosão pode ser melhorada pela adição de níquel, molibdênio e nitrogênio.

O filme passivo pode ser caracterizado através da sua condutividade elétrica e seu comportamento eletroquímico.

Existem muitos estudos que utilizam a espectroscopia Auger e espectroscopia de fotoelétrons emitidos por raios-X que mostram o cromo como 0 elemento de liga presente no aço inoxidável responsável pela formação da película passiva nesses materiais, contribuindo então para o aumento da resistência à corrosão (Sourisseau et al., 2005; Asami et al., 1976, 1977, 1978; Lister e Pinhero, 2003; Bastos et al., 2004).

As reações eletroquímicas que ocorrem na interface entre um material metálico e o meio circunvizinho dependem do potencial de eletrodo. O estudo destas reações pode ser feito através da relação entre um potencial aplicado externamente e a corrente gerada nas reações eletroquímicas (anódicas e catódicas) que se desenvolvem na superfície do eletrodo. Um dos métodos utilizados no estudo do comportamento eletroquímico dos materiais metálicos consiste na varredura contínua do potencial e o correspondente registro da 
corrente gerada, originando a curva de polarização deste material (Gemelli, 2001; Sedriks, 1996).

A polarização potenciodinâmica é a principal técnica utilizada para a obtenção de curvas de polarização. Esta prevê a varredura contínua do potencial, iniciando-se ou no potencial de corrosão, $E_{\text {corr }}$ (aquele que se estabelece quando da estabilização do potencial após imersão do material na solução) ou em potenciais onde predominam reações catódicas (aqueles menores que $\mathrm{E}_{\text {corr }}$ ), e elevando-se o potencial à taxa de varredura constante. A velocidade de varredura, a composição da solução, o tempo de imersão anterior à varredura de potencial e a temperatura de ensaio influenciam a forma das curvas de polarização. A corrente, nas curvas de polarização, é mostrada em valores absolutos, e esta é dividida pela área de material exposta ao meio, criando o conceito de densidade de corrente, que representa a corrente por unidade de área.

\subsubsection{Corrosão por pite em aços inoxidáveis dúplex}

A corrosão por pite é caracterizada por um ataque altamente localizado de metais que se apresentam passivados. Este tipo de corrosão somente ocorre num dado meio em potenciais de eletrodo iguais ou superiores a um determinado potencial, conhecido como potencial de pite ( $\left.E_{\text {pite }}\right)$ (Wolynec,2003).

O PREN (pitting resistance equivalent number) ou também chamado como "índice de pite" dado normalmente por IP $=(\% \mathrm{Cr}+3,3 \% \mathrm{Mo}+16 \% \mathrm{~N})$ é bastante utilizado para avaliar a resistência à corrosão por pite nos aços inoxidáveis dúplex, sendo que quanto maior o valor do PREN maior é a resistência à corrosão por pite do material.

Em aço dúplex solubilizado pode ocorrer pite tanto na austenita como na ferrita: se o aço contém nitrogênio, que se localiza na austenita, a resistência à formação de pites será maior nesta fase; já em aços sem nitrogênio, a ferrita tem maior resistência à formação de pites por apresentar teores mais altos de cromo e molibdênio (Magnabosco, 2001).

Trabalho com aço Zeron 100 (25\%Cr-6,5\%Ni-3,7\%Mo-0,25\%N0,7\%Cu- 0,7\%W) solubilizado, em soluções de cloreto de sódio, mostra a ocorrência de ataque preferencial da ferrita, mostrando maior estabilidade da austenita, seguido de ataque nos contornos de grão nas duas fases e contornos 
de interfase, para então se iniciar a formação de pites na ferrita (Schmidt-Rieder et al., 1996).

\subsubsection{Técnicas eletroquímicas em corrosão e relação com a microestrutura.}

Com o objetivo de investigar os mecanismos e cinética de corrosão de um sistema geralmente empregam-se técnicas eletroquímicas. Pelo uso destas técnicas, taxas de corrosão instantâneas podem ser obtidas. Os métodos eletroquímicos podem ser divididos em técnicas a corrente contínua (d.c.) e a corrente alternada (a.c.) (Wolynec, 2003).

Embora as películas passivas dos aços inoxidáveis apresentem excelentes propriedades de proteção, a presença de íons cloreto, brometo, inclusões, zonas empobrecidas em cromo, planos de escorregamento ativos podem levar à quebra prematura e localizada da película passiva, ocasionando a corrosão localizada. A quebra da película passiva também pode ocorrer em fases precipitadas e nas suas interfaces, como mostra a FIG. 8.

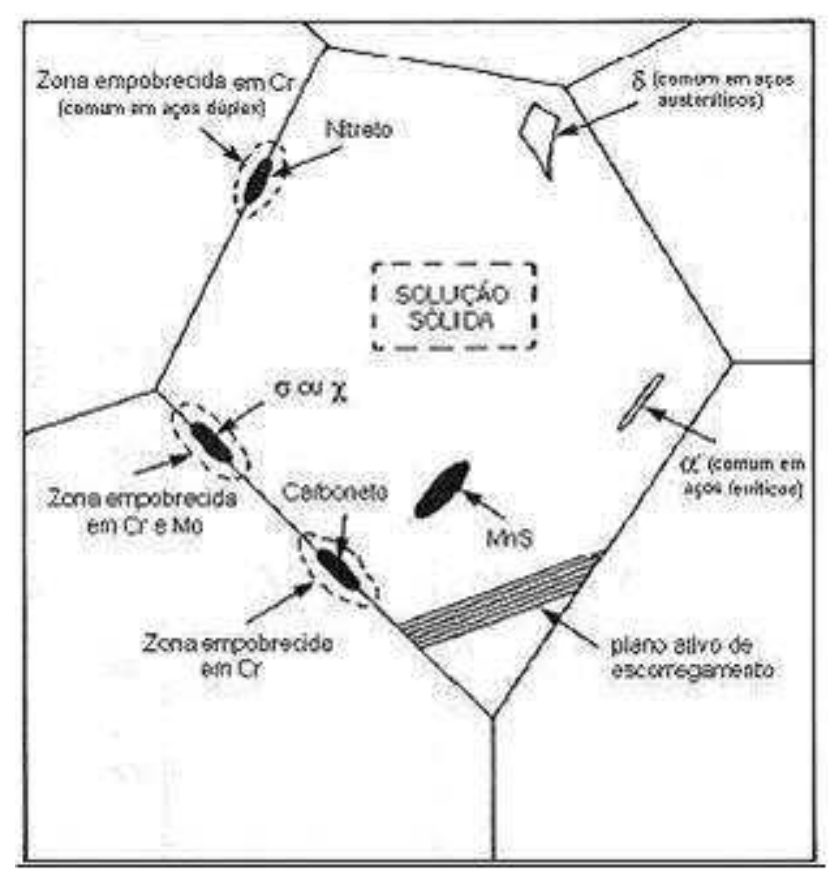

Figura 8: Diagrama esquemático das variáveis metalúrgicas que podem afetar a passividade de aços inoxidáveis (Sedriks, 1986).

O teste eletroquímico mais comum para avaliar a susceptibilidade à corrosão localizada e, particularmente à corrosão por pite, é a polarização 
potenciodinâmica cíclica em soluções contendo íons cloreto e/ou brometo (Magnabosco e Alonso-Falleiros, 2005). Para obtenção das curvas de polarização cíclica, a varredura de potencial inicia-se, via de regra, no potencial de corrosão, elevando-se o potencial até que uma dada densidade de corrente seja atingida; a partir deste ponto a varredura de potencial é realizada no sentido inverso, na mesma velocidade de varredura de potencial.

Uma curva típica de polarização cíclica é a representada na FIG.9 (Magnabosco, 2001). Numa curva de polarização, a ocorrência de pite gera um grande aumento de densidade de corrente, e o potencial eletroquímico onde este ocorre é chamado potencial de pite $\left(E_{\text {pite }}\right)$. Quanto mais elevado for este potencial, maior a resistência do material à formação de pites de corrosão (Sedriks, 1996).

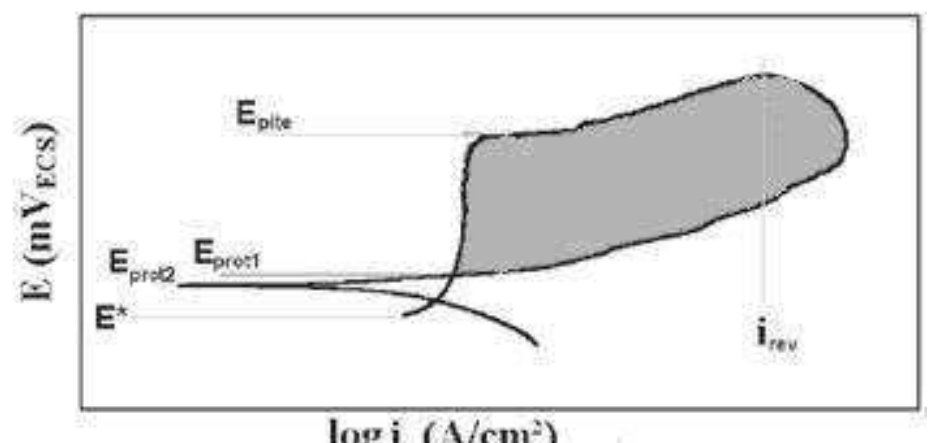

Figura 9: Curva de polarização cíclica típica de um aço inoxidável em solução contendo íons cloreto. $E^{*}$ :potencial de corrosão. $E_{\text {prot1 }}$ e $E_{\text {prot2 }}$ : potencial de proteção. $\mathrm{E}_{\text {pite: }}$ potencial de pite. i irev: densidade de corrente de reversão (Magnabosco, 2001).

O potencial de pite, indicado na FIG. 9 por $E_{\text {pite, representa a }}$ resistência do material ao início da formação de pites; quando estes se iniciam e começam a crescer, a densidade de corrente aumenta rapidamente. Atingida a densidade de corrente de reversão ( $\mathrm{i}_{\text {rev }}$ ) a varredura de potencial é revertida, em direção a potenciais catódicos. Quanto maior o valor de $i_{\text {rev }}$, maior a penetração ou alargamento do pite, ou ainda, maior o número de pites formados. No momento em que a curva descendente cruza a curva original tem-se o chamado potencial de proteção ( $\left.E_{\text {prot1 }}\right)$, que recebe este nome, pois, abaixo de $E_{\text {prot1 não }}$ existe possibilidade de quebra da película passiva, ou de sua não regeneração, sendo o material imune à ocorrência de pites. Alguns autores descrevem ainda 
como potencial de proteção o potencial abaixo de $E_{\text {prot1}}$, no qual ocorre a reversão de corrente para valores catódicos, chamado $E_{\text {prot2, no qual, por também não }}$ existir possibilidade de quebra da película passiva ou de sua não regeneração, o material é imune à ocorrência de pites.

Entre a reversão de varredura de potencial e $E_{\text {prot1 ocorre a }}$ repassivação dos pites formados; assim, a área destacada na FIG.9 é diretamente relacionada à repassivação dos pites formados, e, consequentemente, para o impedimento de seu crescimento. Pode-se concluir, portanto, que quanto maior a área do laço destacada na figura, menor a resistência do material à propagação dos pites (Magnabosco, 2001).

Uma outra técnica eletroquímica que está sendo cada vez mais aplicada em diversos estudos de corrosão é a espectroscopia de impedância eletroquímica (EIE), por possibilitar a separação de vários processos que ocorrem com cinéticas diferentes, além de permitir a identificação de propriedades que não envolvam a transferência de carga, como por exemplo, a capacitância da dupla camada elétrica. (Mansfeld e Shih, 1988).

A EIE consiste em aplicar um sinal de corrente alternada com diferentes valores de freqüência ao material em análise, no presente trabalho o aço inoxidável super-dúplex UR $52 \mathrm{~N}+$ e medir a resposta de corrente ao sinal aplicado.

Uma grande quantidade de parâmetros pode influenciar o comportamento eletroquímico dos materiais metálicos, como pré-tratamentos, recobrimentos e condições de ensaio, tais como temperatura e concentração de oxigênio no meio. A EIE é uma técnica particularmente útil na caracterização de recobrimentos (Bonora et al., 1996) e das películas passivas.

Segundo Wolynec (2003), o método de impedância eletroquímica apresenta diversas vantagens com relação às técnicas de corrente contínua, destacando-se as seguintes:

- Utilização de sinais muito pequenos que não perturbam as propriedades do eletrodo.

- Possibilidade de estudar reações de corrosão e medir taxas de corrosão em meios de baixa condutividade.

- A resistência de polarização e a capacitância da dupla camada podem ser determinadas numa mesma medida. 
Uma das limitações do método de EIE é a de que ele determina somente a resistência de polarização; os declives de Tafel têm que ser determinados por outro método.

A análise dos resultados obtidos experimentalmente no ensaio de EIE pode ser feita através de ajustes de circuitos equivalentes que fornecem modelos que descrevem a resposta da interface em termos de componentes conhecidos de um circuito elétrico, como resistores, capacitores, indutores, elementos de fase constantes (CPE) ou elementos de Warburg. Segundo Bonora et al. (1996), o circuito mais adequado a cada ajuste deve ter o menor número de componentes possível, dentro de um erro aceitável.

De acordo com Ge et al. (2003), as variações dos elementos R e CPE indicam alterações no grau de compactação da camada passiva do aço inoxidável, assim sendo um aumento de resistência $(R)$ e diminuição da capacitância (CPE), sugerem um filme passivo menos defeituoso.

A equação 3 define a impedância do elemento de fase constante (CPE) onde $\omega$ é a freqüência angular descrita por $\omega=2$.П.f, onde f é a freqüência; $Y$ é a combinação de propriedades relacionadas à superfície e às espécies eletroativas independentes, $\mathrm{j}=\sqrt{ }-1$ e $n(0<\mathrm{n}<1)$, o qual está associado com a distribuição não uniforme de corrente devido à rugosidade e imperfeições na superfície (Martini e Muller, 2000).

Se $\mathrm{n}$ for igual à zero, $\mathrm{Y}$ é um resistor puro. Caso $\mathrm{n}$ seja igual a $1 / 2,0$ elemento de fase constante representa a chamada impedância de Warburg, que modela o comportamento difusivo através de uma camada de óxido ou de revestimento superficial (Liu et al., 2003). Se $n$ é igual a 1, Y descreve as condições de um capacitor ideal.

$$
Z_{C P E}=\left[Y .(j . \omega)^{n}\right]^{-1}
$$

Os modelos propostos na literatura para aços inoxidáveis (Azumi et al., 1986; Macdonald, 1990; Bundy et al., 1993; Escudero et al., 1995; Montemor et al, 2000, Liu et al., 2003) são representados na FIG.10. Em todos eles, as capacitâncias foram substituídas por elementos de fase constantes (CPE) que representam o desvio de um capacitor ideal (Terada,2008). 
O modelo da FIG.10a é composto pela resistência correspondente à camada de óxido e a capacitância desta camada em paralelo, representando um sistema passivo simples, onde haveria adsorção acompanhada de transferência de carga (Ge et al., 2001, Wolynec, 2003). A FIG.10b acrescenta a chamada impedância de Warburg ao sistema, sugerindo um processo de difusão iônica através dos produtos de corrosão precipitados na região próxima e/ou no interior dos pites (Polo et al., 2002). O circuito da FIG.10c é utilizado nos casos em que o processo corrosivo inclui uma camada porosa e outra barreira, como no estudo de recobrimentos com tintas ou ligas de titânio (Assis, 2006). A FIG.10d representa um sistema de camada duplex, onde cada componente R-CPE indica a impedância em freqüências diferentes (baixas - R2 e CPE2 ; e altas - R1 e CPE1).

Azumi et al (1986), Gerischer (1989) e Ge et al. (2001) sugerem que estes componentes se referem, respectivamente, ao filme passivo e à dupla camada de Helmholtz na interface filme/solução. No entanto, a literatura (Hakiki et al, 1995; Da Cunha Belo et al., 1998; Hakiki e Da Cunha Belo, 1998; Montemor et al., 2000) também defende que o circuito equivalente composto de dois componentes R-CPE paralelos, em série, e a resistência da solução têm sido proposto para representar as propriedades da camada duplex do filme passivo. Um componente R-CPE estaria relacionado à camada interna do filme passivo, enquanto o outro componente R-CPE que aparece em freqüências mais elevadas, estaria relacionado com a camada externa (Terada, 2008). 
a)

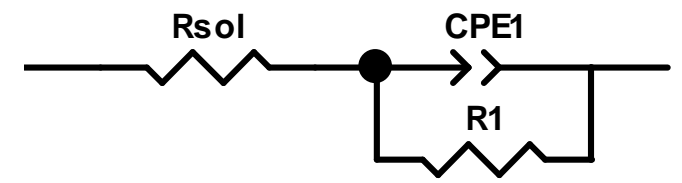

b)

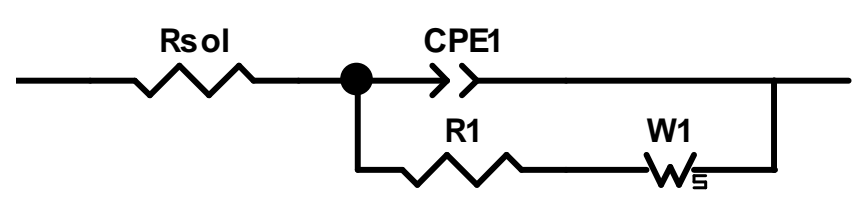

c)

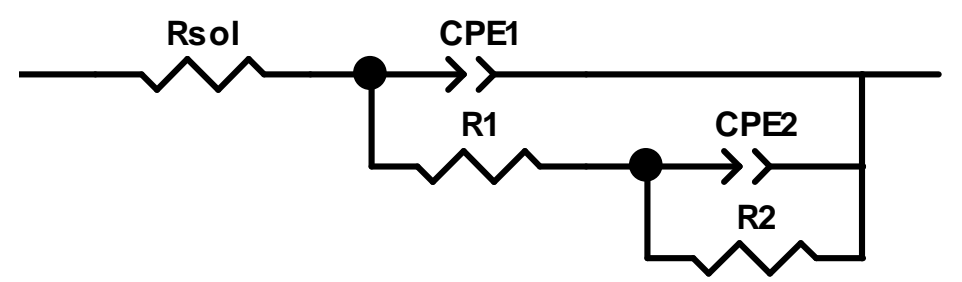

d)

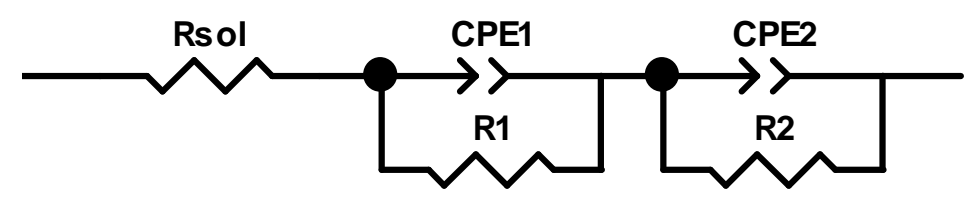

Figura 10: Circuitos elétricos equivalentes propostos para caracterizar a camada passiva dos aços inoxidáveis (Azumi et al., 1986; Bundy et al., 1993; Montemor et al, 2000; Liu et al., 2003; Antunes, 2006; Terada, 2008). 


\section{MATERIAIS E MÉTODOS}

\subsection{Materiais}

O material utilizado neste trabalho foi o aço inoxidável super-dúplex UR $52 \mathrm{~N}+$ produzido pela empresa Usinor Industeel S.A, cuja composição química é mostrada na tabela 1.

Tabela 1- Composição química (\% em massa) do aço estudado.

$\begin{array}{ccccccccccc}\mathrm{Cr} & \mathrm{Ni} & \mathrm{Mo} & \mathrm{N} & \mathrm{C} & \mathrm{Mn} & \mathrm{Cu} & \mathrm{S} & \mathrm{P} & \mathrm{Si} & \mathrm{Fe} \\ 24,9 & 6,5 & 4,04 & 0,218 & 0,0236 & 0,867 & 1,399 & 0,0004 & 0,0464 & 0,295 & \text { Bal. }\end{array}$

\subsection{Preparação das amostras}

As amostras foram primeiramente submetidas a um tratamento de solubilização em $1200^{\circ} \mathrm{C}$ por 1 hora em forno tubular da marca Lindberg (equipamento do CDMatM -FEI) sob atmosfera de nitrogênio puro para que fosse evitada a oxidação excessiva do material, seguido de resfriamento brusco em água.

A partir do material na condição solubilizada em $1200^{\circ} \mathrm{C}$ por 1 hora, corpos-de-prova foram envelhecidos a $475^{\circ} \mathrm{C}$ por $30 \mathrm{~min}, 1 \mathrm{~h}, 4 \mathrm{~h}, 12 \mathrm{~h}, 24 \mathrm{~h}, 48 \mathrm{~h}$, 96h, 576h, 768h e 1032h, esperando-se a obtenção de diferentes frações volumétricas de fase alfa linha na estrutura do aço.

As amostras do aço tratado termicamente foram lixadas em todas as faces em lixa 220 mesh para retirada de imperfeições grosseiras e dos óxidos formados durante o tratamento térmico, em seguida foram cortadas, lixadas novamente em todas as faces até 600 mesh para remoção total de óxidos e prevenção de corrosão por frestas. As amostras foram então embutidas em resina termofixa de cura a quente (baquelite) e posteriormente foram feitos furos roscados M3 gerando corpos-de-prova para análise metalográfica, medição de microdureza, ensaios eletroquímicos e observação da superfície.

A superfície de observação corresponde à seção longitudinal das barras, com relação à direção de laminação. Os corpos-de-prova metalográficos 
foram lixados até 2000 mesh, para, em seguida, serem polidos utilizando pasta de diamante de diâmetros $6 \mu \mathrm{m}, 3 \mu \mathrm{m}$ e $1 \mu \mathrm{m}$, sempre utilizando como lubrificante das etapas de polimento, álcool etílico absoluto. Nesta etapa de lixamento e polimento foi utilizada a politriz automática Struers Abramin (Equipamento do CDMatM -FEI).

Outra parte do material tratado termicamente foi usinada de forma a obter corpos de prova para serem utilizados no ensaio de impacto Charpy de seção reduzida de $5 \mathrm{~mm}$.

\subsection{Métodos}

\subsubsection{Caracterização Microestrutural}

Para a revelação da microestrutura foi utilizado o reativo de Behara modificado (20 mL de ácido clorídrico, $80 \mathrm{~mL}$ de água destilada e deionizada e $1 \mathrm{~g}$ de metabissulfito de potássio). A esta solução de estoque foram adicionados $2 \mathrm{~g}$ de bifluoreto de amônio, e o ataque foi então conduzido por 15 segundos.

Após $\mathrm{o}$ ataque as amostras foram lavadas com água deionizada e com álcool e então foram secas por jato de ar quente para posterior observação das fases ferrita e austenita no microscópio ótico LEICA modelo DMLM (Equipamento do CDMatM -FEI).

Ensaios de difração de raios- $X$ também foram realizados neste trabalho para investigar as fases presentes, empregando-se um difratômetro da Rigaku DEMAX 2000 e radiação de CuKa de comprimento de onda de 0,154 nm. A Faixa de ângulos investigada foi de $5^{\circ}$ a $100^{\circ}$.

\subsubsection{Fração Volumétrica de ferrita}

A fração volumétrica de ferrita (ferromagnética) foi determinada através de um ferritoscópio FISCHER modelo MP30 (Equipamento do CDMatM -FEI).

O ferritoscópio foi calibrado com auxilio de padrões tendo como limite de detecção $0,1 \%$ de ferrita. Foram realizadas 30 medidas em cada uma das amostras nas diferentes condições de tratamento térmico. 


\subsubsection{Ensaios mecânicos}

Foram realizados ensaios de microdureza e ensaios de impacto Charpy em corpos-de-prova de seção reduzida a temperatura ambiente em cada uma das amostras nas diferentes condições de tratamento térmico.

As amostras preparadas metalograficamente, sem ataque, foram submetidas a medidas de dureza conduzidas em um microdurômetro (SHIMADZU HMV-2 - Equipamento do CDMatM -FEI) com carga de 0,5kgf (4,903 N), realizando-se 30 medidas por condição de tratamento térmico.

As dimensões dos corpos-de-prova de seção reduzida seguiram as do anexo A3.1 da Norma ASTM E23-02. Os entalhes do tipo "V" foram feitos após os tratamentos térmicos das amostras. Os corpos-de-prova de seção reduzida foram submetidos ao ensaio de impacto Charpy, determinando-se a influência da fase alfa linha e do tempo de envelhecimento a $475{ }^{\circ} \mathrm{C}$ na energia absorvida à temperatura ambiente.

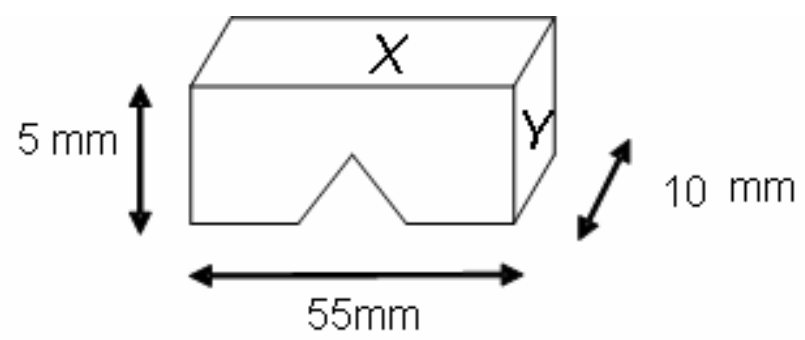

Figura 11: Corpo de prova utilizado no ensaio de impacto Charpy.

\subsubsection{Microscopia Ótica e Microscopia Eletrônica de Varredura}

Os corpos-de-prova atacados pelo reagente de Behara modificado foram observados por microscopia ótica no microscópio ótico LEICA DMLM para identificação das fases ferrita e austenita. Os corpos-de-prova após o ensaio de polarização cíclica também foram observados em microscópio ótico e eletrônico de varredura da marca PHILIPS modelo XL30 (equipamento do IPEN/USP e da EPMT/USP) para caracterização das superfícies.

As amostras submetidas ao ensaio de impacto Charpy também foram observadas em MEV para caracterização da superfície de fratura. 


\subsubsection{Ensaios Eletroquímicos}

Ensaios eletroquímicos foram realizados utilizando-se um analisador de resposta em freqüências Gamry modelo EIS 300 acoplado ao potenciostato Gamry PCl4/300, ambos controlados pelo software Gamry Framework. Os ensaios eletroquímicos realizados foram: medidas do potencial de corrosão, espectroscopia de impedância eletroquímica (EIE) e polarização potenciodinâmica cíclica, respectivamente.

A célula eletroquímica utilizada nos ensaios eletroquímicos foi uma célula de três eletrodos e consistia em um balão de três bocas de $500 \mathrm{~mL}$ de capacidade volumétrica Essa célula permitiu a realização dos ensaios eletroquímicos com o eletrodo de trabalho na posição vertical, evitando assim a deposição na superfície do eletrodo de trabalho de componentes do eletrólito . 0 contra eletrodo utilizado foi um fio de platina enrolado em forma de espiral com área pelo menos três vezes superior ao do eletrodo de trabalho. Como eletrodo de referência, foi utilizado o eletrodo de calomelano saturado (ECS). O contato elétrico do eletrodo de trabalho embutido em resina de cura a quente (baquelite) foi feito através de uma haste M3 de aço inoxidável rosqueada no eletrodo de trabalho.

O eletrólito utilizado consistiu em uma solução naturalmente aerada de $0,6 \mathrm{M}$ de $\mathrm{NaCl}$ (cloreto de sódio) mantida a $22 \pm 1^{\circ} \mathrm{C}$.

O potencial das amostras em função do tempo foi medido a partir do momento de imersão até sua estabilização, obtendo-se dessa forma o potencial de corrosão (Ecorr). Após a estabilização do potencial foram realizados ensaios de espectroscopia de impedância eletroquímica (EIE) adotando a faixa de varredura de freqüência de $100 \mathrm{kHz}$ a $0,01 \mathrm{~Hz}$ e uma taxa de aquisição de dados correspondente a 10 pontos por década de freqüência.

Os ensaios de EIE foram conduzidos após 96h de imersão, quando a estabilização do potencial de circuito aberto tinha sido atingida para todas as amostras, a fim de garantir que o sistema se encontrava na condição de linearidade, validando assim os resultados obtidos no ensaios de EIE. Após o término dos ensaios de EIE, foram obtidas curvas de polarização potenciodinâmica cíclica. As curvas de polarização foram obtidas partindo-se do potencial de corrosão, realizando uma varredura continua e ascendente do potencial, com uma velocidade de varredura de $1 \mathrm{mV} / \mathrm{s}$, revertendo o sentido de 
varredura quando a densidade de corrente anódica atingia o valor de $10^{-3} \mathrm{~A} / \mathrm{cm}^{2}$. $O$ ensaio foi encerrado quando foi atingido o potencial de corrosão medido no inicio do teste. Ao final da polarização, os corpos-de-prova foram lavados com água deionizada, em seguida por álcool absoluto e então secos com jato de ar quente. Foram realizados pelo menos quatro ensaios de EIE e de polarização potenciodinâmica cíclica por condição de tratamento térmico. 


\section{RESULTADOS E DISCUSSÃO}

\subsection{Caracterização Microestrutural}

As microestruturas do aço solubilizado e envelhecido a $475^{\circ} \mathrm{C}$ são apresentadas nas FIG.12 a 14 e o difratograma para a amostra envelhecida a $475^{\circ} \mathrm{C}$ é apresentado na FIG. 15 a seguir.

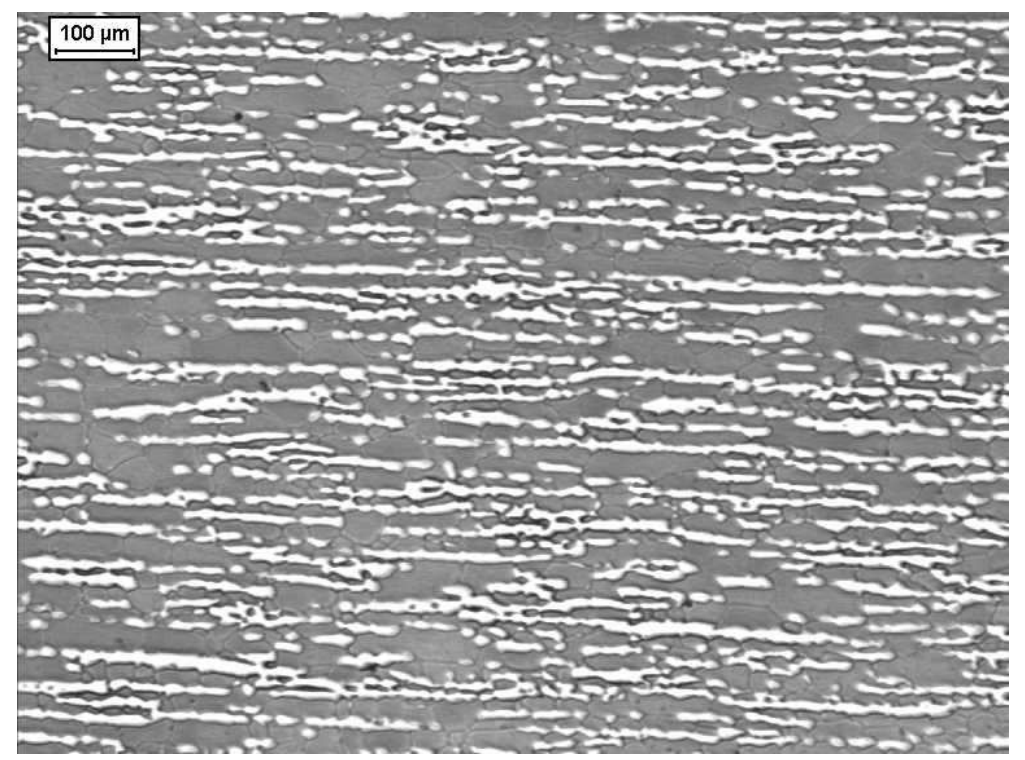

Figura 12: Amostra solubilizada a $1200^{\circ} \mathrm{C}$ por $1 \mathrm{~h}$ do aço inoxidável super-dúplex UR $52 \mathrm{~N}+$. Ataque: Behara Modificado.

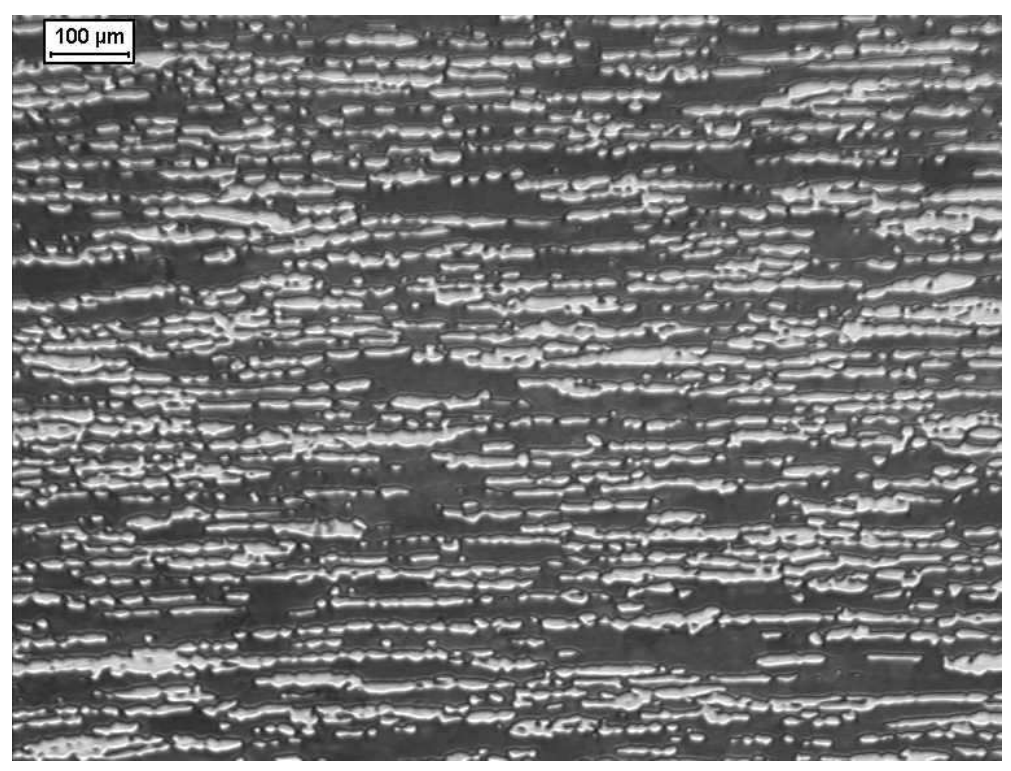

Figura 13: Amostra envelhecida por $4 \mathrm{~h}$ à $475^{\circ} \mathrm{C}$ do aço inoxidável super-dúplex UR $52 \mathrm{~N}+$. Ataque: Behara Modificado. 


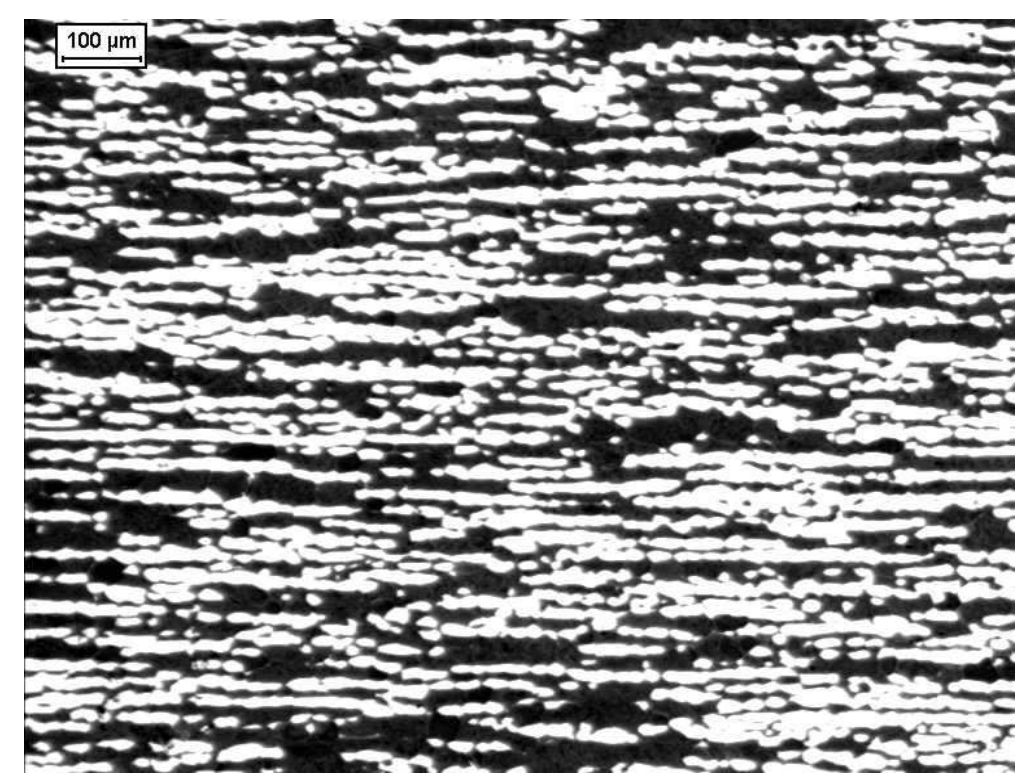

Figura 14: Micrografia da amostra envelhecida por $1032 \mathrm{~h}$ à $475^{\circ} \mathrm{C}$ do aço inoxidável super-dúplex UR 52N+. Ataque: Behara Modificado.

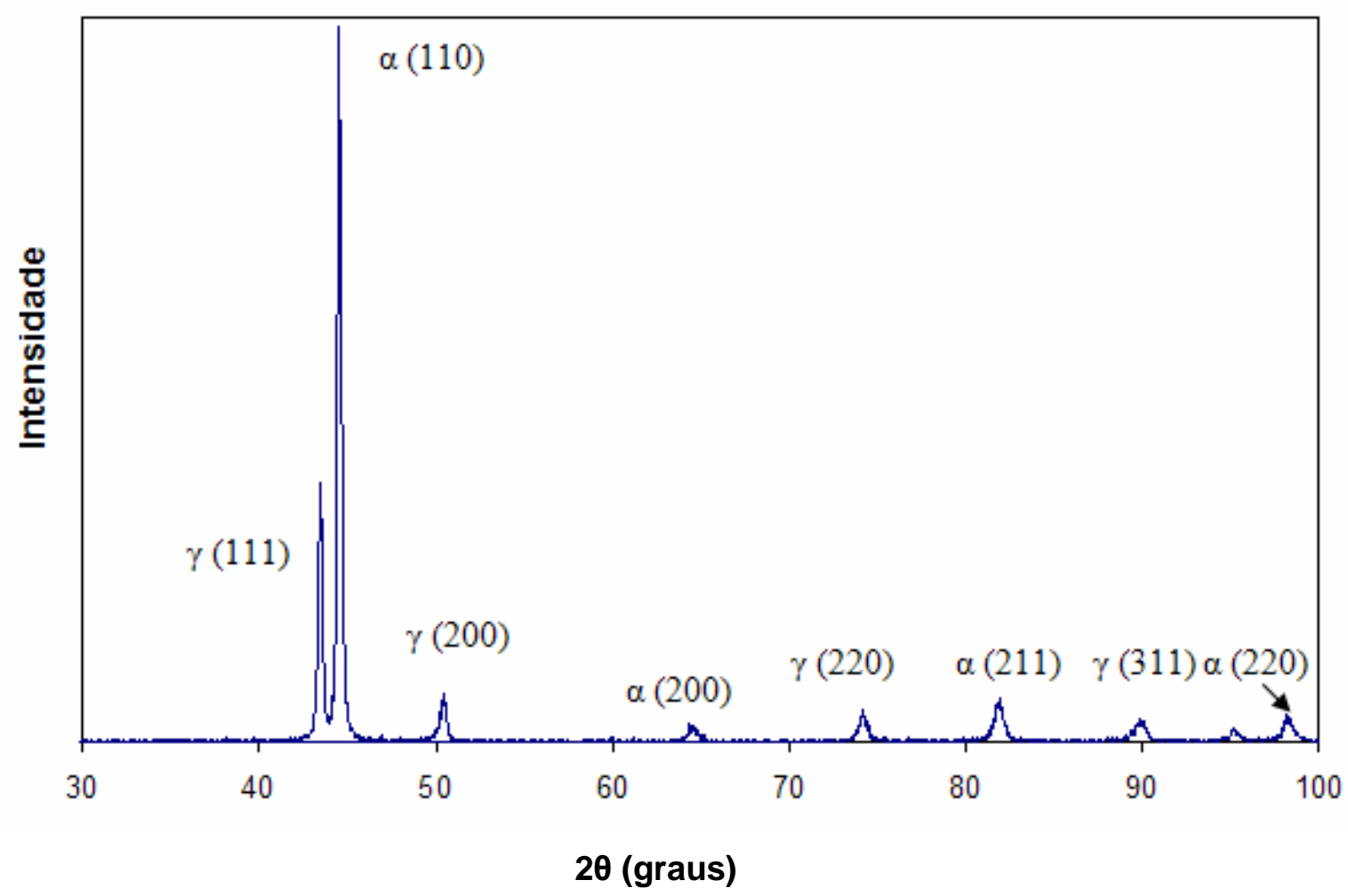

Figura 15: Difratograma da amostra envelhecida por $12 \mathrm{~h}$ a $475^{\circ} \mathrm{C}$.

Em todas as micrografias e também no difratograma pode-se observar a presença das duas fases que constituem o aço inoxidável super-dúplex em estudo: a fase ferrita e a fase austenita. 
Nas micrografias, a fase ferrita é representada pela porção escura e a fase austenita é indicada sendo a de porção clara, ambas orientadas paralelamente em relação à direção de laminação para todos os tempos de tratamento térmico.

No difratograma os picos de ferrita e austenita estão indicados na própria figura. Observa-se o pico mais intenso da ferrita para o plano cristalográfico com orientação (110), um dos planos mais densos para uma estrutura CCC e, o pico mais intenso da austenita para o plano cristalográfico com orientação (111), que é o plano mais compacto da estrutura cristalina cúbica de face centrada.

Os diversos tempos de envelhecimento térmico a $475^{\circ} \mathrm{C}$ foram realizados de forma a obter amostras com diferentes frações volumétricas da fase alfa linha estudada neste trabalho. Contudo, as micrografias da amostra solubilizada e das amostras envelhecidas termicamente não apresentam significativas diferenças quanto à variação da microestrutura aparente observada através de microscopia ótica, podendo apenas ser notadas essas duas fases, confirmando que a fase alfa linha não pode ser observada por microscopia ótica e eletrônica devido ao seu tamanho reduzido e similaridade estrutural com a matriz ferrítica. Há casos de tratamentos térmicos muito longos onde se consegue observar a fase alfa linha por microscopia eletrônica de transmissão. (Terada, 2003, 2009).

Também através do ensaio de difração de raios-X não se pôde observar a presença da fase alfa linha, provavelmente devido à similaridade entre as amplitudes de espalhamento do cromo e do ferro para raios- $X$ e, pelas distâncias interplanares tanto da fase alfa linha como da fase ferrita serem muito próximas, podendo apenas ser identificadas as fases ferrita e austenita. Contudo, o difratograma revela que há uma orientação preferencial tanto para a ferrita (110) quanto para a austenita (111).

Para uma caracterização quantitativa simples da fração volumétrica de ferrita (magnética) foram conduzidos ensaios de ferritoscopia em todas as amostras tratadas termicamente. Esses resultados estão apresentados na TAB.2, TAB.3 e na FIG.16 a seguir. 
Tabela 2 - Fração volumétrica de ferrita (magnética) medida por ferritoscopia.

\begin{tabular}{c|c|c}
\hline $\begin{array}{c}\text { Tempo de } \\
\text { envelhecimento à 475C }\end{array}$ & $\begin{array}{c}\text { \% de ferrita } \\
\text { (ferromagnética) }\end{array}$ & Desvio Padrão \\
\hline Solubilizada & 50,58 & 2,48 \\
$0,5 \mathrm{~h}$ & 50,48 & 4,00 \\
$1 \mathrm{~h}$ & 49,83 & 2,65 \\
$4 \mathrm{~h}$ & 49,74 & 3,59 \\
$12 \mathrm{~h}$ & 49,1 & 4,42 \\
$24 \mathrm{~h}$ & 47,85 & 5,49 \\
$48 \mathrm{~h}$ & 46,1 & 5,19 \\
$96 \mathrm{~h}$ & 43,53 & 5,49 \\
$576 \mathrm{~h}$ & 40,68 & 2,18 \\
$768 \mathrm{~h}$ & 39,5 & 2,81 \\
$1032 \mathrm{~h}$ & 38,43 & 1,06 \\
\hline
\end{tabular}

Tabela 3 - Variação da fração volumétrica de ferrita medida por ferritoscopia para os diversos tempos de envelhecimento térmico a $475^{\circ} \mathrm{C}$.

\begin{tabular}{c|c}
\hline Tempo de envelhecimento à $\mathbf{4 7 5}^{\circ} \mathbf{C}$ & \% de variação \\
\hline Solubilizada & 0,00 \\
$0,5 \mathrm{~h}$ & 0,20 \\
$1 \mathrm{~h}$ & 1,48 \\
$4 \mathrm{~h}$ & 1,66 \\
$12 \mathrm{~h}$ & 2,93 \\
$24 \mathrm{~h}$ & 5,40 \\
$48 \mathrm{~h}$ & 8,86 \\
$96 \mathrm{~h}$ & 13,94 \\
$576 \mathrm{~h}$ & 19,57 \\
$768 \mathrm{~h}$ & 21,91 \\
$1032 \mathrm{~h}$ & 24,02 \\
\hline
\end{tabular}




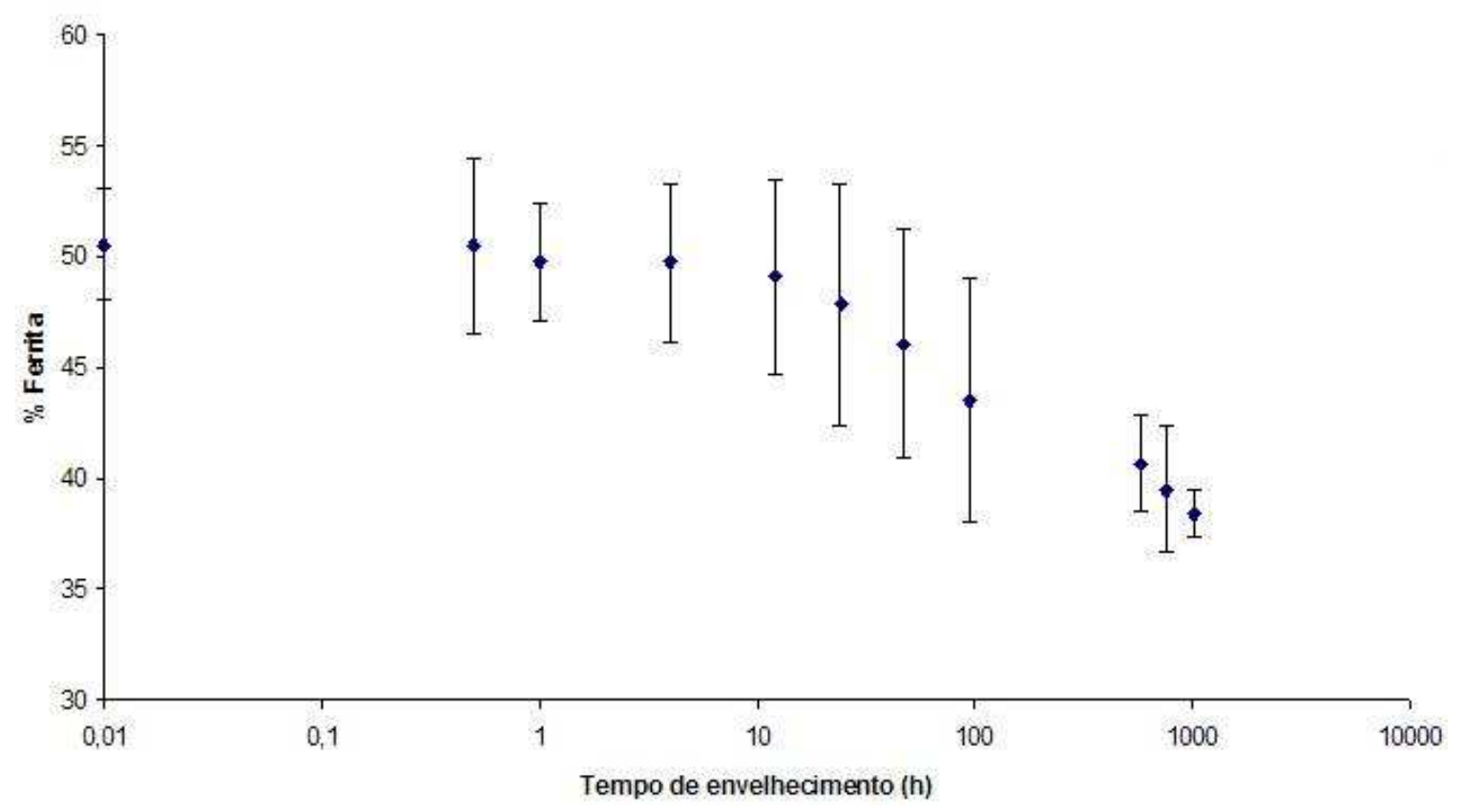

Figura 16: Variação da fração volumétrica de ferrita versus tempo de tratamento térmico à $475^{\circ} \mathrm{C}$. O tempo de $0,01 \mathrm{~h}$ representa a amostra solubilizada a $1200^{\circ} \mathrm{C}$ por $1 \mathrm{~h}$.

Conforme ilustrado na TAB. 2 e na FIG.16 nota-se o decréscimo nos teores de ferrita (ferromagnética) com o tempo de envelhecimento determinados através do ferritoscópio. Essa diminuição da fração volumétrica de ferrita sugere a formação da fase alfa linha que é uma fase paramagnética segundo a literatura (Vasconcelos et al., 2009; Lo et al., 2009; Bley, 1992) e formada a partir da ferrita original, portanto no material envelhecido percebe-se um aumento do teor de fase paramagnética com a conseqüente diminuição da fase ferromagnética medida pelo ferritoscópio.

Como indicado na TAB.2, a amostra solubilizada apresenta um teor de ferrita de $50,58 \%$, esse teor de ferrita magnética apresenta uma pequena variação para as amostras envelhecidas por até $4 \mathrm{~h}$ indicando, portanto que a fase ferrita embora contenha precipitados de alfa linha ainda permanece com a fração volumétrica de ferrita magnética próxima à da amostra solubilizada.

Essa pequena variação da fração volumétrica observada para tempos de envelhecimento de até $4 \mathrm{~h}$ a $475^{\circ} \mathrm{C}$ indica que aparentemente a formação de alfa linha ocorre de forma gradual para os tempos iniciais de envelhecimento, podendo este comportamento também estar associado ao mecanismo de formação da fase alfa linha através da decomposição espinodal. 


\subsection{Ensaio de microdureza}

Foram realizadas 30 medidas de microdureza por condição de tratamento térmico com carga de 0,5 kgf (4,903 N). Os valores médios obtidos das medidas do ensaio de microdureza Vickers e respectivos desvios padrão, bem como a porcentagem de variação destes valores em relação às amostras solubilizadas estão apresentados nas TAB.4 e TAB.5, respectivamente.

Tabela 4 - Medidas obtidas no ensaio de microdureza.

\begin{tabular}{c|c|c}
\hline Tempo de envelhecimento à 475C & Dureza (HV) & Desvio Padrão \\
\hline Solubilizada & 345 & 6,81 \\
$0,5 \mathrm{~h}$ & 414 & 6,51 \\
$1 \mathrm{~h}$ & 428 & 5,95 \\
$4 \mathrm{~h}$ & 442 & 6,38 \\
$12 \mathrm{~h}$ & 461 & 6,38 \\
$24 \mathrm{~h}$ & 489 & 6,96 \\
$48 \mathrm{~h}$ & 480 & 5,98 \\
$96 \mathrm{~h}$ & 483 & 3,78 \\
$576 \mathrm{~h}$ & 484 & 4,12 \\
$768 \mathrm{~h}$ & 482 & 4,21 \\
$1032 \mathrm{~h}$ & 481 & 4,52 \\
\hline
\end{tabular}

Tabela 5 - de variação da dureza para os diversos tempos de envelhecimento.

\begin{tabular}{c|c}
\hline Tempo de envelhecimento à $475^{\circ} \mathrm{C}$ & \% de variação \\
\hline Solubilizada & 0,00 \\
$0,5 \mathrm{~h}$ & 20,00 \\
$1 \mathrm{~h}$ & 24,06 \\
$4 \mathrm{~h}$ & 28,12 \\
$12 \mathrm{~h}$ & 33,62 \\
$24 \mathrm{~h}$ & 41,74 \\
$48 \mathrm{~h}$ & 39,13 \\
$96 \mathrm{~h}$ & 40,00 \\
$576 \mathrm{~h}$ & 40,29 \\
$768 \mathrm{~h}$ & 39,71 \\
$1032 \mathrm{~h}$ & 39,42 \\
\hline
\end{tabular}


De acordo com os dados obtidos no ensaio de microdureza apresentados nas TAB.4, TAB.5 e na FIG.17 pode-se notar que a dureza do material aumenta gradualmente com o tempo de envelhecimento a $475^{\circ} \mathrm{C}$.

Para pequenos tempos de envelhecimento, como por exemplo, de $0,5 \mathrm{~h}$ é verificado um aumento significativo em torno de $20 \%$ na dureza do material em relação à amostra solubilizada. Esse aumento de dureza é ainda mais intenso para tempos de envelhecimento superiores a $0,5 \mathrm{~h}$, atingindo então o ponto de máxima dureza em $24 \mathrm{~h}$ de envelhecimento, indicando provavelmente que a decomposição espinodal se completa.

Para amostras envelhecidas para tempos superiores a $24 \mathrm{~h}$ pode-se notar que há uma discreta queda no valor de dureza comparada à amostra envelhecida por 24h. Essa discreta queda tende a permanecer constante até o último tempo de envelhecimento que foi realizado neste trabalho que corresponde a $1032 \mathrm{~h}$ e, pode estar associada ao coalescimento da fase alfa linha formada anteriormente.

O ponto de máxima dureza pode ser associado à máxima formação da fase alfa linha no material envelhecido por $24 \mathrm{~h}$ a $475^{\circ} \mathrm{C}$, gerando maiores quantidades de barreiras que impedem a livre movimentação das discordâncias e, portanto, aumentando a dureza do material.

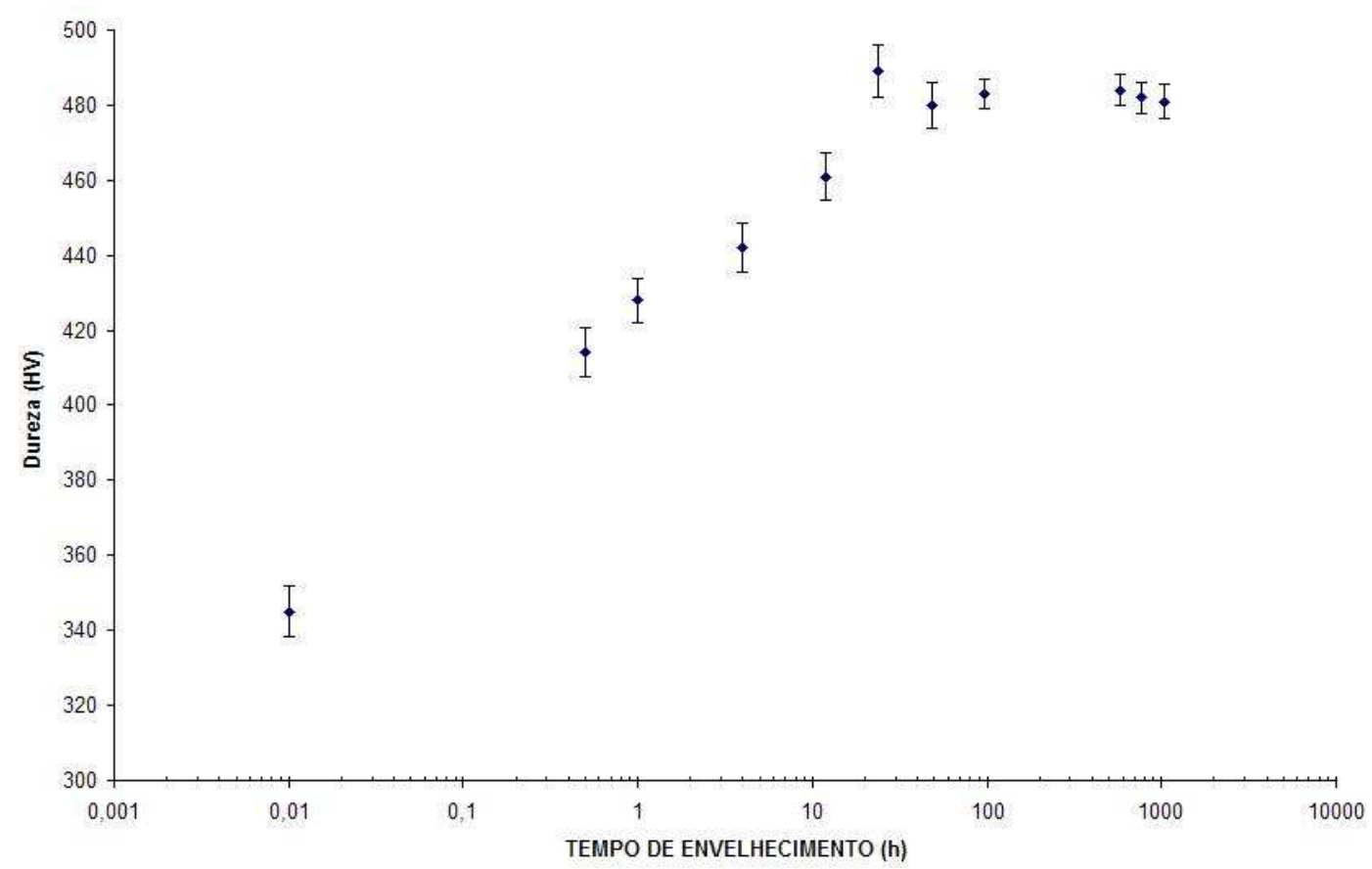

Figura 17: Gráfico de dureza da amostra solubilizada e envelhecidas à $475^{\circ} \mathrm{C}$. $\mathrm{O}$ tempo de $0,01 \mathrm{~h}$ representa a amostra solubilizada a $1200^{\circ} \mathrm{C}$ por $1 \mathrm{~h}$. 


\subsection{Ensaio de impacto}

O ensaio de impacto Charpy de seção reduzida conforme o anexo A3.1 da norma ASTM E23-02 foi conduzido a temperatura ambiente com as amostras solubilizada e envelhecidas por até $1032 \mathrm{~h}$ a $475^{\circ} \mathrm{C}$.

Os resultados obtidos do referido ensaio estão apresentados na TAB.6 e na FIG.18.

Tabela 6 - Dados obtidos no ensaio de impacto Charpy.

\begin{tabular}{c|c|c}
\hline $\begin{array}{c}\text { Tempo de } \\
\text { envelhecimento à 475C }\end{array}$ & $\begin{array}{c}\text { \% perda da energia } \\
\text { absorvida comparada com } \\
\text { a amostra solubilizada }\end{array}$ \\
\hline Solubilizada & 90 & 0 \\
$0,5 \mathrm{~h}$ & 43 & 52,22 \\
$1 \mathrm{~h}$ & 38 & 57,78 \\
$4 \mathrm{~h}$ & 40 & 55,56 \\
$12 \mathrm{~h}$ & 10 & 88,89 \\
$24 \mathrm{~h}$ & 10 & 88,89 \\
$48 \mathrm{~h}$ & 7 & 92,22 \\
$96 \mathrm{~h}$ & 6 & 93,33 \\
$576 \mathrm{~h}$ & 5 & 94,44 \\
$768 \mathrm{~h}$ & 4 & 95,56 \\
$1032 \mathrm{~h}$ & 4 & 95,56 \\
\hline
\end{tabular}




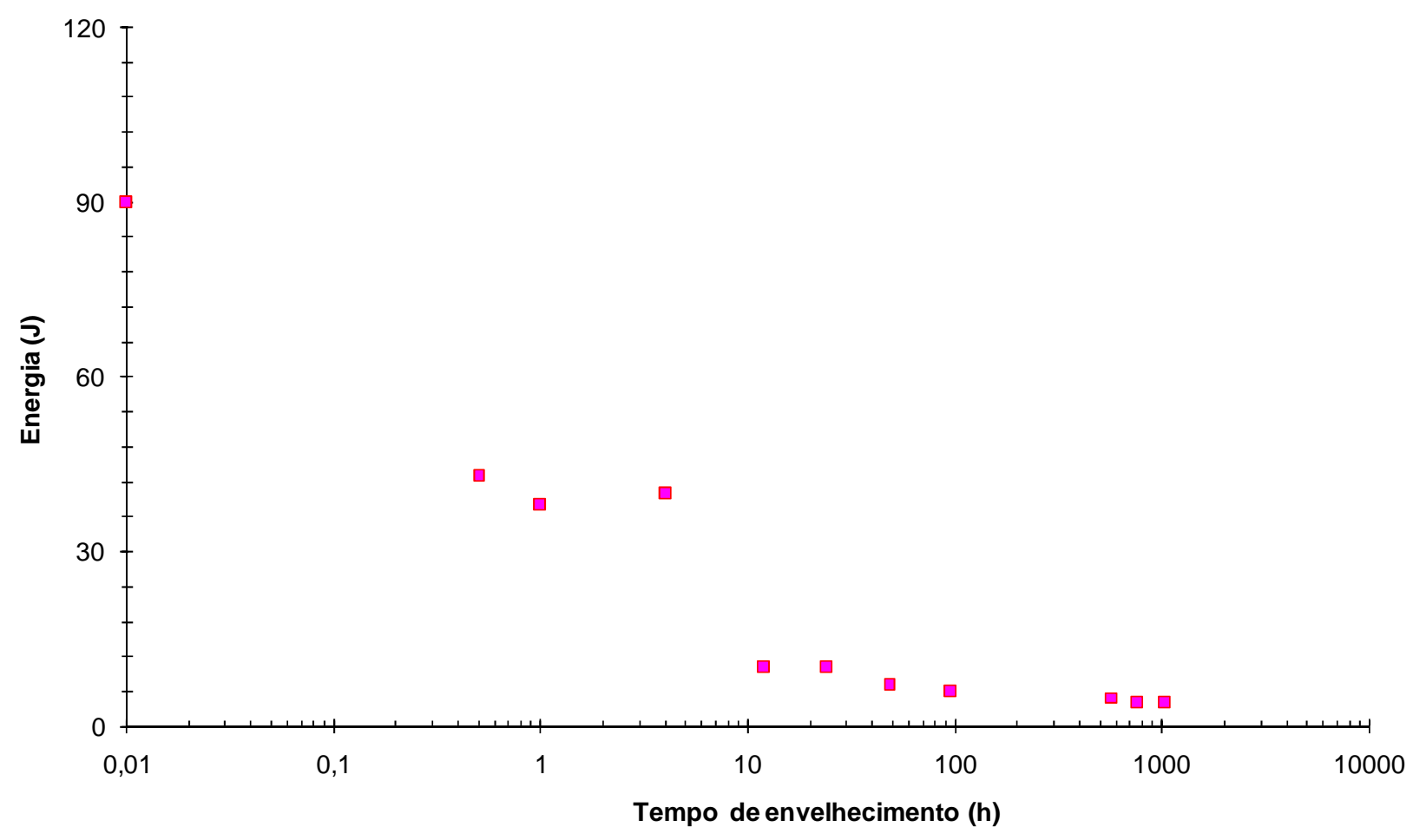

Figura 18: Gráfico de Energia absorvida no ensaio de impacto em função do tempo de envelhecimento a $475^{\circ} \mathrm{C}$, e aspecto dos corpos-de-prova fraturados. $\mathrm{O}$ tempo de $0,01 \mathrm{~h}$ corresponde à amostra solubilizada.

Os dados mostrados na TAB.6 indicam que com apenas $0,5 \mathrm{~h}$ de envelhecimento térmico a $475^{\circ} \mathrm{C}$ o material perde consideravelmente a capacidade de absorver energia no ensaio de impacto. Este comportamento observado é um indicador muito importante para a determinação indireta da presença da fase alfa linha no material.

Nota-se também uma crescente degradação da tenacidade do material com o tempo de envelhecimento, evidenciando que esse efeito deletério está diretamente associado à quantidade de alfa linha precipitada nos diversos tempos de tratamento térmico de envelhecimento a $475^{\circ} \mathrm{C}$.

A perda drástica da tenacidade à fratura com $12 \mathrm{~h}$ de envelhecimento, conforme ilustrada na FIG.18, deve-se a uma dada concentração de alfa linha atingida para este tempo de tratamento térmico, a qual dificulta muito a movimentação das discordâncias e restringe o escorregamento a poucos planos, levando o material a fraturar de modo frágil. Para melhor visualizar o tipo de 
fratura que ocorreu nas amostras estudadas foram feitas algumas micrografias no MEV que estão apresentadas na FIG.19 a 21.

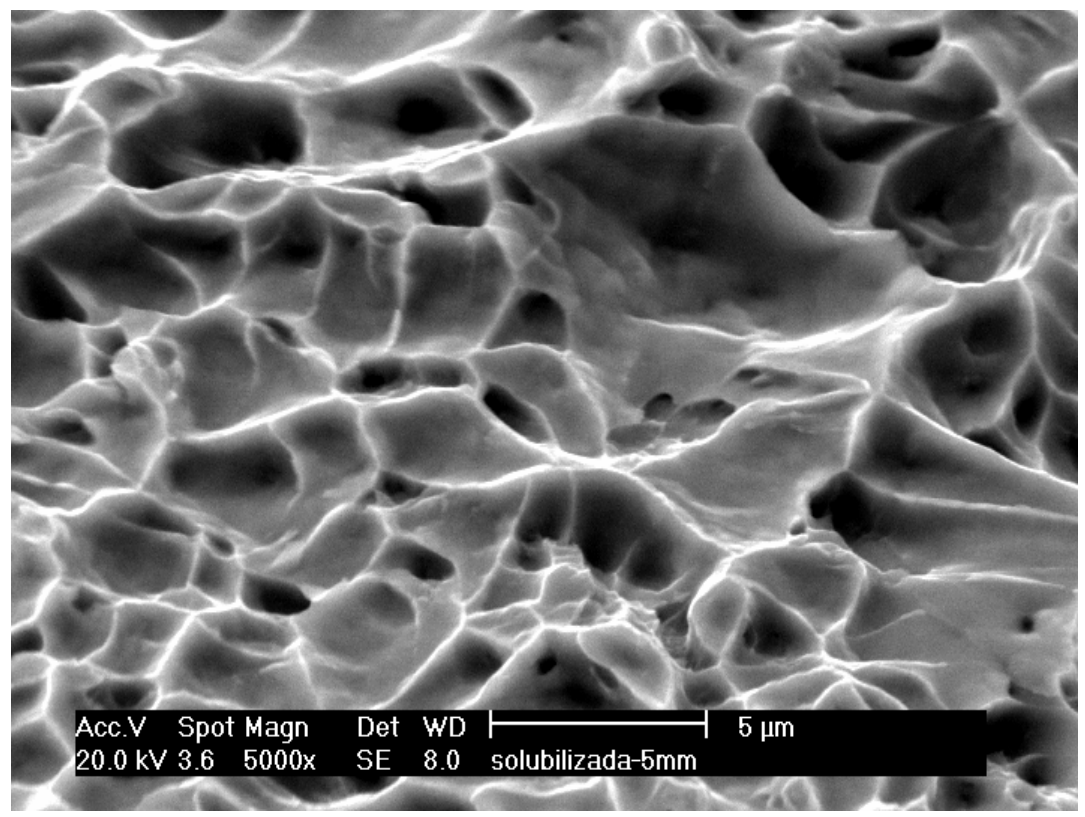

Figura 19: MEV da amostra solubilizada após ensaio de impacto.Nota-se a presença de muitos alvéolos (dimples), característicos de fratura dúctil.

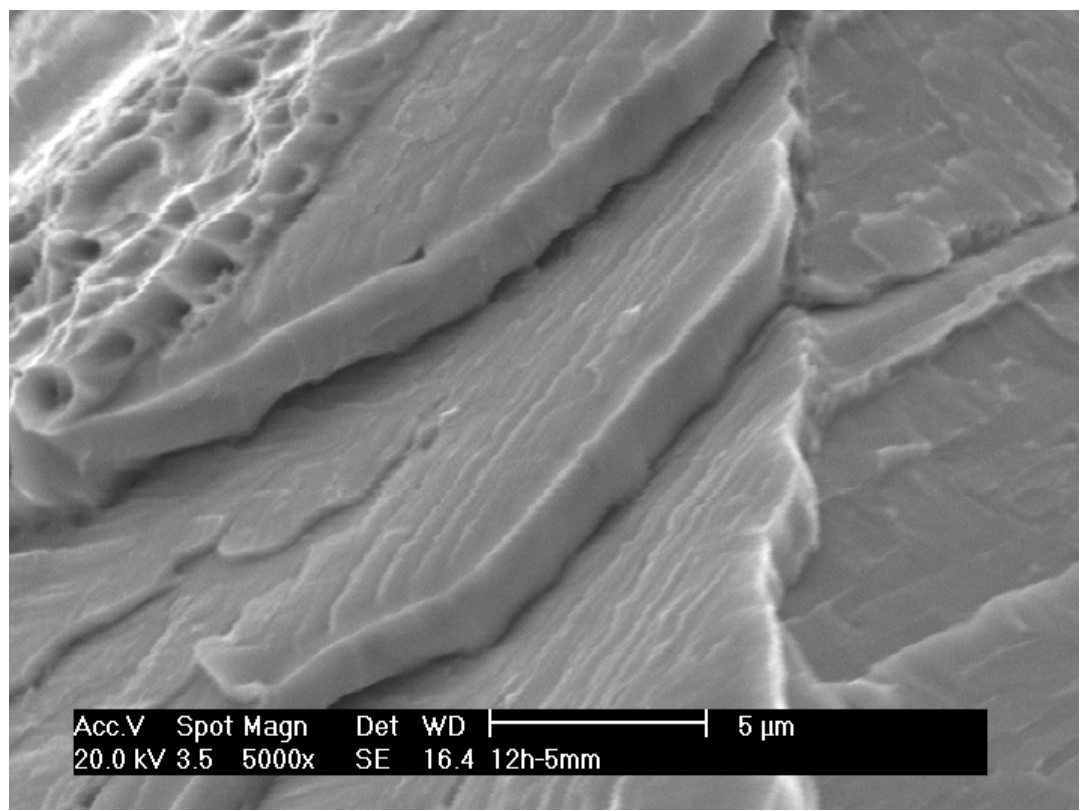

Figura 20: MEV da amostra envelhecida por 12h após ensaio de impacto. Nota-se a presença de planos de clivagem em grande extensão da superfície de fratura e poucos alvéolos (dimples) no canto superior esquerdo. 


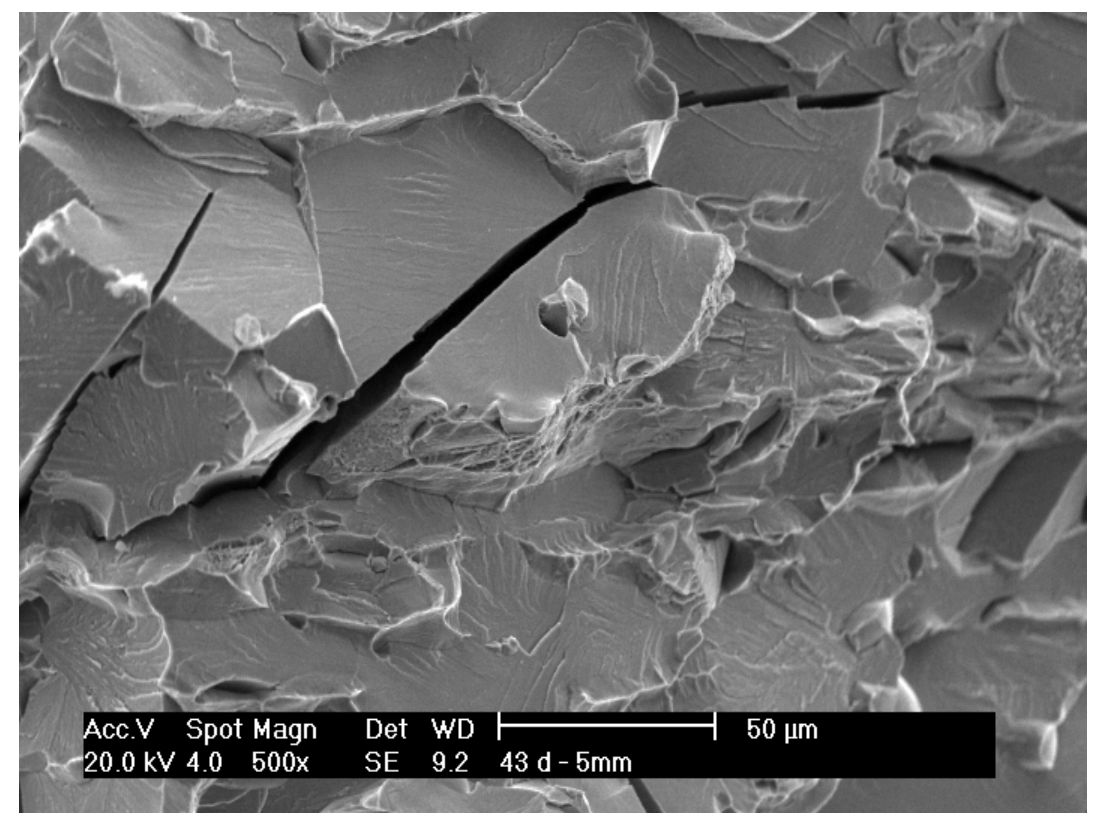

Figura 21: MEV da amostra envelhecida por 1032h após ensaio de impacto. Notase a presença de planos de clivagem em praticamente toda a extensão da superfície de fratura, característicos de fratura frágil.

A amostra solubilizada submetida ao ensaio de impacto, observada em MEV, conforme ilustra a FIG.19, apresentou em toda a sua extensão, alvéolos (dimples), indicativos de fratura dúctil.

No entanto, a partir de $12 \mathrm{~h}$ de envelhecimento, nota-se que o material já está praticamente sem capacidade de absorver energia. Em quase toda a extensão da superfície de fratura observada em MEV para a amostra envelhecida por $12 \mathrm{~h}$, predominam típicos planos de clivagem ao invés dos alvéolos (dimples), que só foram observados no canto superior esquerdo, conforme mostra a Figura 6, o que evidencia o comportamento frágil do material com o decorrer do tempo de envelhecimento. Essa tendência segue para as amostras envelhecidas por até 1032h, conforme mostrado na FIG.21, onde se observam planos de clivagem em praticamente toda a superfície de fratura, evidenciando um aspecto de fratura extremamente frágil. Embora seja uma fratura tipicamente frágil, a amostra ainda assim apresenta alguns alvéolos (dimples), característicos da fase austenita que permanece constante durante a precipitação da fase alfa linha no material. 


\subsection{Ensaios de polarização cíclica}

As FIG.22 a 27 mostram o comportamento das amostras no ensaio de polarização cíclica. Para cada condição estudada foram repetidos os ensaios pelos menos quatro vezes e observou-se a reprodutibilidade dos comportamentos observados.

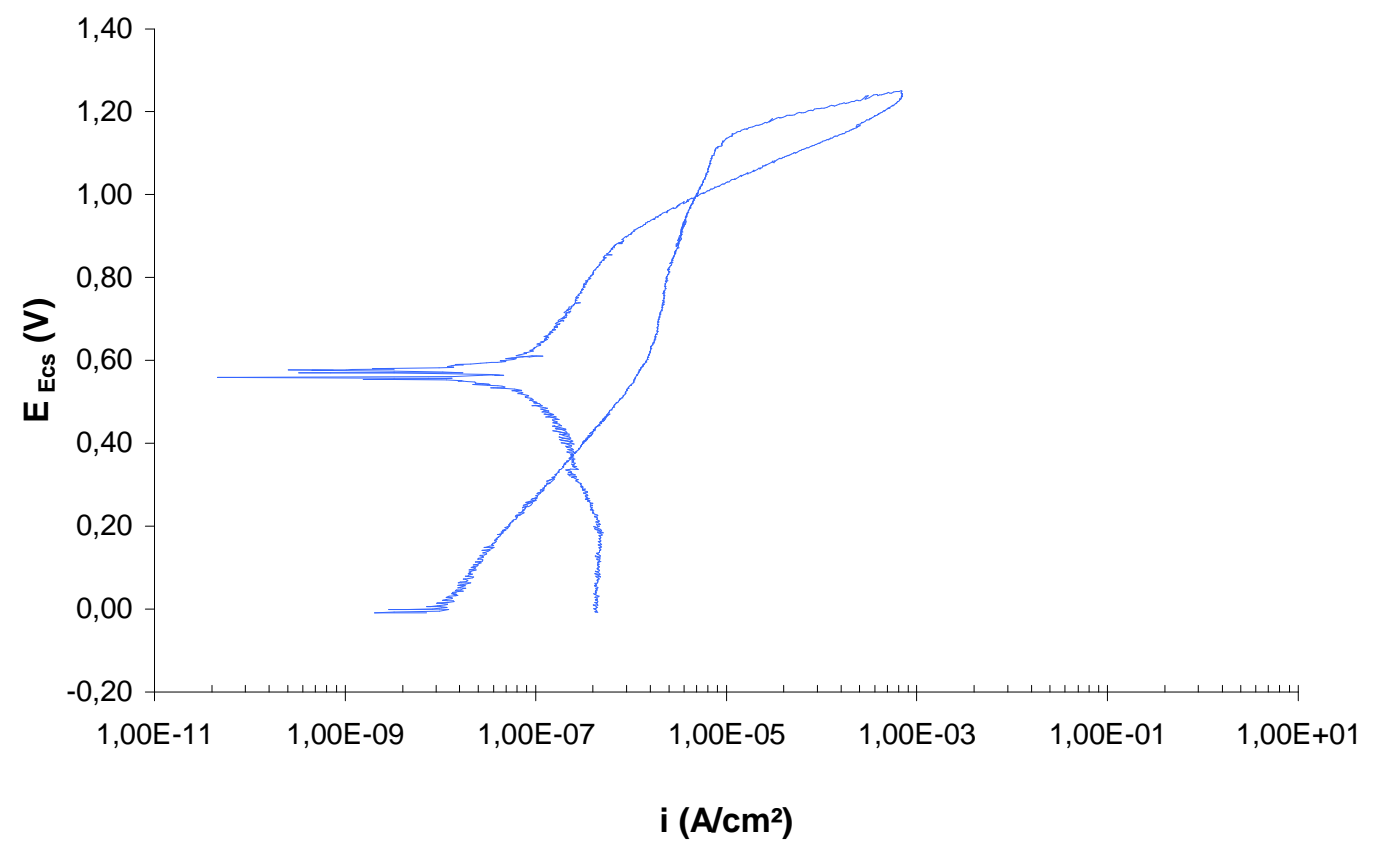

Figura 22: Curva de polarização cíclica da amostra solubilizada. 


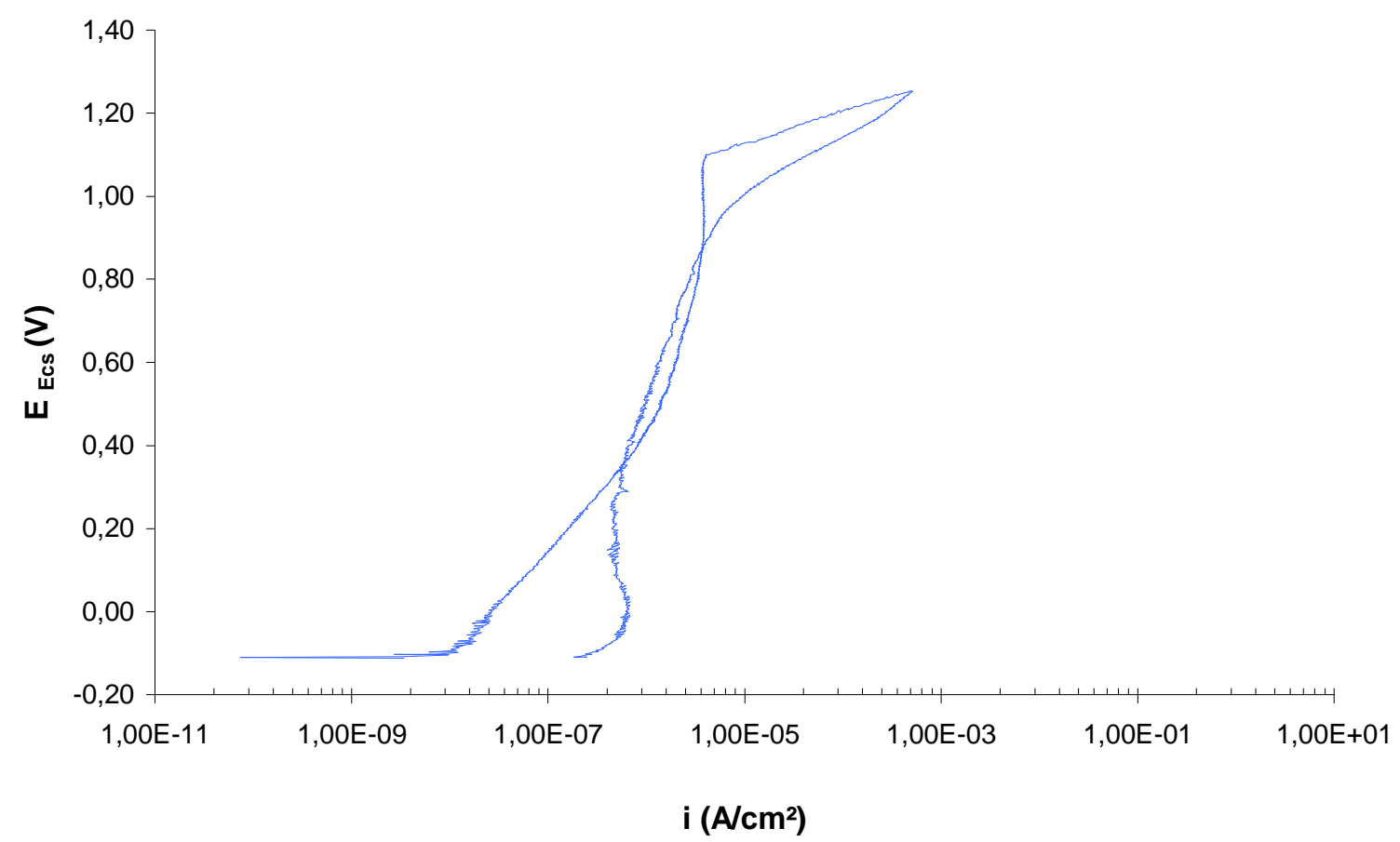

Figura 23: Curva de polarização cíclica da amostra envelhecida por 4 h a $475^{\circ} \mathrm{C}$.

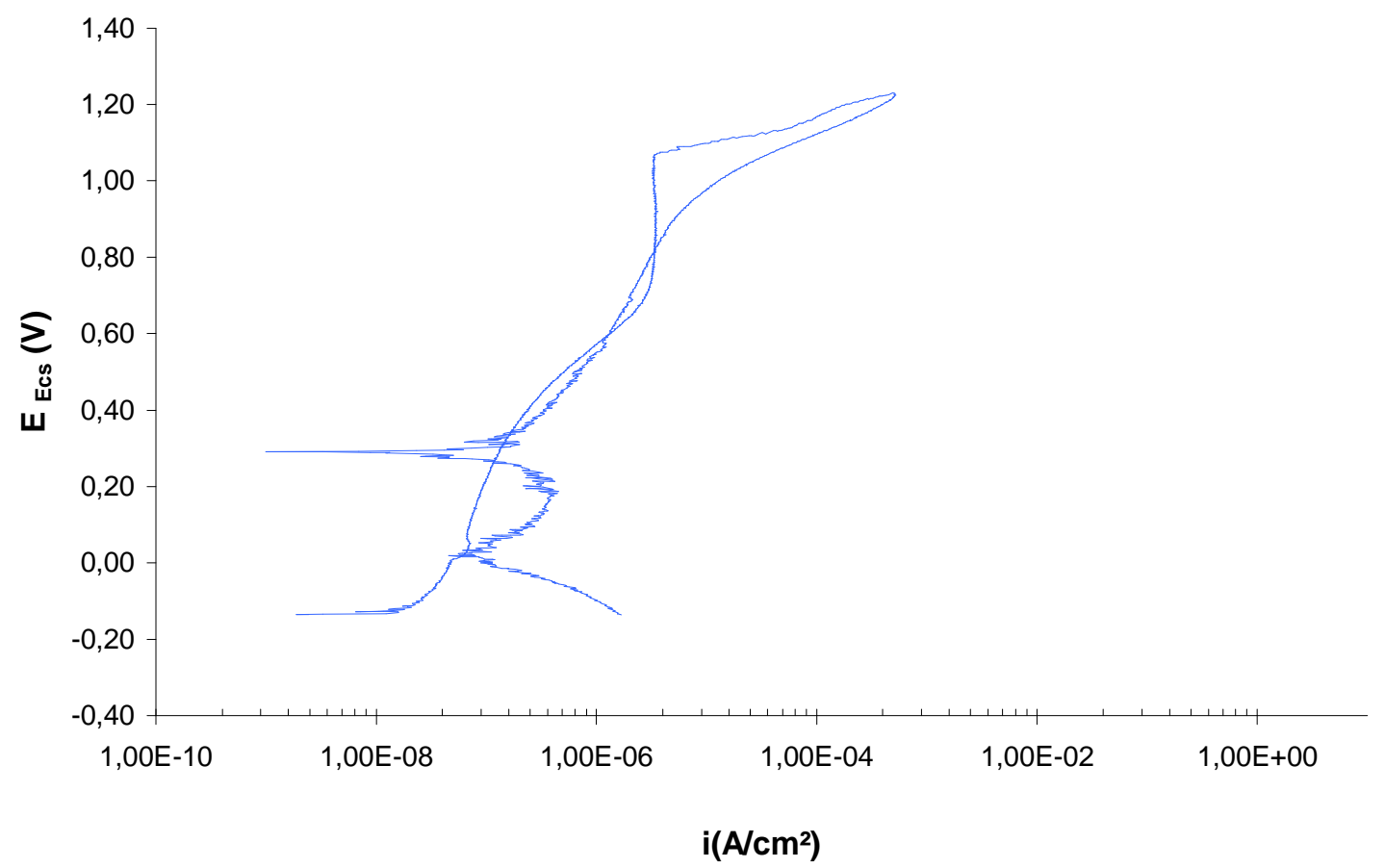

Figura 24: Curva de polarização cíclica da amostra envelhecida por $12 \mathrm{~h}$ a $475^{\circ} \mathrm{C}$. 


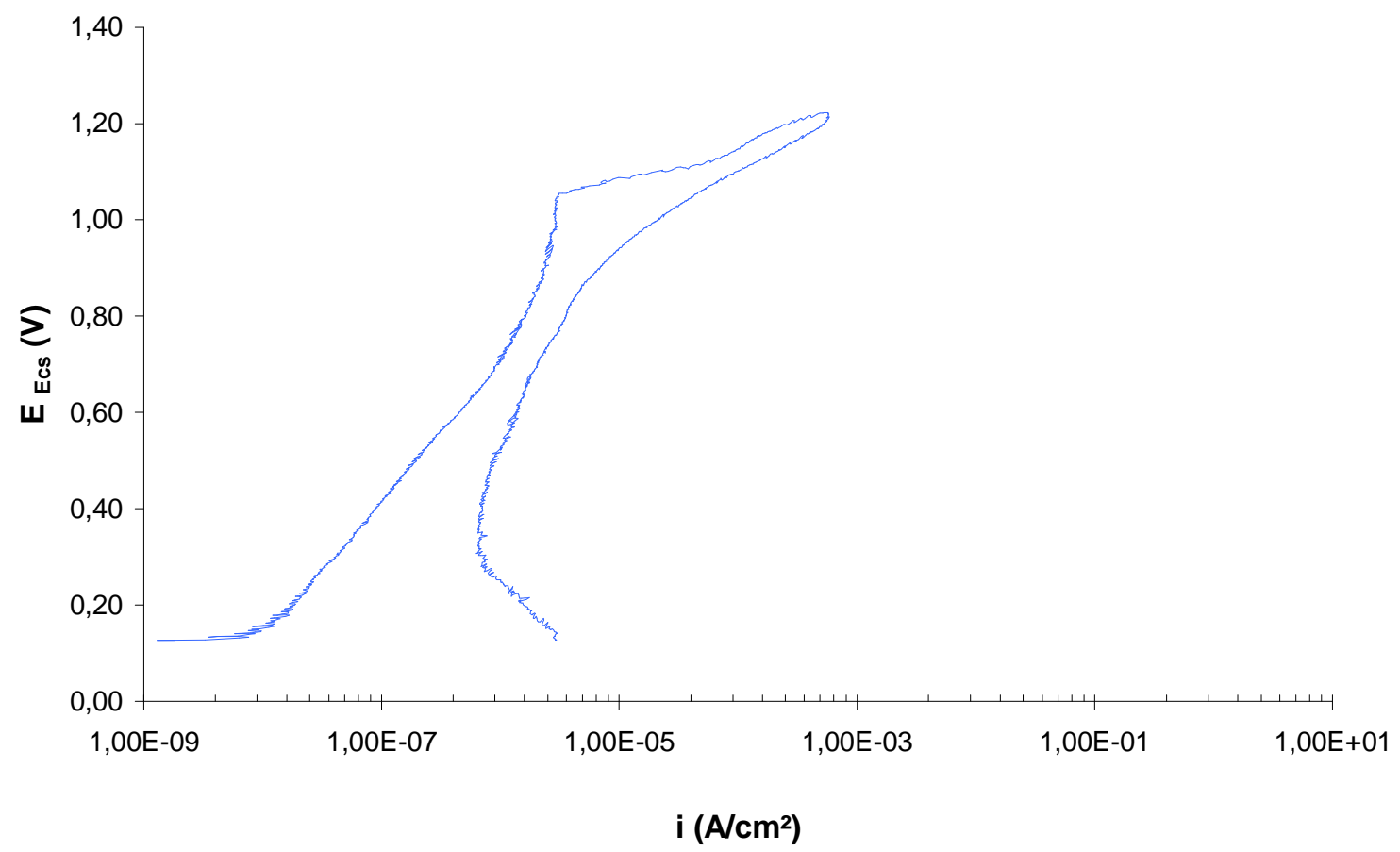

Figura 25: Curva de polarização cíclica da amostra envelhecida por $48 \mathrm{~h}$ a $475^{\circ} \mathrm{C}$.

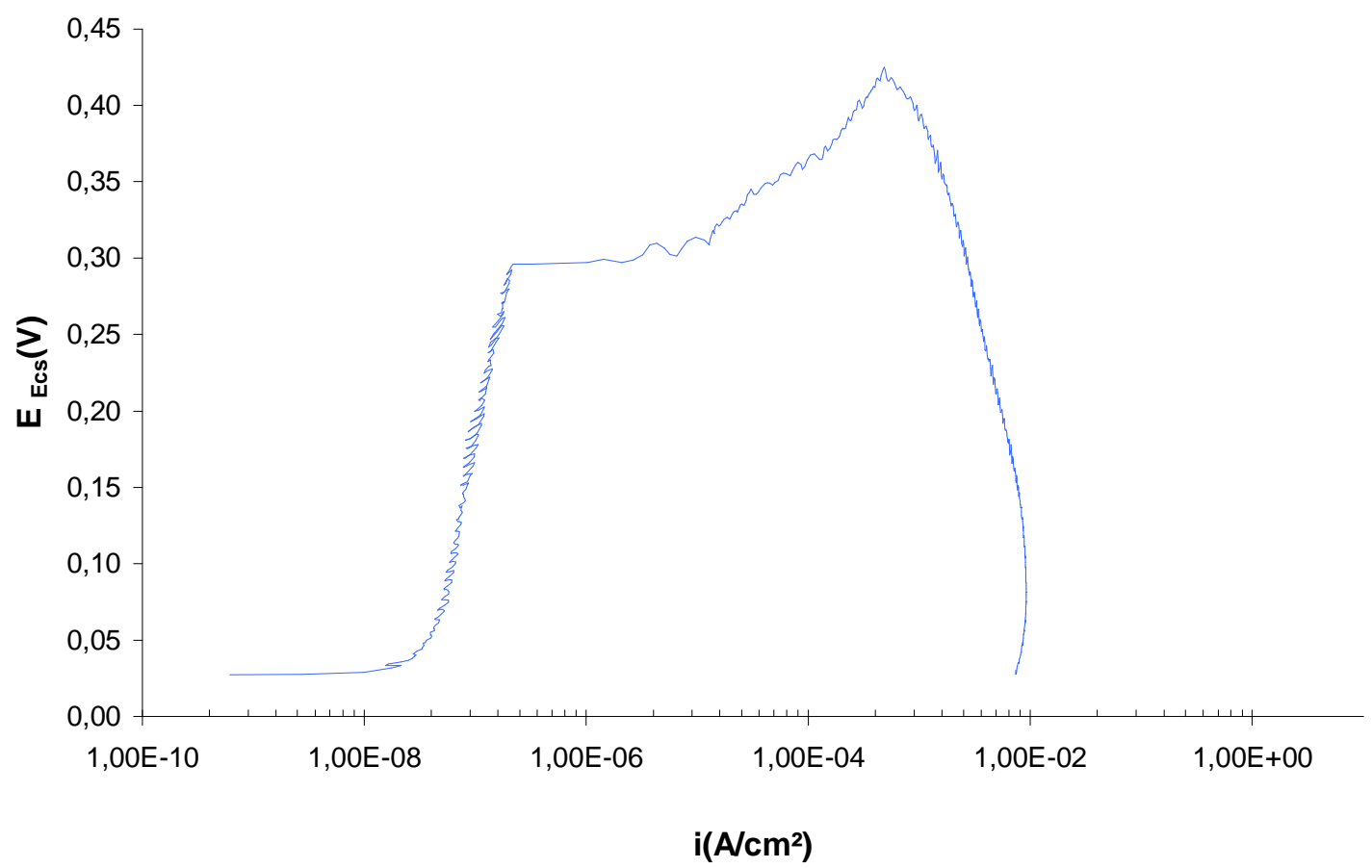

Figura 26: Curva de polarização cíclica da amostra envelhecida por 1032h a $475^{\circ} \mathrm{C}$. 


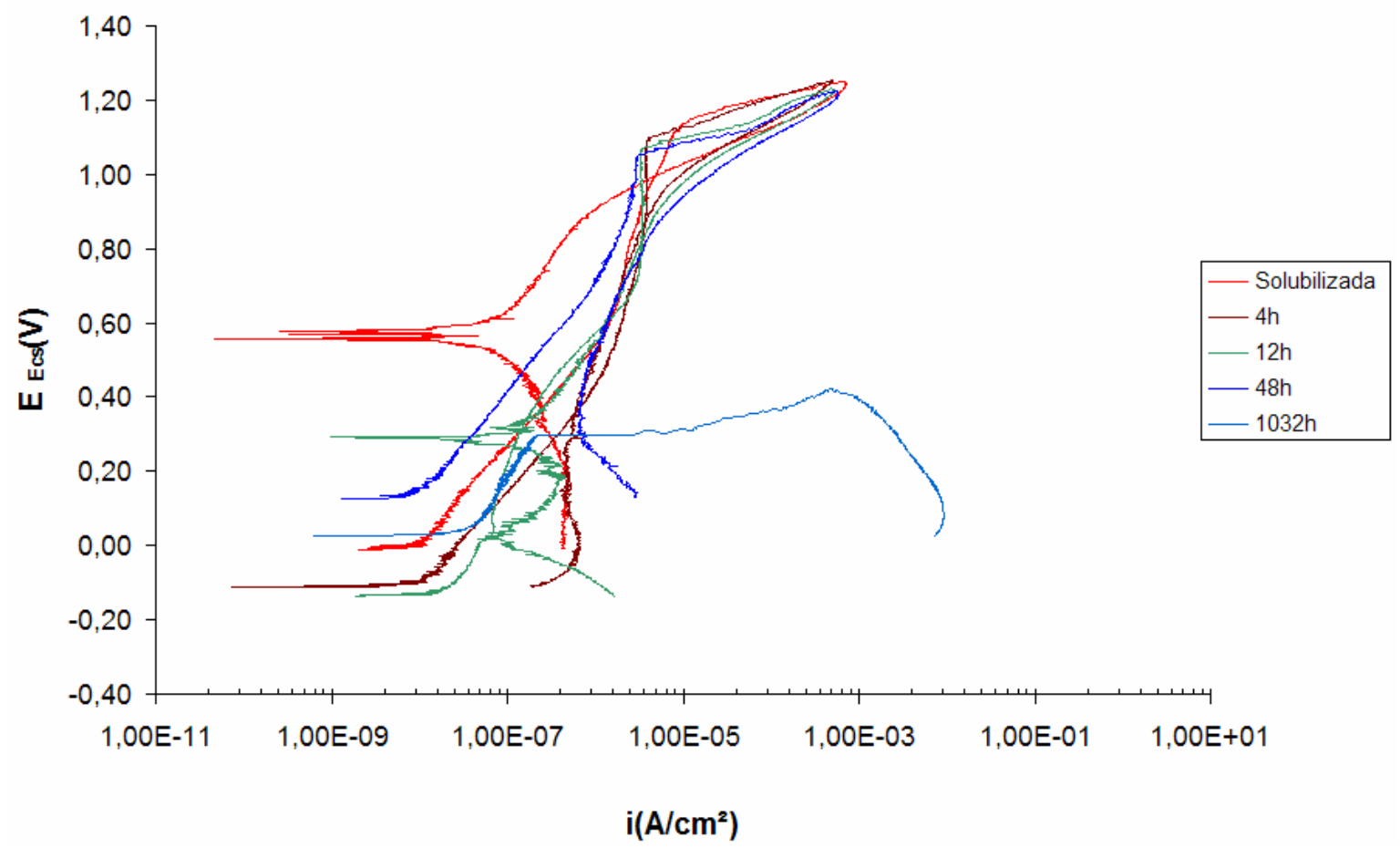

Figura 27: Curva de polarização cíclica das amostras solubilizada e envelhecidas a $475^{\circ} \mathrm{C}$ sobrepostas.

É possível notar nas curvas de polarização cíclica apresentadas que o potencial de pite vai se reduzindo com o progresso do tempo de envelhecimento comparado com o potencial de pite da amostra solubilizada.

Embora a redução do potencial de pite das amostras envelhecidas por até $48 \mathrm{~h}$ seja discreta, conservando-se com valores próximos ao da amostra solubilizada da ordem de 1,15 $\mathrm{V}_{\mathrm{ECS}}$ consegue-se perceber que a resistência à corrosão por pite vai se deteriorando devido à presença da fase alfa linha. Esse comportamento pode ser observado pela área do laço na curva de polarização cíclica, que vai aumentando com o tempo de envelhecimento.

Para a amostra com 48h de envelhecimento não há mais repassivação dos pites formados, isto pode ser explicado pela dificuldade na redistribuição do cromo na matriz ferrítica devido à formação da fase alfa linha que consome grande parte deste elemento, ou seja, os pites uma vez formados, tendem a continuar aumentando de tamanho e consumindo o material, uma vez que não há cromo suficiente para formar a película passiva de óxidos protetores.

Já para a amostra envelhecida por 1032h, conforme ilustrado na FIG.26 e 27, nota-se que o potencial de pite reduziu bruscamente e que a 
densidade de corrente teve um grande aumento, indicando que o processo corrosivo no material se intensificou. Outro indicativo de que a resistência à corrosão dessas amostras diminuiu bruscamente é a incapacidade de repassivação dos pites formados.

O elevado potencial de pite encontrado na amostra solubilizada e envelhecida por até $48 \mathrm{~h}$ poderia também ser associado à reação de evolução de oxigênio, a qual aumenta a densidade total de corrente medida e gera bolhas de oxigênio na superfície das amostras, fazendo com que o processo de quebra do filme passivo seja facilitado (Magnabosco e Alonso-Falleiros, 2005). Para tanto, as amostras após ensaio de polarização cíclica foram analisadas em um microscópio eletrônico de varredura e notou-se a presença de pite nas superfícies de todas as amostras polarizadas, conforme ilustrado na FIG. 28 e FIG.29 e, portanto o potencial no qual ocorre aumento significativo de corrente está associado à quebra do filme passivo com formação de pite. Pode-se notar ainda que para a amostra solubilizada, os pites têm pequenas dimensões, e não estão presentes em grandes quantidades. Já para a amostra envelhecida por 1032h, notam-se pites em grande extensão da mesma. As partes mais fundas e escuras da amostra evidencia 0 ataque seletivo dos grãos ferrita devido ao empobrecimento em cromo e às flutuações pontuais deste elemento na matriz ferrítica, que foi utilizado para formação de alfa linha.
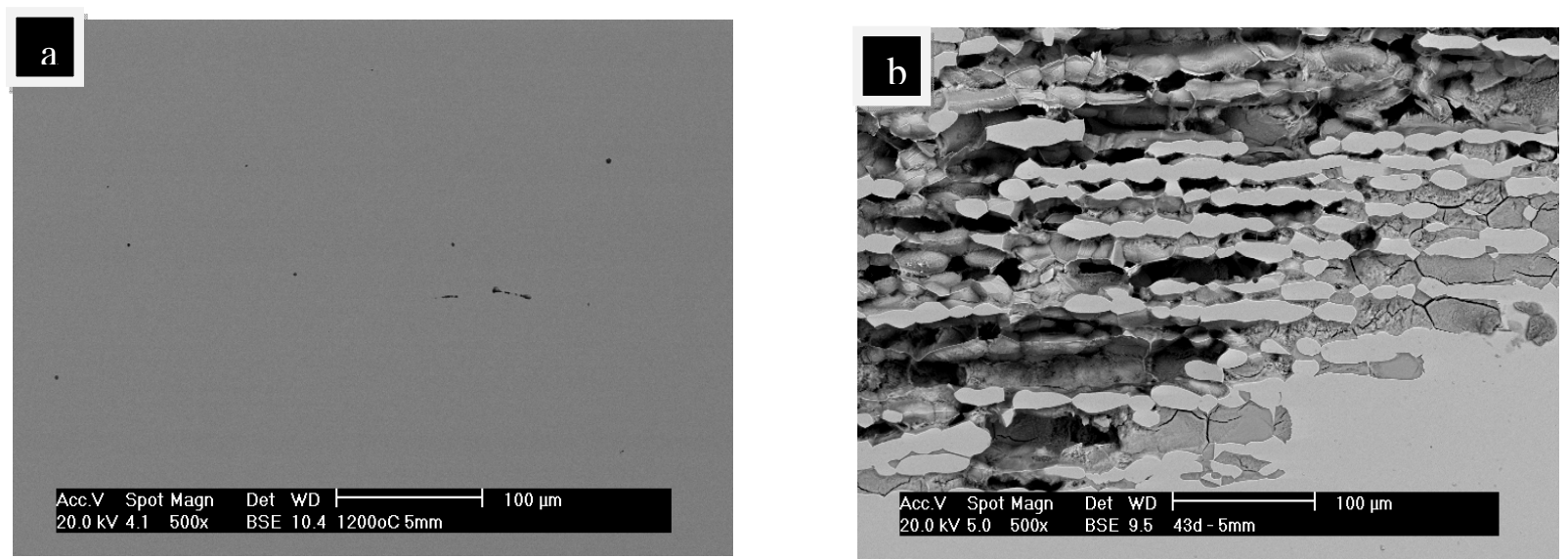

Figura 28: MEV da amostra solubilizada ( figura 28 a) e envelhecida (figura 28 b) por $1032 \mathrm{~h}$ a $475^{\circ} \mathrm{C}$ do aço UR $52 \mathrm{~N}+$ após polarização cíclica em $\mathrm{NaCl}$. 


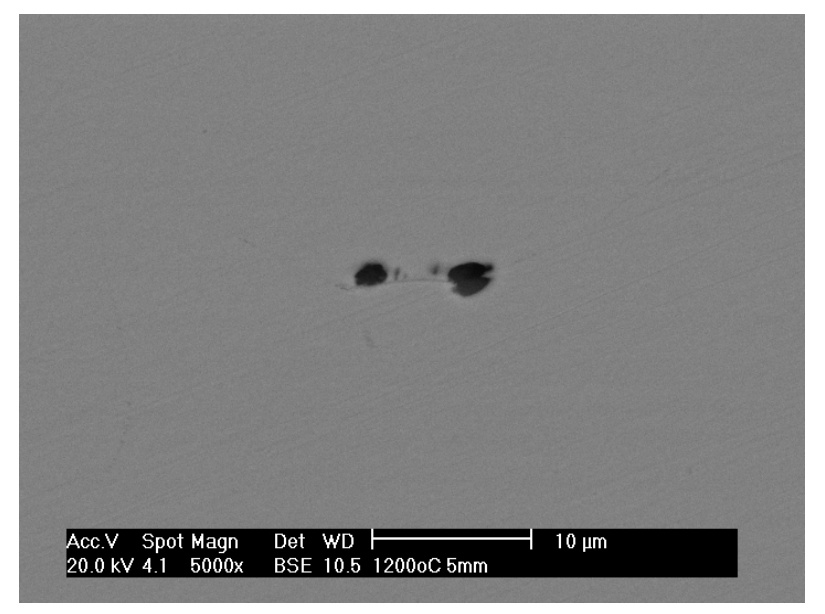

Figura 29: Detalhe ampliado dos pites da amostra solubilizada obtido por MEV.

\subsection{Ensaios de espectroscopia de impedância eletroquímica}

Os resultados obtidos no ensaio de EIE estão apresentados nas Fig.30 a 32 que são respectivamente: o diagrama de Nyquist, o diagrama de módulo de Z e o diagrama de ângulo de fase.

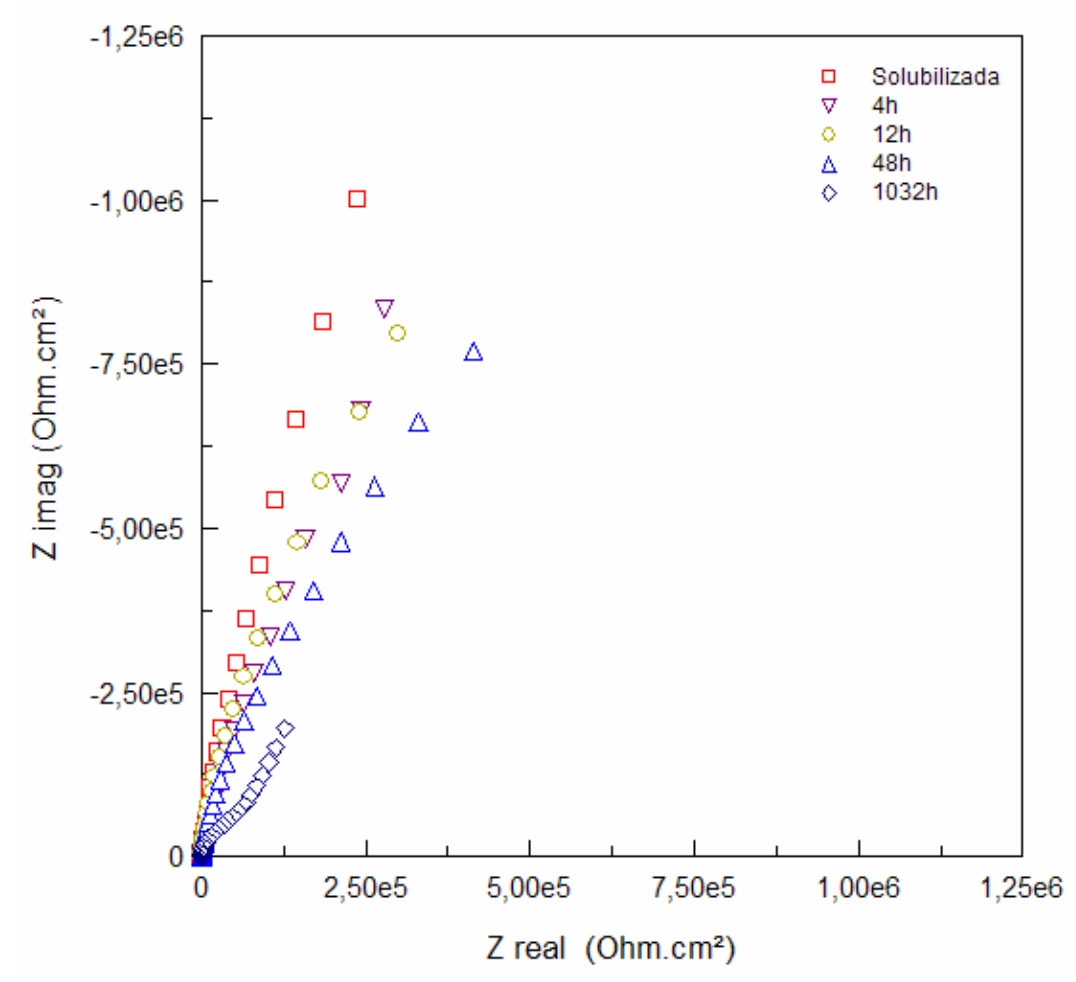

Figura 30: Diagramas de Nyquist da amostra solubilizada e envelhecidas a $475^{\circ} \mathrm{C}$.

Os diagramas de Nyquist da Fig.30 sugerem o início de um arco capacitivo que não se completa na região de baixas freqüências tanto para a 
amostra solubilizada quanto para todas as amostras envelhecidas a $475^{\circ} \mathrm{C}$. É possível notar também que há uma diminuição da impedância nas baixas freqüências com o tempo de envelhecimento das amostras.

Este comportamento sugere que o tempo de envelhecimento prejudica a formação de uma camada passiva homogênea, o que a torna cada vez menos protetora e com maior densidade de defeitos, podendo o eletrólito penetrar nesta camada mais facilmente.

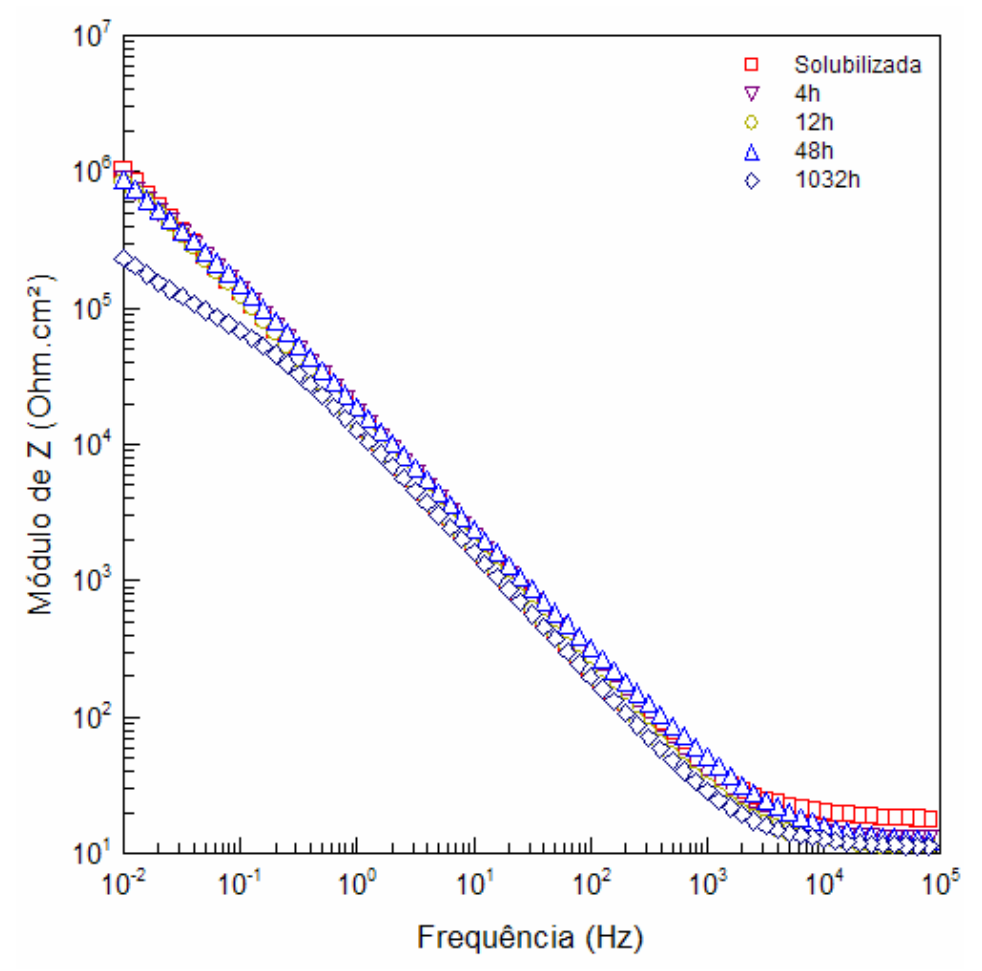

Figura 31: Diagramas de Módulo de Z da amostra solubilizada e envelhecidas a $475^{\circ} \mathrm{C}$.

Os diagramas apresentados na Fig.31 mostram que tanto para a amostra solubilizada quanto para as amostras envelhecidas por até 48h, não há um grande desvio do comportamento capacitivo, sendo que na região de baixas freqüências essas amostras apresentaram valores de módulo de impedância próximos a $10^{6} \mathrm{ohm} . \mathrm{cm}^{2}$.

A queda acentuada do valor de impedância na região de baixa freqüência para a amostra envelhecida por 1032h evidencia uma maior deterioração da capacidade protetora a camada passiva.

Nota-se um desvio do comportamento capacitivo da amostra de $1032 \mathrm{~h}$ de envelhecimento na região de baixas freqüências em torno de 0,1 e 0,01 Hz, 
este desvio coincide ao ponto de mínimo referente ao ângulo de fase em torno de $-50^{\circ} \mathrm{C}$ e ao início da formação da segunda constante de tempo, conforme pode ser visto na FIG.32.

Os valores de módulo de impedância mostrados na Fig.31 indicam que o material mesmo na condição envelhecida, contendo a fase alfa linha na sua microestrutura, apresenta ainda grande resistência à corrosão, visto que possui um elevado valor no módulo de impedância na faixa de $10^{5}$ a $10^{6} \mathrm{ohm} . \mathrm{cm}^{2}$ na região de $0,01 \mathrm{~Hz}$, região associada à camada interna (rica em cromo) da película passiva de caráter dúplex.

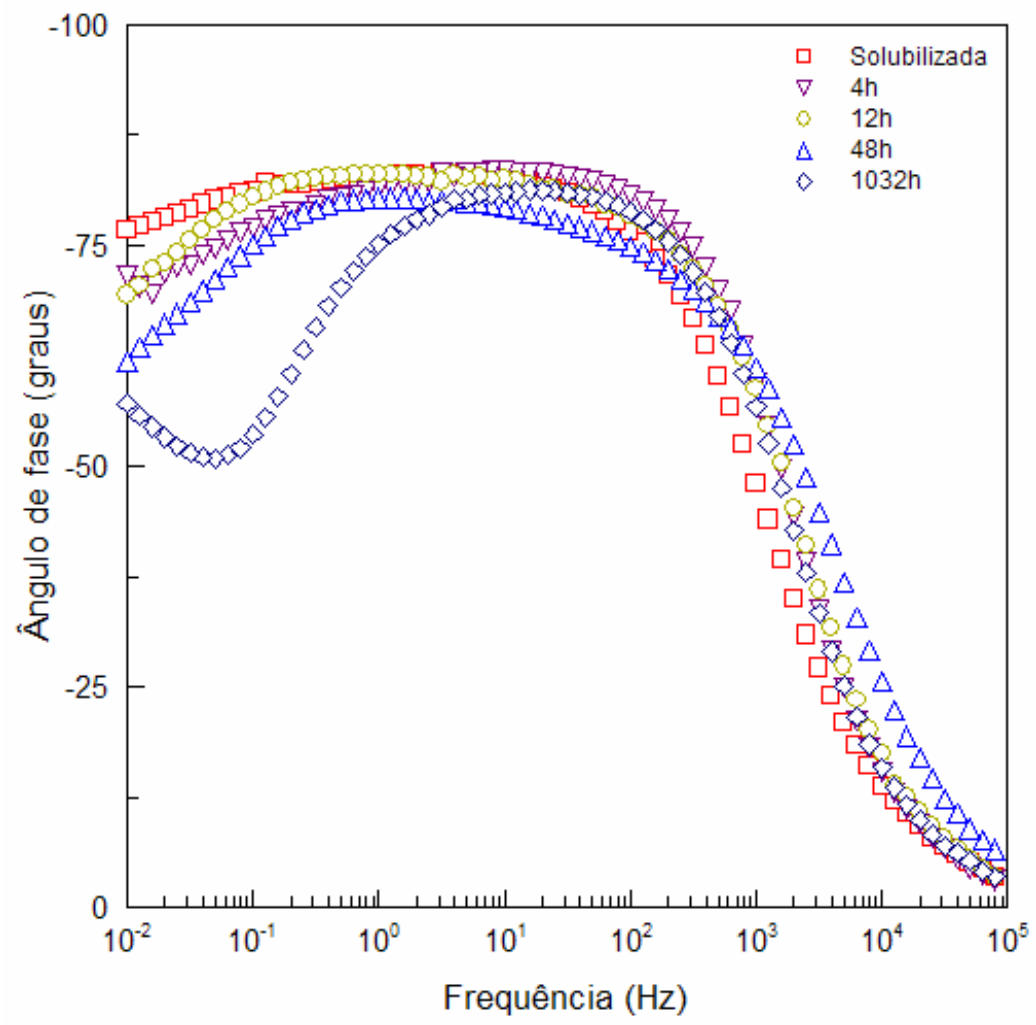

Figura 32: Diagramas de Ângulo de Fase de Bode da amostra solubilizada e envelhecidas a $475^{\circ} \mathrm{C}$.

A Fig.32 apresenta os diagramas de ângulo de fase de Bode. Para a amostra solubilizada verifica-se um comportamento altamente capacitivo com ângulo de fase próximo à $-76^{\circ}$ na região de baixa freqüência. Este comportamento é típico de materiais passivos (Terada et al., 2009).

Para todas as condições ensaiadas nota-se a presença de duas constantes de tempo parcialmente sobrepostas, sendo que a primeira aparece nas regiões de médias freqüências caracterizada pelo ombro aproximadamente 
entre 10 e $100 \mathrm{~Hz}$ e, a segunda na região de baixas freqüências caracterizada pelo início da alteração na inclinação da curva em torno de 0,1 e $1 \mathrm{~Hz}$.

Nota-se ainda que com o tempo de envelhecimento os valores de ângulo de fase vão diminuindo bem como os valores de impedância, indicando que a camada passiva do aço inoxidável super-dúplex vai se tornando cada vez menos protetora com o tempo de envelhecimento e mais defeituosa e, portanto a resistência à corrosão do material vai se deteriorando com a presença da fase alfa linha que é formada durante o tratamento de envelhecimento a $475^{\circ} \mathrm{C}$.

O diagrama mostra ainda que para a amostra solubilizada e envelhecida por até $12 \mathrm{~h}$ há a formação de um ombro em regiões de freqüência em torno de $100 \mathrm{~Hz}$ acompanhado de um patamar até as baixas freqüências. Esse patamar pode ser associado a uma provável sobreposição das constantes de tempo.

Para as amostras envelhecidas a partir de $48 \mathrm{~h}$ nota-se que há um deslocamento do ombro formado para as regiões de freqüências menores, indicando um comportamento menos capacitivo dessas amostras.

\subsection{Ajuste dos dados de EIE através de circuitos elétricos equivalentes}

Para melhor analisar os resultados obtidos através do ensaio de EIE, foram realizados ajustes através do circuito elétrico equivalente (CEE) que é indicado na FIG.33. Este circuito representa a camada protetora de caráter dúplex do aço inoxidável conforme indica a literatura (Montemor et al., 2000; Terada, 2008; Da cunha Belo et al., 1998, Hakiki, et al., 1995).

A camada mais externa indicada pelo elemento $\mathrm{R} 1$, é a camada que está em contato com o eletrólito que no caso é a solução de $\mathrm{NaCl}$, esta camada é mais porosa e é composta principalmente por óxidos de ferro de caráter menos protetor. Já a camada interna indicada pelo elemento R2, é a camada que está em contato com o substrato, é uma camada que apresenta menos densidade de defeitos, portanto é menos porosa e mais protetora e é constituída por óxidos de cromo. 


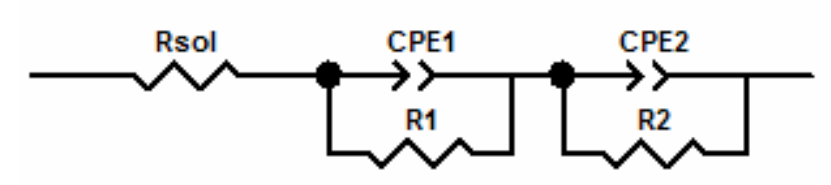

Figura 33: Circuito equivalente utilizado para ajuste dos dados do ensaio de EIE.

O elemento Rsol se refere à resistência do eletrólito e os elementos CPE 1 e CPE 2 referem-se aos elementos de fase constante no lugar de capacitores ideais, sendo que o CPE 1 indica a capacitância da camada externa e o CPE 2 indica a capacitância da camada interna.

O CPE1-R1 é utilizado para descrever os processos eletroquímicos na interface eletrólito/ filme passivo. As alterações no comportamento de R e CPE mostram mudanças no grau de compactação da camada passiva do material conforme o tempo de envelhecimento a $475^{\circ} \mathrm{C}$, sendo que a diminuição da resistência (R) e aumento da capacitância (CPE) indica uma camada passiva mais defeituosa ou menos espessa. $O$ parâmetro $n$ se refere à potência do CPE.

Os valores obtidos através do ajuste de dados com o circuito elétrico equivalente são mostrados na TAB.8 e os erros correspondentes a cada componente do CEE são mostrados no APÊNDICE 1.

Tabela 7 - Valores dos parâmetros ajustados utilizando o CEE apresentado na FIG.33.

\begin{tabular}{|c|c|c|c|c|c|c|c|}
\hline Condição & $\begin{array}{c}\begin{array}{c}\text { R sol } \\
\left(\Omega . \mathrm{cm}^{2}\right)\end{array} \\
\end{array}$ & $\begin{array}{c}\text { CPE1 } \\
\left(\mathrm{cm}^{-2} \mathrm{~s}^{-1} \Omega\right)\end{array}$ & $n_{1}$ & $\begin{array}{c}\mathbf{R 1} \\
\left(\Omega . \mathrm{cm}^{2}\right)\end{array}$ & $\begin{array}{c}\text { CPE2 } \\
\left(\mathrm{cm}^{-2} \mathrm{~s}^{-n} \Omega\right)\end{array}$ & $n_{2}$ & $\begin{array}{c}\mathbf{R 2} \\
\left(\Omega . \mathrm{cm}^{2}\right)\end{array}$ \\
\hline Solubilizada & 18,69 & $3,75 \times 10^{-5}$ & 0,82 & $1,21 \times 10^{5}$ & $1,60 \times 10^{-5}$ & 0,99 & $6,18 \times 10^{6}$ \\
\hline Env. a 4h & 12,79 & $2,54 \times 10^{-5}$ & 0,88 & $1,25 \times 10^{5}$ & $1,73 \times 10^{-5}$ & 0,98 & $4,15 \times 10^{6}$ \\
\hline Env. a 12h & 11,37 & $2,70 \times 10^{-5}$ & 0,86 & $3,29 \times 10^{5}$ & $2,23 \times 10^{-5}$ & 0,99 & $4,15 \times 10^{6}$ \\
\hline Env. a 48h & 12,54 & $2,35 \times 10^{-5}$ & 0,81 & $2,13 \times 10^{5}$ & $1,75 \times 10^{-5}$ & 0,98 & $2,11 \times 10^{6}$ \\
\hline $\begin{array}{l}\text { Env. a } \\
1032 h\end{array}$ & 11,59 & $1,96 \times 10^{-5}$ & 0,90 & 67249 & $5,77 \times 10^{-5}$ & 0,92 & $9,72 \times 10^{5}$ \\
\hline
\end{tabular}

Observa-se que para a amostra solubilizada o valor da R2 associada à camada mais protetora de óxidos de cromo é maior para todas as outras amostras envelhecidas e o valor do CPE2 é o menor para todas as outras condições, indicando que realmente quando ainda não há a formação da fase alfa linha a resistência à corrosão do material é maior para a amostra solubilizada e que a camada passiva formada para esta amostra é a que apresenta 
provavelmente a menor densidade de defeitos, oferecendo assim maior resistência à transferência de cargas em comparação com as amostras envelhecidas a $475^{\circ} \mathrm{C}$.

No caso das amostras envelhecidas nota-se a tendência de diminuição da resistência sugerindo que a camada vai se tornando cada vez mais defeituosa e sujeita à maior penetração do eletrólito. É notado também que os valores de R2 são pelo menos 10 vezes maiores que os valores de R1 o que realmente comprova a teoria de que a camada de óxidos responsável pela resistência à corrosão do material é a camada interna rica em cromo.

Embora a camada passiva se torne cada vez mais defeituosa e menos protetora, os valores de resistência da camada interna é elevado em torno de $10^{6}$ ohm. $\mathrm{cm}^{2}$, comportamento típico de materiais passivos e com elevada resistência a corrosão. Ressalta-se também que o valor dos parâmetros $n$ é relativamente alto, principalmente para a camada interna, se aproximando a um capacitor ideal.

Os valores CPE2 para todas as condições de tratamento foram maiores aos de CPE1. A diferença observada pode ser causada pela menor espessura da camada interna mais rica em cromo que a camada externa mais rica em ferro e níquel.

Esses valores observados também sugerem uma maior concentração de defeitos na camada de óxido interna, devido provavelmente ao empobrecimento em cromo da matriz causado pela formação da fase alfa linha, diminuindo o teor de cromo livre para a formação da camada passiva protetora.

\subsection{Comparação entre os resultados obtidos}

Embora exista um considerável aumento no valor da dureza com o tempo de envelhecimento conforme é mostrado na FIG.34, nota-se também que a diminuição dos valores de energia absorvida durante o ensaio de impacto apresenta valores críticos com apenas 30 minutos de envelhecimento e que com apenas $12 \mathrm{~h}$ o material já perde mais de $80 \%$ no valor de energia absorvida em comparação com a amostra solubilizada, tornando-se cada vez mais frágil.

A perda drástica da tenacidade à fratura com $12 \mathrm{~h}$ de envelhecimento é um indício da presença da fase alfa linha, que dificulta a movimentação das discordâncias e restringe o escorregamento a poucos planos, levando o material a 
fraturar de modo frágil. Por essa razão o uso do material está limitado nessas condições, uma vez que sua integridade estrutural está gravemente prejudicada, podendo falhar catastroficamente.

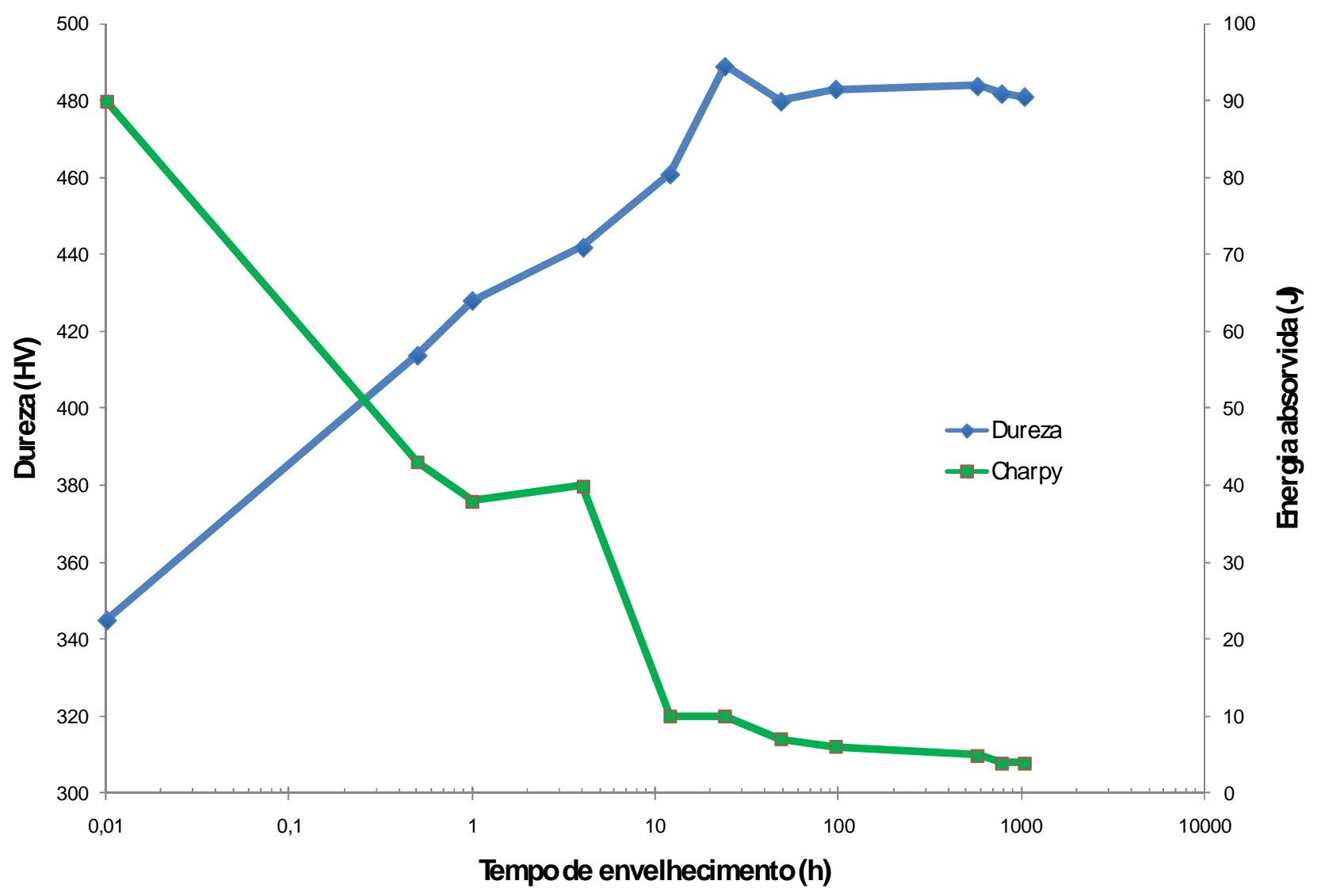

Figura 34: Energia absorvida e dureza em função do tempo de envelhecimento. $O$ tempo de $0,01 \mathrm{~h}$ corresponde à amostra solubilizada. 


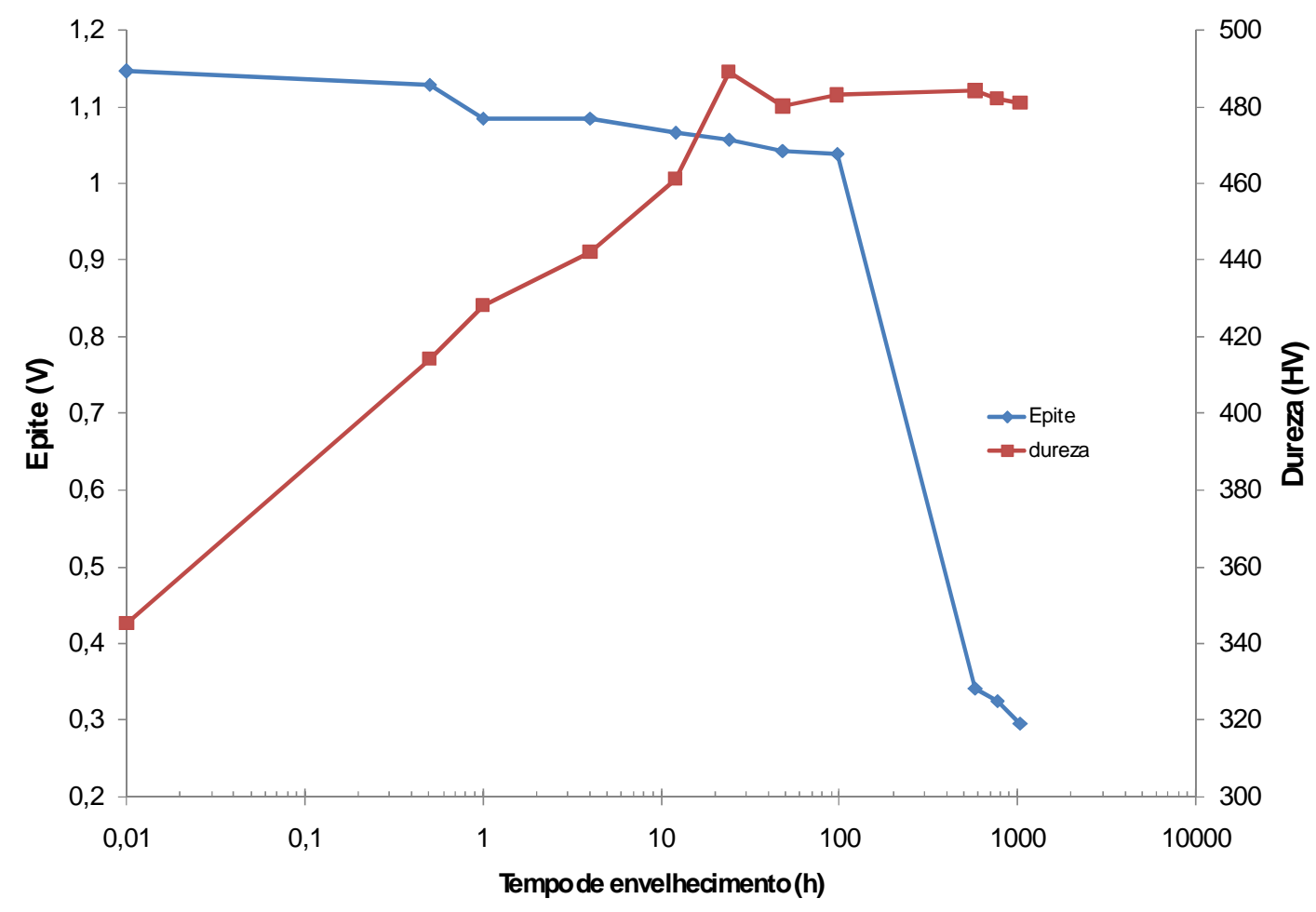

Figura 35: Dureza e Potencial de Pite em função do tempo de envelhecimento à $475^{\circ} \mathrm{C} . \mathrm{O}$ tempo de $0,01 \mathrm{~h}$ corresponde à amostra solubilizada.

A formação da fase alfa linha fica evidenciada indiretamente com a degradação da tenacidade e da resistência à corrosão da película passiva. $\mathrm{A}$ diminuição dos valores do potencial de pite ao longo do tempo de envelhecimento e também a perda da capacidade de repassivação dos pites formados é uma característica dos materiais que apresentam alfa linha em sua estrutura (Park e Kwon, 2002; Terada, 2003).

Para a amostra envelhecida por $1032 \mathrm{~h}$, notou-se além de uma queda drástica no potencial de pite, a perda total da capacidade de repassivação dos pites formados nesta amostra. Apesar disso, os resultados de densidade de corrente no potencial de corrosão para todas as amostras mostraram valores típicos de materiais passivos, o que indica que há ainda uma camada de óxido passivante sobre a superfície da liga, porém esta camada deve apresentar uma elevada concentração de defeitos, ocasionando a redução na resistência à corrosão por pite.

O potencial de pite permanece praticamente sem nenhuma alteração significativa nas amostras envelhecidas por até 96h, conforme pode ser verificado 
na FIG.35, porém a partir de 48h de envelhecimento já se nota uma grande diminuição na capacidade de repassivação dos pites formados, onde não mais se visualiza a ocorrência de potencial de proteção, como foi mostrado na FIG.25 e FIG.26 e essa tendência segue para as amostras envelhecidas até 1032h.

A partir de 576h de envelhecimento conforme mostrado na FIG.35, nota-se que há uma redução drástica no potencial de pite em comparação com a amostra solubilizada e essa tendência é observada para amostras envelhecidas até 1032h. Esse processo de deterioração da resistência à corrosão, e formação de pite, deve-se à formação de alfa linha que consome o cromo presente na matriz ferrítica, empobrecendo esta fase, gerando flutuações pontuais no teor de cromo no material e dificultando a redistribuição deste elemento na matriz para o processo de repassivação. Embora os potenciais de pite para as amostras até 96h de envelhecimento apresentam valores próximos aos da amostra solubilizada, nota-se que a capacidade de repassivação é altamente prejudicada ao longo do tempo de envelhecimento.

No entanto, apenas com 30 minutos de envelhecimento já é notado um significativo aumento no valor de dureza do material que vai aumentando de forma gradual, chegando ao seu máximo valor em $24 \mathrm{~h}$ de envelhecimento que também pode ser associado à máxima formação de alfa linha. Nota-se que atingido o máximo valor de dureza, este decresce em pequenas proporções, mantendo-se praticamente constante até 1032h.

A ligeira diminuição dos valores de dureza após $24 \mathrm{~h}$ de envelhecimento até a estabilização dos mesmos, está associada ao coalescimento dos precipitados de alfa linha, no entanto o potencial de pite para a amostra envelhecida por $24 \mathrm{~h}$ ainda permanece próximo ao da amostra solubilizada. 


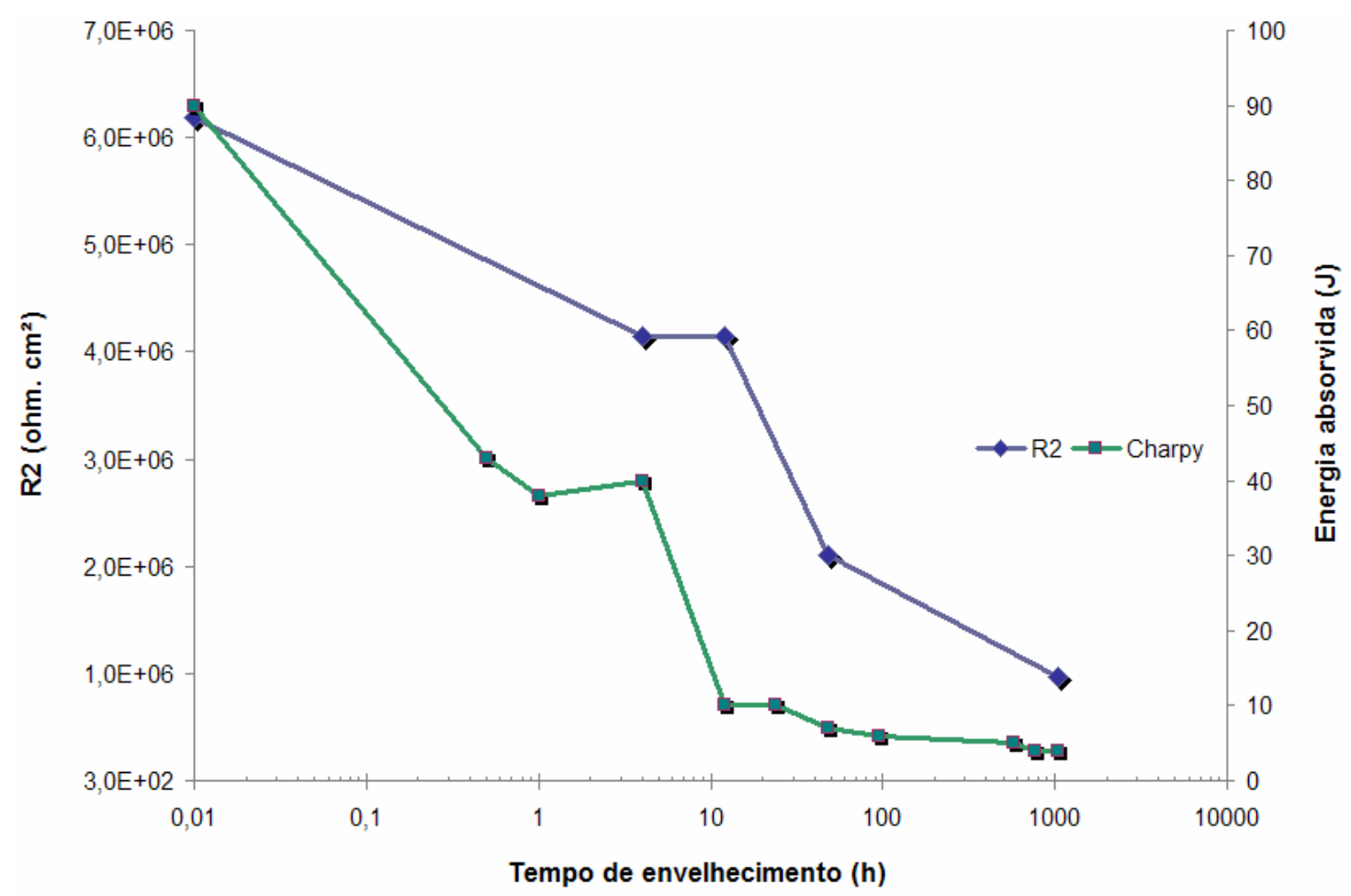

Figura 36:R2 e energia absorvida em função do tempo de envelhecimento à $475^{\circ} \mathrm{C}$. O tempo de $0,01 \mathrm{~h}$ corresponde à amostra solubilizada.

A FIG.36 compara os resultados obtidos no ensaio de impacto Charpy com os valores de R2 obtidos através do ajuste dos dados de EIE através do circuito elétrico equivalente.

Embora os ensaios de EIE mostrem valores típicos de materiais passivos, nota-se que o comportamento dessas duas curvas é semelhante, sendo percebidas variações significativas tanto nos valores de energia absorvida que decresce bruscamente quanto nos valores de resistência da camada interna (R2), a qual vai se degradando com o aumento do tempo de envelhecimento, indicando as modificações microestruturais que estão sendo ocasionadas pela formação da fase alfa linha de maneira mais evidente que no ensaio de dureza, por exemplo, onde a variação ocorre de forma gradual.

Pode-se notar também que no intervalo entre $12 \mathrm{~h}$ e $48 \mathrm{~h}$ de envelhecimento a variação dos valores de R2 é maior, o que pode estar associada à máxima formação da fase alfa linha indicando que a decomposição espinodal se completa possivelmente em $24 \mathrm{~h}$ de envelhecimento conforme verificado nas FIG. 34 e FIG.35. Como a fase alfa linha consome o cromo da 
matriz ferrítica, os valores de R2 diminuem bruscamente neste intervalo mostrando que há uma maior diminuição do teor de cromo livre, prejudicando assim a formação de uma película protetora homogênea.

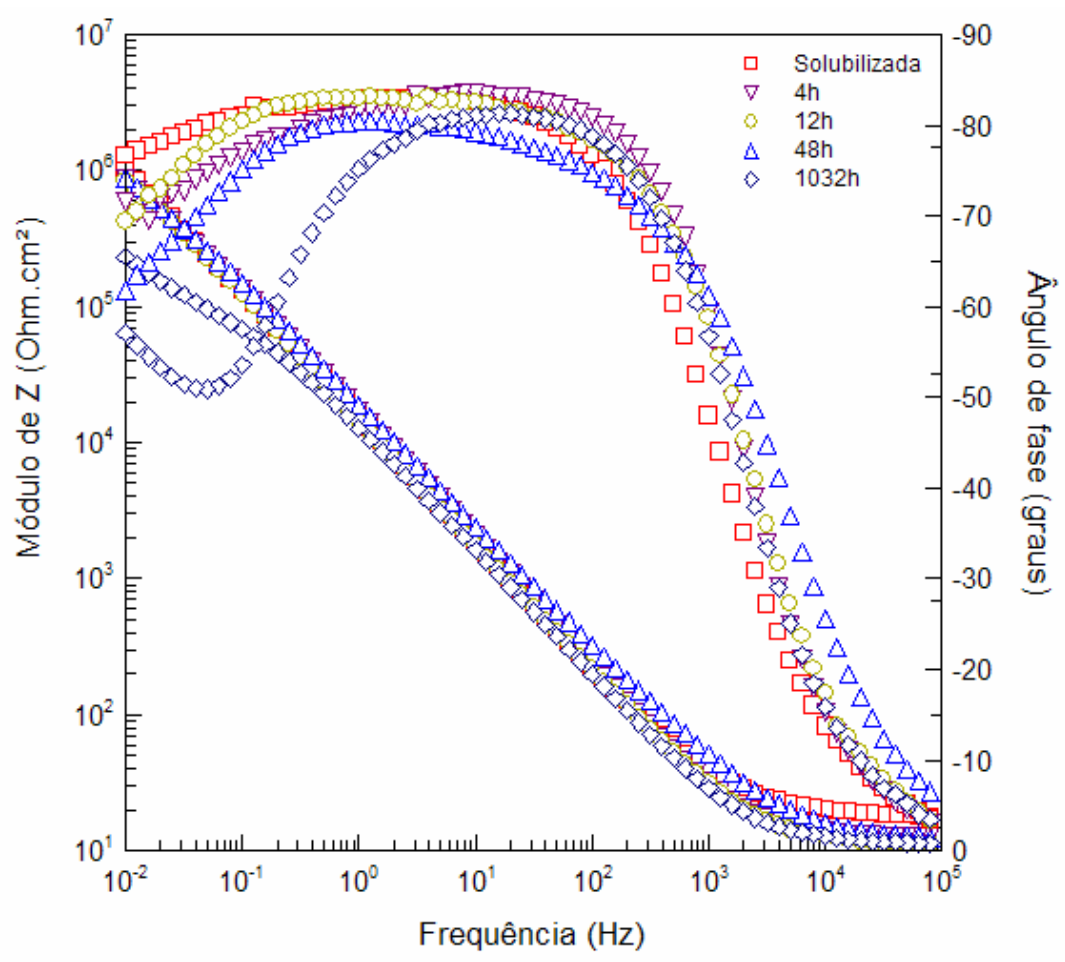

Figura 37: Diagramas de Bode (Módulo de Z e Ângulo de fase) para a amostra solubilizada e envelhecida a $475^{\circ} \mathrm{C}$.

Através dos dados observados nos diagramas de Bode da FIG.37 notase que a impedância e os valores do ângulo de fase na região de baixa freqüência, região que está associada à camada interna rica em óxido de cromo, vão diminuindo gradualmente com o tempo de envelhecimento devido ao empobrecimento em cromo na matriz, impedindo a formação de uma camada passiva de boa qualidade e que seja efetivamente protetora ao meio agressivo.

Porém, essas variações observadas nos resultados de EIE indicam ainda assim valores elevados, típicos de materiais que apresentam elevada resistência à corrosão mesmo para amostra envelhecida a $1032 \mathrm{~h}$, condição esta que no ensaio de impacto mostrou que o material perdeu completamente sua capacidade de absorver energia tornando-se extremamente frágil, podendo falhar sem que nenhuma tensão externa seja aplicada, inviabilizando o seu uso quando 
se necessita de um material que apresente boa qualidade nas propriedades mecânicas.

A FIG.38 mostra a variação das propriedades ao longo do tempo de envelhecimento comparada com os valores obtidos da amostra solubilizada.

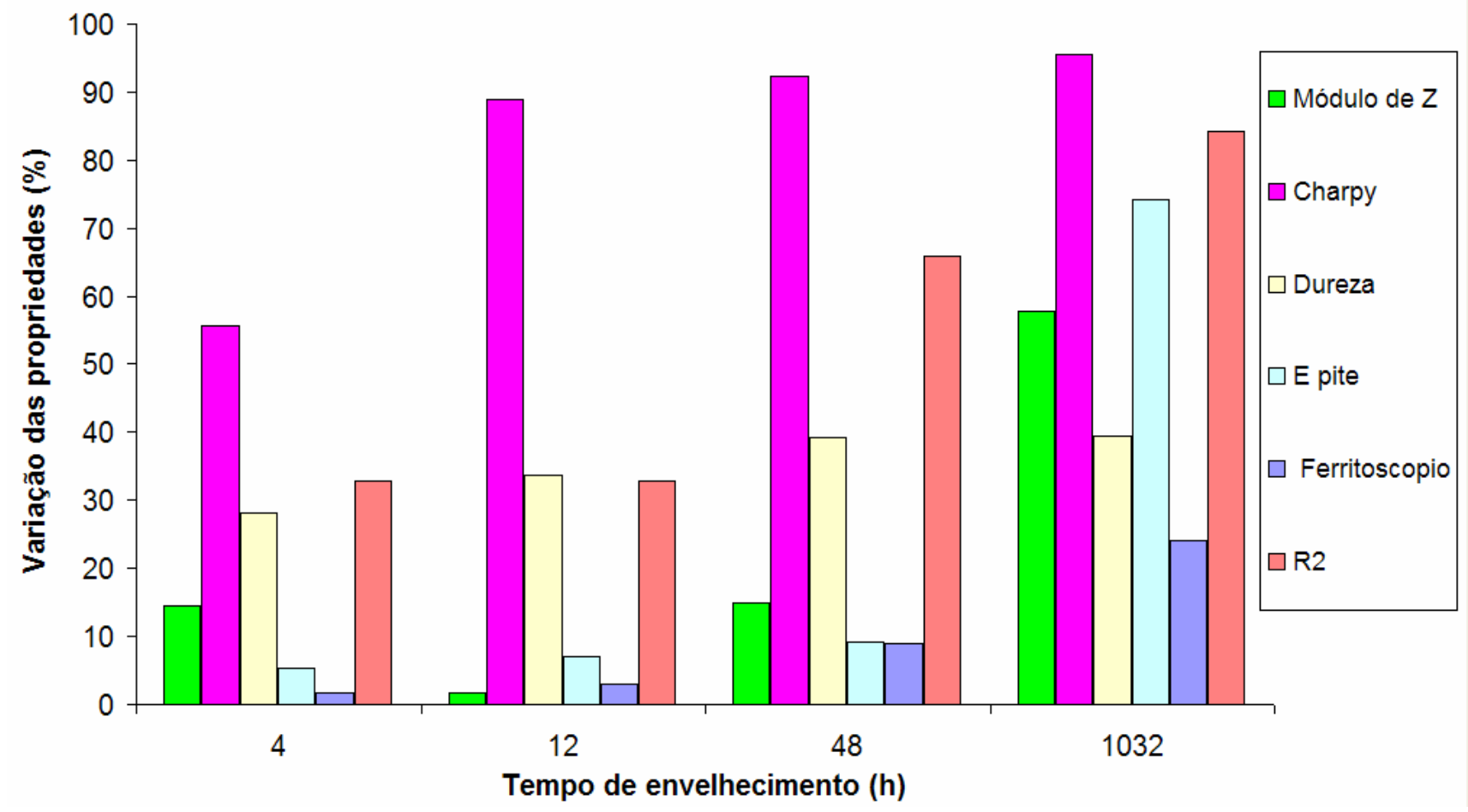

Figura 38: Comparativo da variação das propriedades com o tempo de envelhecimento.

Conforme ilustra a FIG.38, os ensaios de ferritoscopia mostraram ser os ensaios de menor sensibilidade na detecção da presença da fase alfa linha mesmo para altos tempos de envelhecimento já que há uma variação pouco significativa desta propriedade, principalmente para tempos de envelhecimento de até $4 \mathrm{~h}$, onde mostra que os valores não se alteram praticamente.

Essa tendência segue para os ensaios de espectroscopia de impedância eletroquímica e de polarização cíclica, porém para tempos superiores a 48 h de envelhecimento nota-se que existe variação significativa do potencial de pite e do módulo de Z. No entanto mesmo com uma variação de pouco mais de $57 \%$ no módulo de Z para a amostra envelhecida por $1032 \mathrm{~h}$, os valores obtidos no ensaio de espectroscopia de impedância ainda são típicos de materiais altamente passivos. 
Nota-se que com 30 minutos de envelhecimento a $475^{\circ} \mathrm{C}$ já se observa uma variação significativa na perda da capacidade do material em absorver energia conforme os dados obtidos no ensaio de impacto Charpy. Para tempos de envelhecimento superiores à $4 \mathrm{~h}$, a variação desta propriedade medida chega a ser maior que $50 \%$ comparada com a amostra solubilizada.

O ensaio de impacto charpy mostrou ser o ensaio mais sensível de todos para detectar a presença da fase alfa linha, no entanto o ensaio de dureza e os valores de resistência da camada interna (R2) obtidos através do ajuste dos dados de EIE através de circuitos elétricos equivalentes também mostraram boa sensibilidade na detecção da fase alfa linha, pois com pouco tempo de envelhecimento já é possível notar variações significativas nessas propriedades. 


\section{CONCLUSÃO}

Através dos dados obtidos no presente trabalho podem ser extraídas as seguintes conclusões:

> A presença de alfa linha pode ser indiretamente verificada através da mudança nos comportamentos eletroquímico e mecânico do material.

$>$ A diminuição do potencial de pite que ocorre para tempos superiores a 96h e a dificuldade na repassivação observada para amostras envelhecidas a partir de 48h são indícios da presença de alfa linha .

$>O$ ensaio de impacto mostrou ser o ensaio de maior sensibilidade para verificação da presença de alfa linha no material, pois a partir de $12 \mathrm{~h}$ de envelhecimento a tenacidade à fratura do material apresenta uma grande redução, podendo ocorrer falhas catastróficas enquanto que diferenças no potencial de pite, por exemplo são detectadas apenas após 96h de envelhecimento isotérmico à $475^{\circ} \mathrm{C}$, no entanto o ensaio de dureza e os valores de resistência da camada interna (R2) obtidos através do ajuste dos dados de EIE através de circuitos elétricos equivalentes também mostraram boa sensibilidade na detecção da fase alfa linha, pois com pouco tempo de envelhecimento já é possível notar variações significativas nessas propriedades.

$>O$ ensaio de ferritoscopia não se mostrou uma ferramenta com boa sensibilidade na determinação da presença da fase alfa linha.

$>$ Os resultados obtidos no presente trabalho indicam que tanto a diminuição da resistência da camada passiva avaliada pela técnica de EIE e por ajuste de circuitos equivalentes quanto à redução de potencial de pite são causadas pelo empobrecimento em cromo na matriz ferrítica devido à formação de fase alfa linha.

> A fase alfa linha é uma fase deletéria para o material, pois além de diminuir a resistência à corrosão por pite, tornar a camada passiva menos estável, prejudica intensamente a capacidade do material em absorver energia tornando o material muito frágil. No entanto a dureza do material é aumentada consideravelmente. 
$>$ O tipo de fratura predominante nos materiais envelhecidos a $475^{\circ} \mathrm{C}$ é de natureza frágil por clivagem e a visualização desse tipo de fratura se torna mais acentuada para tempos de envelhecimento superiores a $12 \mathrm{~h}$. 


\section{APÊNDICE 1 - Ajuste de CEE para a amostra solubilizada e envelhecidas a 475ㄷ.}

Ajuste de CEE para a amostra solubilizada.

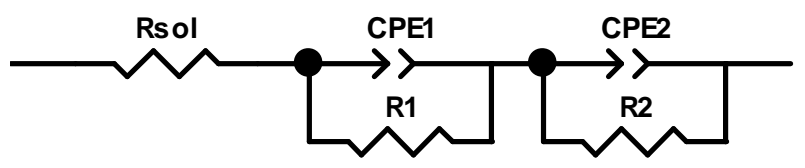

\begin{tabular}{|c|c|c|c|c|}
\hline Element & Freedom & $\underline{\text { Value }}$ & Error & Error \% \\
\hline Rsol & Free $(+)$ & 18,69 & 0,11122 & 0,5950 \\
\hline CPE1-T & Free $(+)$ & $3,7538 E-5$ & $5,9885 E-7$ & 1,5953 \\
\hline CPE1-P & Fixed $(X)$ & 0,82207 & $\mathrm{~N} / \mathrm{A}$ & $\mathrm{N} / \mathrm{A}$ \\
\hline $\mathrm{R} 1$ & Free(+) & $1,2128 \mathrm{E} 5$ & 19366 & 15,968 \\
\hline CPE2-T & Free $(+)$ & $1,5989 \mathrm{E}-5$ & $2,5702 E-7$ & 1,6075 \\
\hline CPE2-P & Fixed $(X)$ & 0,9998 & $\mathrm{~N} / \mathrm{A}$ & $\mathrm{N} / \mathrm{A}$ \\
\hline $\mathrm{R} 2$ & Free(+) & $6,1771 \mathrm{E} 6$ & $6,7094 \mathrm{E} 5$ & 10,862 \\
\hline
\end{tabular}

Chi-Squared: $\quad 0,0032027$

Weighted Sum of Squares: $\quad 0,43877$

Data File: C:IDocuments and Settings $\backslash$ TalitalDesktoplImpedan

Circuit Model File: $\quad$ C:IDocuments and Settings $\backslash$ TalitalDesktoplMestradk

Mode:

Run Fitting / Freq. Range (0,001 - 1000000)

Maximum Iterations: $\quad 100$

Optimization Iterations: $\quad 0$

Type of Fitting:

Complex

Type of Weighting: Calc-Modulus 
Ajuste de CEE para a amostra envelhecida por $4 \mathrm{~h}$ a $475^{\circ} \mathrm{C}$.

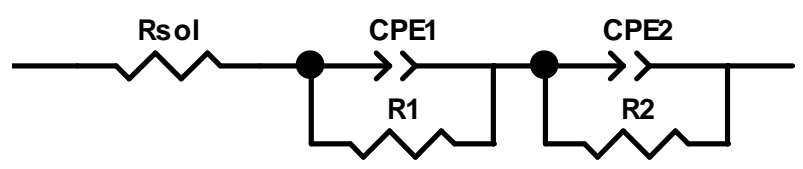

\begin{tabular}{|c|c|c|c|c|}
\hline Element & Freedom & $\underline{\text { Value }}$ & Error & Error \% \\
\hline Rsol & Free $(+)$ & 12,79 & 0,052041 & 0,40689 \\
\hline CPE1-T & Free $(+)$ & $2,5416 \mathrm{E}-5$ & $5,0468 \mathrm{E}-7$ & 1,9857 \\
\hline CPE1-P & Free $(+)$ & 0,88061 & 0,0016829 & 0,19111 \\
\hline $\mathrm{R} 1$ & Free $(+)$ & $1,2532 \mathrm{E} 5$ & 8934,9 & 7,1297 \\
\hline CPE2-T & Free $(+)$ & $1,7353 \mathrm{E}-5$ & 2,6964E-7 & 1,5539 \\
\hline CPE2-P & Fixed $(X)$ & 0,98 & $\mathrm{~N} / \mathrm{A}$ & $\mathrm{N} / \mathrm{A}$ \\
\hline $\mathrm{R} 2$ & Free $(+)$ & $4,1514 \mathrm{E} 6$ & $2,9649 \mathrm{E} 5$ & 7,1419 \\
\hline \multicolumn{2}{|c|}{ Chi-Squared: } & \multicolumn{3}{|l|}{0,0013362} \\
\hline \multicolumn{2}{|c|}{ Weighted Sum of Squares: } & \multicolumn{3}{|l|}{0,18172} \\
\hline \multicolumn{2}{|c|}{ Data File: } & \multicolumn{3}{|c|}{ C:IDocuments and Settings $\mid$ TalitalDesktop $\backslash$ Impedan } \\
\hline \multicolumn{2}{|c|}{ Circuit Model File: } & \multicolumn{3}{|c|}{ C:IDocuments and Settings $\backslash$ TalitalDesktop $\backslash$ Mestradk } \\
\hline \multicolumn{2}{|c|}{ Mode: } & \multicolumn{3}{|c|}{ Run Fitting / Freq. Range $(0,001-1000000)$} \\
\hline \multicolumn{2}{|c|}{ Maximum Iterations: } & \multicolumn{3}{|l|}{100} \\
\hline \multicolumn{2}{|c|}{ Optimization Iterations: } & \multicolumn{3}{|l|}{0} \\
\hline \multicolumn{2}{|c|}{ Type of Fitting: } & \multicolumn{3}{|l|}{ Complex } \\
\hline \multicolumn{2}{|c|}{ Type of Weighting: } & \multicolumn{3}{|c|}{ Calc-Modulus } \\
\hline
\end{tabular}


Ajuste de CEE para a amostra envelhecida por $12 \mathrm{~h}$ a $475^{\circ} \mathrm{C}$.

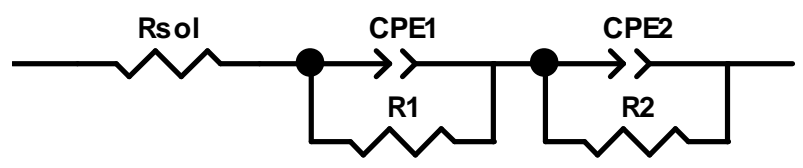

\begin{tabular}{|c|c|c|c|c|}
\hline Element & Freedom & $\underline{\text { Value }}$ & Error & Error \% \\
\hline Rsol & $\overline{\text { Free }(+)}$ & $\overline{11,37}$ & $\overline{0,03912}$ & $\overline{0,34406}$ \\
\hline CPE1-T & Free $(+)$ & $2,7036 \mathrm{E}-5$ & $2,1404 \mathrm{E}-7$ & 0,79169 \\
\hline CPE1-P & Fixed $(X)$ & 0,86 & $\mathrm{~N} / \mathrm{A}$ & $\mathrm{N} / \mathrm{A}$ \\
\hline R1 & Free $(+)$ & 3,2939E5 & 18525 & 5,624 \\
\hline CPE2-T & Free $(+)$ & $2,228 E-5$ & $2,6327 \mathrm{E}-7$ & 1,1816 \\
\hline CPE2-P & Fixed(X) & 0,998 & $N / A$ & $N / A$ \\
\hline R2 & Free $(+)$ & $4,1545 \mathrm{E} 6$ & $2,6553 \mathrm{E} 5$ & 6,3914 \\
\hline \multicolumn{2}{|c|}{ Chi-Squared: } & \multicolumn{3}{|l|}{0,00091577} \\
\hline \multicolumn{2}{|c|}{ Weighted Sum of Squares: } & \multicolumn{3}{|l|}{0,12546} \\
\hline \multicolumn{2}{|c|}{ Data File: } & \multicolumn{3}{|c|}{ C:IDocuments and Settings $\backslash$ TalitalDesktop $\backslash I m p e d a n$} \\
\hline \multicolumn{2}{|c|}{ Circuit Model File: } & \multicolumn{3}{|c|}{ C:IDocuments and Settings $\backslash$ TalitalDesktop $\backslash$ Mestradk } \\
\hline \multicolumn{2}{|c|}{ Mode: } & \multicolumn{3}{|c|}{ Run Fitting / Freq. Range (0,001 - 1000000) } \\
\hline \multicolumn{2}{|c|}{ Maximum Iterations: } & \multicolumn{3}{|c|}{100} \\
\hline \multicolumn{2}{|c|}{ Optimization Iterations: } & \multicolumn{3}{|l|}{0} \\
\hline \multicolumn{2}{|c|}{ Type of Fitting: } & \multicolumn{3}{|l|}{ Complex } \\
\hline \multicolumn{2}{|c|}{ Type of Weighting: } & \multicolumn{3}{|c|}{ Calc-Modulus } \\
\hline
\end{tabular}


Ajuste de CEE para a amostra envelhecida por $48 \mathrm{~h}$ a $475^{\circ} \mathrm{C}$.

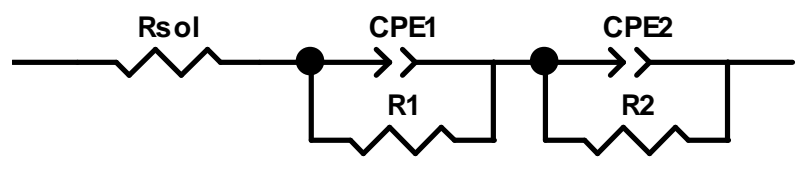

\begin{tabular}{|c|c|c|c|c|}
\hline Element & Freedom & Value & Error & Error \% \\
\hline Rsol & Free(+) & 12,54 & 0,084036 & 0,67014 \\
\hline CPE1-T & Free $(+)$ & $2,3557 \mathrm{E}-5$ & $2,699 \mathrm{E}-7$ & 1,1457 \\
\hline CPE1-P & Fixed $(X)$ & 0,81 & $\mathrm{~N} / \mathrm{A}$ & $N / A$ \\
\hline R1 & Free $(+)$ & $2,1305 \mathrm{E} 5$ & 22278 & 10,457 \\
\hline CPE2-T & Free $(+)$ & $1,7556 \mathrm{E}-5$ & $3,4359 \mathrm{E}-7$ & 1,9571 \\
\hline CPE2-P & Fixed $(X)$ & 0,98 & $\mathrm{~N} / \mathrm{A}$ & $N / A$ \\
\hline $\mathrm{R} 2$ & Free $(+)$ & $2,1087 \mathrm{E} 6$ & 92395 & 4,3816 \\
\hline \multicolumn{2}{|c|}{ Chi-Squared: } & \multicolumn{3}{|l|}{0,0020393} \\
\hline \multicolumn{2}{|c|}{ Weighted Sum of Squares: } & \multicolumn{3}{|l|}{0,27938} \\
\hline \multicolumn{2}{|c|}{ Data File: } & \multicolumn{3}{|c|}{ C:IDocuments and Settings $\backslash$ TalitalDesktop $\backslash I m p e d a n$} \\
\hline \multicolumn{2}{|c|}{ Circuit Model File: } & \multicolumn{3}{|c|}{ C:IDocuments and Settings $\backslash$ TalitalDesktoplMestradk } \\
\hline \multicolumn{2}{|l|}{ Mode: } & \multicolumn{3}{|c|}{ Run Fitting / Freq. Range $(0,001-1000000)$} \\
\hline \multicolumn{2}{|c|}{ Maximum Iterations: } & \multicolumn{3}{|l|}{100} \\
\hline \multicolumn{2}{|c|}{ Optimization Iterations: } & \multicolumn{3}{|l|}{0} \\
\hline \multicolumn{2}{|c|}{ Type of Fitting: } & \multicolumn{3}{|l|}{ Complex } \\
\hline \multicolumn{2}{|c|}{ Type of Weighting: } & \multicolumn{3}{|c|}{ Calc-Modulus } \\
\hline
\end{tabular}


Ajuste de CEE para a amostra envelhecida por $1032 \mathrm{~h}$ a $475^{\circ} \mathrm{C}$.

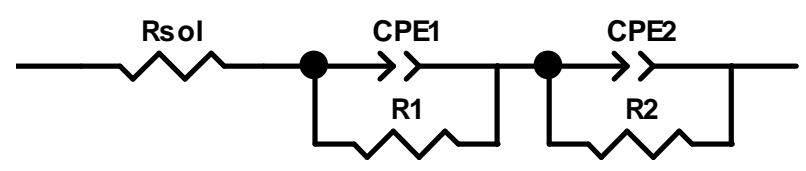

\begin{tabular}{|c|c|c|c|c|}
\hline Element & Freedom & $\underline{\text { Value }}$ & Error & Error \% \\
\hline Rsol & $\overline{\text { Free }(+)}$ & $\overline{11,59}$ & $\overline{0,055118}$ & $\overline{0,47557}$ \\
\hline CPE1-T & Free $(+)$ & $1,9586 \mathrm{E}-5$ & $1,4546 \mathrm{E}-7$ & 0,74267 \\
\hline CPE1-P & Free $(+)$ & 0,90152 & 0,0012381 & 0,13733 \\
\hline $\mathrm{R} 1$ & Free $(+)$ & 67249 & 1304,5 & 1,9398 \\
\hline CPE2-T & Free $(+)$ & $5,7699 \mathrm{E}-5$ & 8,0707E-7 & 1,3988 \\
\hline CPE2-P & Fixed $(X)$ & 0,92 & $\mathrm{~N} / \mathrm{A}$ & $\mathrm{N} / \mathrm{A}$ \\
\hline $\mathrm{R} 2$ & Free(+) & $9,7166 \mathrm{E} 5$ & 75351 & 7,7549 \\
\hline \multicolumn{2}{|c|}{ Chi-Squared: } & \multicolumn{3}{|l|}{0,0013694} \\
\hline \multicolumn{2}{|c|}{ Weighted Sum of Squares: } & \multicolumn{3}{|l|}{0,18623} \\
\hline \multicolumn{2}{|c|}{ Data File: } & \multicolumn{3}{|c|}{ c:Idocuments and settings|talitaldesktoplimpedancii } \\
\hline \multicolumn{2}{|c|}{ Circuit Model File: } & \multicolumn{3}{|c|}{ C:IDocuments and Settings $\backslash$ TalitalDesktoplMestrad } \\
\hline \multicolumn{2}{|l|}{ Mode: } & \multicolumn{3}{|c|}{ Run Fitting / Freq. Range $(0,001-1000000)$} \\
\hline \multicolumn{2}{|c|}{ Maximum Iterations: } & \multicolumn{3}{|l|}{100} \\
\hline \multicolumn{2}{|c|}{ Optimization Iterations: } & \multicolumn{3}{|l|}{0} \\
\hline \multicolumn{2}{|c|}{ Type of Fitting: } & \multicolumn{3}{|l|}{ Complex } \\
\hline \multicolumn{2}{|c|}{ Type of Weighting: } & \multicolumn{3}{|c|}{ Calc-Modulus } \\
\hline
\end{tabular}




\section{REFERÊNCIAS BIBLIOGRÁFICAS}

1. ABM. Análise de fraturas. 2 ed. São Paulo: ABM, 1979.

2. American Society for Testing and Materials. Standard Test Methods for Notched Bar Impact Testing of Metallic Materials. 2002. (ASTM E 2302).

3. Anglada, M.; Rodriguez, J.; Isalgué, A. Influence of the plastic strain amplitude on the stability of the spinodal microstructure in the cyclic deformation of a Fe-28Cr-2Mo-4Ni-Nb alloy. Scripta Metallurgica, v. 23, n. 9, p. 1633-1638, 1989.

4. Asami, K., Hashimoto, K., Shimodaira, S. An XPS study of the passivity of a series of iron-chromium alloys in sulphuric acid. Corrosion Science, v. 18, n. 2, p. 151-160, 1978.

5. Asami, K., Hashimoto, K., Shimodaira, S. XPS determination of compositions of alloy surfaces and surface oxides on mechanically polished iron-chromium alloys. Corrosion Science, v. 17, n. 7, p. 713-723, 1977.

6. Asami,K.; Hashimoto, K.;Masumoto,T.;Shimodara, S. ESCA study of the passive film on an extremely corrosion-resistant amorphous iron alloy.Corrosion Science, v.16, n.12, p. 909-914, 1976.

7. ASM. Metals Handbook Desk Edition. Ohio, $\mathrm{OH}$.: Metals Park -ASM International,1985.

8. ASM. Metals Handbook. v.1- Properties and Selection:Iron, Steels and High Performance Alloys. 10.ed.Ohio, OH.:Metals Park - ASM International, 1990.

9. Assis, S. L. Investigação da resistência à corrosão da liga Ti-13Nb-13Zr por meio de técnicas eletroquímicas e de análise de superfície.2006. Tese (doutorado)-Instituto de Pesquisas Energéticas e Nucleares, São Paulo.

10. Azumi, K. Ohtsuka, T., Sato, N. Impedance of iron electrode passivated in borate and phosphate solutions. Transactions of the Japan Institute of Metals, v. 27, p. 382-392, 1986.

11. Bandel, G.; Tofaute, W. Die versprödung von hochlegierten chromstählen im temperaturgebiet um $500^{\circ}$. Archiv für das Eisenhüttenwesen, v. 14, p. 307-319, 1942.

12. Bastos, A. C.;Simões, A. M.; González, S.; González-García, Y.; Souto, R. M. Imaging concentration profiles of redox-active species in open-circuit corrosion processes with the scanning electrochemical microscope.

Electrochemistry Communications, v. 6, n. 11, p. 1212-1215, 2004. 
13. Bernauer, J.; Giardino, R.; Chiesa, R.; Cigada, A. A new austenitic stainless steel with negligible nickel content: an in vitro and in vivo comparative investigation. Biomaterials, v.24, p. 4929-4939, 2003.

14. Blackburn, M. J.; Nutting, J. Metallography of an iron-21\% chromium alloy subject to $475^{\circ} \mathrm{C}$ embrittlement. Journal of the Iron and Steel Institute, $v$. 202, p. 610-613, 1964.

15. Bley, F. Neutron small angle scattering study of unmixing In Fe-Cr alloys. Acta Metall. Mater., v.40, p. 1505-1517, 1992.

16. Bojinov, M.; Betova, I.; Fabricius, G.; Laitinen, T.; Raicheff, R.; Saario, T. The stability of the passive state of iron-chromium alloys in sulphuric acid solution. Corrosion Science. v. 41, n. 8, p. 1557-1584, 1999.

17. Bonora, P. L.; Deflorian, F.; Fedrizzi, L. Electrochemical impedance spectroscopy as a tool for investigating underpaint corrosion.

Electrochimica Acta, v. 41, n. 7-8, p. 1073-1082, 1996.

18. Bundy, K. J., Dillard, J., Luedemann, R. Use of a.c. impedance methods to study the corrosion behaviour of implant alloys. Biomaterials. v., 14, n. 7, p. 529-536, 1993.

19. Callister Jr., W.D. Ciência e engenharia dos materiais: uma introdução. 5.ed. São Paulo:LTC, 2002.

20. Calonne, V.; Berdin, C.; Saint-Germain, B.; Jayet-Gendrot, S. Damage and dynamic strain aging in a thermal aged cast duplex stainless steel. Journal of Nuclear Materials, v. 327, p.202-210, 2004.

21. Castle, J. E.; Clayton, C. R. The use of X-ray photo-electron spectroscopy in the analyses of passive layers on stainless steel. Corrosion Science, v.17,n. 1, p. 7-26, 1977.

22. Chandra, D.; Schwartz, L. H. Mössbauer effect study of the $475^{\circ} \mathrm{C}$ decomposition of Fe-Cr. Metallurgical Transactions, v. 2, p. 511-519, 1971.

23. Charles,J.; Mithieux, J.-D. ; Santacreu, P.-O. ; Peguet, L. The ferritic stainless family: the appropriate answer to nickel volatility? Revue de Méttalurgie,v.3, p. 124-139,2009.

24. Cheon, J.S.; Kim, I.S. Evaluation of thermal aging embrittlement in CF8 duplex stainless steel by small punch test. Journal of Nuclear Materials, v 278, p.96-103, 2000.

25. Chung, H.M.; Chopra, O.K. Microstructures of cast-duplex stainless steel after long-term aging. In: 2nd Environmental Degradation of Materials in Nuclear Power Systems -Water Reactors, 9 Sep. 1985,Monterey. Proceedings: Monterey: American Nuclear Society, 1985, p.289-292. 
26. Cícero, S.; Setién, J.; Gorrochategui, I. Assessment of thermal aging embrittlement in a cast stainless steel valve and its effect on the structural integrity. Nuclear Engineering and Design, v. 239, p.16-22, 2009.

27. Cortie, M.B.; Pollak, A.H. Embrittlement and aging at $475^{\circ} \mathrm{C}$ in an experimental ferritic stainless steel containing 38 wt.\% chromium. Materials Science and Engineering A, v.199, p. 153 163, 1995.

28. Da Cunha Belo, M.; Walls, M.; Hakiki, N. E.; Corset, J.; Picquenard, E.; Sagon, G.; Noël, D. Composition, structure and properties of the oxide films formed on the stainless steel $316 \mathrm{~L}$ in a primary type PWR environment. Corrosion Science, v. 40,p. 447-463, 1998.

29. Da Silva, M.R.; Tavares, S.S.M.; Fruchart, D.; Miraglia, S.; Neto, J.M. The use of thermomagnetic analysis for detection and quantification of $475^{\circ} \mathrm{C}$ embrittlement of duplex stainless steels. Journal of Magnetism and Magnetic Materials, v. 226-230, p.1103-1105, 2001.

30. Di Cocco, V.; Franzese, E.; lacoviello, F.; Natali, S. 22 Cr 5 Ni duplex and $25 \mathrm{Cr} 7 \mathrm{Ni}$ superduplex stainless steel: Hydrogen influence on fatigue crack propagation resistance.Engineering Fracture Mechanics,v.75, p.705-714, 2008.

31. Do Nascimento, A.M.; lerardi, M.C.F.; Kina, A.Y.; Tavares, S.S.M. Pitting Corrosion Resistance of cast duplex stainless steels in $3.5 \% \mathrm{NaCl}$ solution. Materials Characterization,v.59, p.1736-1740, 2008.

32. Escudero, M. L.; González-Carrasco, J. L.; García-Alonso, C.; Ramírez, E. Eletrochemical impedance spectroscopy of preoxidized MA 956 superalloy during in vitro experiments. Biomaterials, v. 16, n. 9, p. 735-740, 1995.

33. Fan, G.W.; Liu, J.;. Han, P.D.; Qiao, G.J. Hot ductility and microstructure in casted 2205 duplex stainless steels. Materials Science and Engineering $\boldsymbol{A}$, v.515, p.108-112, 2009.

34. Fini,M.; Aldini, N.N.; Torricelli, P.; Giavaresi, G.; Borsari, V.; Lenger, H.;

35. Fisher, R. M.; Dullis, E. J.; Carroll, K. G. Identification of the precipitate accompanying 885을 embrittlement in chromium steels. Transactions of The Metallurgical Society of AIME (Journal of Metals), v. 197, p. 690695, 1953.

36. Floreen, S.; Rayden,H.W .The influence of austenite and ferrite on the mechanical properties of two-phase stainless steels having microduplex structures. ASM Trans Quart, v. 61, p. 489-499, 1968.

37. Fontana, M. G., Greene, N. D. Corrosion Engineering.2.ed.New York: McGraw-Hill, 1978. 
38. Garfias-Mesias, L.F.; Sykes, J.M.; Tuck, C.D.S. The effect of phase compositions on the pitting corrosion of $25 \mathrm{Cr}$ duplex stainless steel in chloride solutions. Corrosion Science,v. 38,p.1319-1330,1996.

39. Ge, H.; Zhou, G.; Wu, W. Passivation model of 316 stainless steel in simulated cooling water and the effect of sulfide on the passive film. Applied Surface Science, v. 211, p. 321-334, 2003.

40. Gelles, D.S. Comments on "Embrittlement of Cr-Mo steels after low fluence irradiation in high flux isotope reactor". Journal of Nuclear Materials, v.230, p.187-190, 1996.

41. Gelles, D.S.; Hamilton, M.L. Effects of irradiation on low activation ferrítica alloys. Journal of Nuclear Materials, v.148, p.272-278, 1987.

42. Gemelli,E. Corrosão de materiais metálicos e sua caracterização.Rio de Janeiro: LTC, 2001.

43. Gentil,V. Corrosão.3.ed.Rio de Janeiro: LTC,1996.

44. Gerischer, H. Models for the discussion of the photo-electrochemical response of xoide layers on metals. Corrosion Science, v. 29, n.2-3, p. 257-266, 1989.

45. Gironès, A.; Llanes,L.; Anglada, M.; Mateo, A. Dynamic strain ageing effects on superduplex stainless steels at intermediate temperatures. Materials Science and Engineering A, v. 367, p 322-328, 2004.

46. Grobner, P. J. The $885^{\circ} \mathrm{F}\left(475^{\circ} \mathrm{C}\right)$ embrittlement of ferritic stainless steels. Metallurgical Transactions, v. 4A, p. 251-260, 1973.

47. Hakiki, N. E.; Boudin, S., Rindot, B.;Da Cunha Belo, M. The electronic structure of passive films formed on stainless steels. Corrosion Science, v. 37, n. 11, p. 1809-1822, 1995.

48. Hakiki, N. E.; Da Cunha Belo, M. Semiconducting properties of passive films formed on stainless steels. Influence of the alloying elements. Journal of Electrochemical Society, v. 145, p. 3821-3829, 1998.

49. Hattestrand, M.; Larsson, P.; Chai, G.; Nilsson, J-O.; Odqvist, J. Study of decomposition of ferrite in a duplex stainless steel cold worked and aged at 450-500ํ․ Materials Science and Engineering A,v.499,p.489-492, 2009.

50. Iacoviello, F.; Casari, F.; Gialanella, S. Corrosion Science, v.47, p.909922, 2005.

51. lacoviello,F.;Boniardi,M.; La Vecchia,G.M. Fatigue crack propagation in austeno-ferritic duplex stainless steel $22 \mathrm{Cr} 5 \mathrm{Ni}$, International Journal of Fatigue, v.21,p. 957-963, 1999. 
52. IARC. Monographs on the Evaluation of Carcinogenic Risks to Humans: Surgical Implants and Other Foreign Bodies. v. 74.Lyon, France.: International Agency for Research on Cancer, 1999.

53. Isalgué, A., Anglada, M. Study of the spinodal decomposition of a Fe-28Cr$2 \mathrm{Mo}-4 \mathrm{Ni}-\mathrm{Nb}$ alloy by small-angle neutron scattering. Journal of Materials Science, v. 25, p. 4977-4980, 1990.

54. Jacobsson, P.; Bergström, Y.; Aronsson, B. Kinetics and hardening mechanism of $475^{\circ} \mathrm{C}$ embrittlement in $18 \mathrm{Cr}$-2Mo ferritic steels.

Metallurgical Transactions, v. 6A, p. 1577-1580, 1975.

55. Johnson, J.; Reck, B.K.; Wang, T.; Graedel, T.E. The energy benefit of stainless steel recycling. Energy Policy, v.36, p.181-192, 2008.

56. Kawaguchi, Y.; Yamanaka, S. Mechanism of the change in thermoelectric power of cast duplex stainless steel due to thermal aging. Journal of Alloys and Compounds, v. 336, p. 301-314, 2002.

57. Kimura, T. Contact hypersensitivity to stainless steel cages (chromium metal) in hairless descendants of mexican hairless dogs. Environmental Toxicology, v.22.p.176-184, 2007.

58. Kuwano, H.; Ishikawa, Y.; Yoshimura, T.; Hamaguchi, Y. Characterization of the spinodal decomposition of $\mathrm{Fe}-\mathrm{Cr}$ alloys by Mössbauer spectroscopy. Hyperfine Interactions, v. 69, p. 501-504, 1991.

59. Lee, J.S.; Jang, C.H.; Kim, I.S.; Kimura, A. Embrittlement and hardening during thermal aging of high $\mathrm{Cr}$ oxide dispersion strengthened alloys. Journal of Nuclear Materials, v.367-370, p. 229-233, 2007.

60. Lister, T. E., Pinhero, P. J. The effect of localized electric fields on the detection of dissolved sulfur species from Type 304 stainless steel using scanning electrochemical microscopy. Electrochimica Acta,v.48, n.17, p. 2371-2378, 2003.

61. Liu, C.; Bi, Q.; Leyland, A.; Matthews, A. An electrochemical impedance spectroscopy study of the corrosion behaviour of PVD coated steels in $0.5 \mathrm{~N}$ $\mathrm{NaCl}$ aqueous solution: Part I. Establishment of equivalent circuits for EIS data modeling. Corrosion Science, v. 45, n. 6, p.1243-1256, 2003.

62. Lo, K.H.; Shek, C.H.; Lai, J.K.L. Recent developments in stainless steels. Materials Science and Engineering R, v.65, p. 39-104, 2009.

63. Macdonald, J. R. Impedance spectroscopy: old problems and new developments. Electrochimica Acta. v. 35, n. 10, p. 1483-1492,1990.

64. Magnabosco, R. Influência da microestrutura no comportamento eletroquímico do aço inoxidável SAF 2205. 2001. Tese (Doutorado)Escola Politécnica da Universidade de São Paulo, São Paulo. 
65. Magnabosco, R.; Alonso-Falleiros, N. Pit Morphology and its Relation to Microstructure of $850{ }^{\circ} \mathrm{C}$ Aged Duplex Stainless Steel . Corrosion, v. 6, p.130-136, 2005.

66. Mansfeld, F.,; Shih, H. Detection of pitting with electrochemical impedance spectroscopy. Journal of the Electrochemical Society: Electrochemical Science and Technology, v. 138, n. 5, p. 1171-1172, 1988.

67. Marcinkowski, M. J.; Fischer, R. M.; Szirma, E. A. Effect of $500^{\circ} \mathrm{C}$ aging on the deformation behaviour of an iron-chromium alloy. Transactions of the Metallurgical Society of AIME, v. 230, p. 676-689, 1964.

68. Martini, E. M. A.; Muller, I. L. Characterization of the film formed on iron in borate solution by electrochemical impedance spectroscopy. Corrosion Science, v. 42, n. 3, p. 443-454, 2000.

69. Martins, M.; Rossitti, S.M.; Ritoni,M.;Casteletti, L.C. Effect of stress relief at $350{ }^{\circ} \mathrm{C}$ and $550^{\circ} \mathrm{C}$ on the impact properties of duple $\mathrm{x}$ stainless steels.

Materials Characterization, v.58, p. 909-916, 2007.

70. Mathew, M.D; Lietzan, L.M.; Murty,K.L.; Shah, V.N. Low temperature aging embrittlement of CF-8 stainless steel. Materials Science and Engineering A, v.269, p.186-196, 1999.

71. Mathon, M.H.; De Carlan, Y.; Geoffroy, G.; Averty, X.; Alamo, A.; De Novion, C.H. A SANS investigation of the irradiation-enhanced $\alpha-\alpha$ phases separation in 7-12 Cr martensitic steels. Journal of Nuclear Materials, v.312,p.236-248,2003.

72. Metal Prices. < http://www.metalprices.com/freesite/historical/pricequery.asp?metal=\&unit=\&currency=USD\&start=//\&end=//\&ironscrap=> Acessado em: 16 set.2009.

73. Miller, M.K.; Stoller, R.E.; Russell, K.F. Effect of neutron irradiation on the spinodal decomposition of Fe- 32\%Cr model alloy. Journal of Nuclear Materials, v.230, p. 219-225, 1996.

74. Montanaro,L.; Cerellati, M.; Campoccia, D.; Arciola, C.R. Promising in vitro performances of a new nickel-free stainless steel. Journal of Materials:

Materials in Medicine, v. 17, n.3,p. 267-275,2006.

75. Montemor, M. F.; Ferreira, M. G. S.; Hakiki, N. E.; Da Cunha Belo, M. Chemical composition and eletronic structure of the oxide films formed on $316 \mathrm{~L}$ stainless steel and nickel based alloys in high temperature aqueous environments. Corrosion Science, v. 42, n. 9, p. 1635-1650, 2000.

76. Mori, G.; Bauernfeind, D. Pitting and crevice corrosion of superaustenitic stainless steels.Materials and Corrosion, v. 55, p.164-173, 2004. 
77. Newell, H. D. Properties and characteristics of $27 \%$ chromium-iron. Metal Progress, v. 50, p. 997-1035, 1946.

78. Niffenegger,M.; Leber, H.J. Monitoring the embrittlement of reactor pressure vessel steels by using the Seebeck coefficient. Journal of Nuclear Materials, v.389, n.1, p.62-67, 2009.

79. Park, C.-J.; Kwon, H.-S. Effects of aging at $475^{\circ} \mathrm{C}$ on corrosion properties of tungsten-containing duplex stainless steels. Corrosion Science,v. 44,p. 2817-2830, 2002.

80. Park, C-J.; Ahn, M-K.;Kwon,H-S. Influences of Mo substitution by W on the precipitation kinetics of secondary phases and the associated localized corrosion and embrittlement in $29 \% \mathrm{Cr}$ ferritic stainless steels. Materials Science and Engineering A, v.418,p. 211-217, 2006.

81. Park, C-J.; Kwon, H-S. Electrochemical noise analysis of localized corrosion of duplex stainless steel aged at $475^{\circ} \mathrm{C}$. Materials Chemistry and Physics, v.91, p.355-360, 2005.

82. Park, C-J.; Kwon, H-S.; Lohrengel, M.M. Micro-electrochemical polarization study on $25 \%$ Cr duplex stainless steel. Materials Science and Engineering A, v.372, p.180-185,2004.

83. Pedrosa,P.D.S.; Teodósio, J.R.; Tavares, S.S.M.; Neto,J.M.; Da Silva, M.R. Magnetic and mechanical hardening of Fe-based alloys. Journal of Alloys and Compounds, v.329, p. L14-L17, 2001.

84. Polo, J. L.; Cano, E.; Bastidas, J. M. An impedance study on the influence of molybdenum in stainless steel pitting corrosion. Journal of

Electroanalytical Chemistry. v. 537, n. 1-2, p. 183-187, 2002.

85. Rechemberg, H. R.; Brandi, S. D.; Padilha, A. F. Utilização da espectroscopia Mössbauer no estudo da formação da fase $\alpha$ em aços inoxidáveis duplex. In: Congresso Anual da ABM, 48,1993, São Paulo. Anais,São Paulo: ABM, 1994. p. 477-487.

86. Sahu, J.K.; Krupp, U.; Ghosh, R.N.; Christ, H.-J. Effect of $475^{\circ} \mathrm{C}$ embrittlement on the mechanical properties of duplex stainless steel.

Materials Science and Engineering A, v. 508, p. 1-14, 2009.

87. Sandvik.Sandvik SAF 2707 HD® (UNS S32707) a hyper-duplex stainless steel for severe chloride containing environments. Sandvik Materials Technology.Nov.2006.Disponível em: <http://www.smt.sandvik.com/sandvik/0140/internet/s001664.nsf/3aa39d67 5f7cc278c12569b900513b28/3c85c80ff467214fc1257267005814da/\$FILE/ S-51-63-ENG\%20061101.pdf>. Acesso em:13 jul.2009. 
88. Schmidt -Rieder, E.; Tong, X.Q.; Farr, J.P.G.; Aindow, M. "In situ" electrochemical scanning probe microscopy corrosion studies on duplex stainless steel in aqueous $\mathrm{NaCl}$ solutions. British Corrosion Journal, v.31, p.139-145, 1996.

89. Sedriks, A.J. Effects of alloy composition and microstructure on the passivity of stainless steels. Corrosion, v.42, p.376-389, 1986.

90. Sedriks, A.J. Corrosion of stainless steels,2.ed.New York: John Wiley,1996.

91. Shiao, J.J.; Tsai, C.H.; Huang, J.H.; Kai, J.J. Phase transformations in ferrite phase of a duplex stainless steel aged at $500^{\circ} \mathrm{C}$. Scripta Metallurgica et Materialia, v.29, p.1451-56, 1993.

92. Shiao, J.J.; Tsai, C.H.; Kai, J.J.; Huang, J.H. Aging embrittlement and lattice image analysis in a Fe-Cr-Ni duplex stainless steel aged at $400{ }^{\circ} \mathrm{C}$. Journal of Nuclear Materials,v. 217, p. 269-278, 1994.

93. Sieurin, H.; Sandstrom,R.; Westin, E.M. Fracture toughness of the lean duplex stainless steel LDX 2101. Metallurgical and Materials

Transactions A, v. 37, p. 2975-2981, 2006.

94. Solomon, H. D. Devine Jr., T. M. Duplex stainless steels - a tale of two phases. In: Duplex stainless steel Conference, 1982, St.Louis, USA.Proceedings. Ohio: ASM Metals, 1983. p. 693-756.

95. Solomon, H. D.; Levinson, L. M. Mössbauer effect study of $475^{\circ} \mathrm{C}$ embrittlement of duplex and ferritic stainless steels. Acta Metallurgica, v. 26, p. 429-442, 1978.

96. Sourisseau, T., Chaveau, E., Baroux, B. Mechanism of copper action on pitting phenomena observed on stainless steels in chloride media. Corrosion Science, v. 47, n. 5, p. 1097-1117, 2005.

97. Tan,H.; Jiang,Y.;Deng,B.;Sun,T.;Xu,J.;Li,J.Effect of annealing temperature on the pitting corrosion resistance of super duplex stainless steel UNS S32750. Materials Characterization,v.60,p.1049-1054, 2009.

98. Tavares, S.S.M.; Da Silva, M.R.; Neto, J.M. Magnetic property changes during embrittlement of a duplex stainless steel. Journal of Alloys and Compounds,v. 313, p.168-173, 2000.

99. Tavares, S.S.M.; Pedrosa, P.D.S.; Teodósio, J.R.; Da Silva, M.R.; Neto, J.M.; Pairis, S. Magnetic properties of the UNS S39205 duplex stainless steel. Journal of Alloys and Compounds, v. 351, p.283-288, 2003. 
100. Terada, M. Estudo da fragilização de $475^{\circ} \mathrm{C}$ nos aços inoxidáveis ferríticos DIN W. Nr. 1.4575 (28\%Cr-4\%Ni-2\%Mo-Nb) e INCOLOY MA 956 (20\% Cr-5\%Al-Ti-Y2O3).2003.Dissertação (Mestrado)-Escola Politécnica da Universidade de São Paulo, São Paulo.

101. Terada, M. Corrosao de aços inoxidaveis avançados em meios fisiológicos.2008. Tese (doutorado)- Instituto de Pesquisas Energéticas e Nucleares, São Paulo.

102. Terada, M.; Padilha, A.F.; Simões, A.M.P.; De Melo, H.G.; Costa, I. Use of SECM to study the electrochemical behaviour of DIN 1.4575 superferritic stainless steel aged at 475ㄷ. Materials and Corrosion, v.60, 2009.

103. Truman, J.E.; Pirt, K.R. Properties Of A Duplex (Austenitic-Ferritic) Stainless Steel And Effects Of Thermal History. In: Duplex Stainless Steel Conference,1982, St. Louis. Proceedings.Ohio: Asm Metals, 1983 P. 113142.

104. Tujikura, Y.; Urata,S. Fracture mechanics evaluation of cast duplex stainless steel after thermal aging. Nuclear Engineering and Design, v.191, p.255-261, 1999.

105. Turnbull,A.; Francis, P.E.; Ryan, M.P.; Orkney, L.P.; Griffiths, A.J.; Hawkins, B. A Novel Approach to Characterizing the Corrosion Resistance of Super Duplex Stainless Steel Welds. Corrosion,v. 58, n. 12, p. 10391048, 2002.

106. Uggowitzer, P.J.; Magdowski, R.; Speidel, M.O.Nickel Free High Nitrogen Austenitic Steels. ISIJ International, v.36, p.901-908,1996.

107. Ura, M. M.; Padilha, A. F.; Alonso, N. Influência da fase alfa linha ( $\left.\alpha^{\prime}\right)$ sobre a resistência à corrosão por pite em aços inoxidáveis dúplex. In: Congresso Anual da ABM, 49,1994,São Paulo. Anais. São Paulo: ABM, 1995. p.337-349.

108. Vasconcelos,I.F; Tavares,S.S.M.;Reis,F.E.U.; Abreu,H.F.G. Ageing effects on a'precipitation and resistance to corrosion of a novel $\mathrm{Cr}$ Mo stainless steel with high Mo content. Journal of Materials Science, v.44, p.293299,2009.

109. Vitek, J.M.; David, S.A.; Alexander, D.J.; Keiser, J.R.; Nanstad, R.K. Low temperature aging behaviour of type 308 stainless steel weld metal. Acta Metall. Mater., v.39, p.503-516, 1991.

110. Williams, R.O.; Paxton,H.W. The nature of aging of binary iron-chromuim Alloys around $500^{\circ} \mathrm{C}$. Journal of the Iron Steel Institute, v.185, p.358374, 1957.

111. Wolynec, S. Técnicas eletroquímicas em corrosão.São Paulo: EDUSP,2003. 
112. Yamada,T.; Okano, S.; Kuwano, H. Mechanical property and microstructural change by thermal aging of SCS14A cast duplex stainless steel. Journal of Nuclear Materials, v.350, p.47-55, 2006.

113. Yi, Y.S.; Shoji, T. Quantitative evaluation of material degradation of thermally aged duplex stainless steels using chemical immersion test. Journal of Nuclear Materials,v. 240, p. 62-69, 1996. 